\title{
Translating Flowering Time from Arabidopsis thaliana to Brassicaceae and Asteraceae Crop Species
}

\author{
Willeke Leijten ${ }^{1} \mathbb{D}$, Ronald Koes ${ }^{2}$, Ilja Roobeek ${ }^{1, * \mathbb{D}}$ and Giovanna Frugis ${ }^{3, *}$ \\ 1 ENZA Zaden Research \& Development B.V., Haling 1E, 1602 DB Enkhuizen, The Netherlands; \\ W.Leijten@enzazaden.nl \\ 2 Swammerdam Institute for Life Sciences (SILS), University of Amsterdam, Science Park 904, \\ 1098 XH Amsterdam, The Netherlands; r.e.koes@uva.nl \\ 3 Istituto di Biologia e Biotecnologia Agraria (IBBA), Operative Unit of Rome, \\ Consiglio Nazionale delle Ricerche (CNR), via Salaria Km. 29,300, 00015 Monterotondo Scalo, Roma, Italy \\ * Correspondence: I.Roobeek@enzazaden.nl (I.R.); giovanna.frugis@cnr.it (G.F.); \\ Tel.: +31-(0)228-350100 (I.R.); +39-06-9067-2889 (G.F.)
}

Received: 1 November 2018; Accepted: 13 December 2018; Published: 16 December 2018

check for updates

\begin{abstract}
Flowering and seed set are essential for plant species to survive, hence plants need to adapt to highly variable environments to flower in the most favorable conditions. Endogenous cues such as plant age and hormones coordinate with the environmental cues like temperature and day length to determine optimal time for the transition from vegetative to reproductive growth. In a breeding context, controlling flowering time would help to speed up the production of new hybrids and produce high yield throughout the year. The flowering time genetic network is extensively studied in the plant model species Arabidopsis thaliana, however this knowledge is still limited in most crops. This article reviews evidence of conservation and divergence of flowering time regulation in A. thaliana with its related crop species in the Brassicaceae and with more distant vegetable crops within the Asteraceae family. Despite the overall conservation of most flowering time pathways in these families, many genes controlling this trait remain elusive, and the function of most Arabidopsis homologs in these crops are yet to be determined. However, the knowledge gathered so far in both model and crop species can be already exploited in vegetable crop breeding for flowering time control.
\end{abstract}

Keywords: Brassicaceae; Asteraceae; flowering time; photoperiod; vernalization; ambient temperature; gibberellins; age; plant breeding

\section{Introduction}

The switch from vegetative stage to flowering is essential for plant reproduction, and flowering time diversity has adaptive value in natural populations [1]. The time at which flowering occurs plays a major role in agricultural production as it affects the quality and quantity of leaf, flower, seed and fruit products, ease of harvest and marketing. Shifting the seasonal timing of reproduction is a major goal of plant breeders to develop novel varieties that are better adapted to local environments and changing climatic conditions [2]. Over the last few years, climate underwent significant changes, such as relatively mild winters, dry and warm summers, and more heavy rain fall in spring and autumn. All of those changes affect plant growth and flowering time. Besides natural occurring climate change, adapting varieties to new environments makes crop production more flexible [2]. To produce varieties that are more robust and predictable in flowering time is also a desirable trait for reliable production. Obtaining varieties with increased yield is also a major breeding goal, and will enhance food production within the same amount of land in a world where the population is growing, 
and demanding more food production. However, yield is influenced by several factors, including premature bolting (see Glossary in Table 1) during crop production, and therefore, a prolonged vegetative phase will increase yield for leafy crops that are harvested before the transition to the reproductive phase.

Table 1. Glossary of main terms as used in the review.

\begin{tabular}{|c|c|}
\hline Term & Definition \\
\hline flowering time & the switch from plant vegetative growth to reproductive development \\
\hline bolting & rapid elongation of the inflorescence/flowering stem \\
\hline annuals & $\begin{array}{l}\text { plants that complete their entire life cycle from seed to flower within one year and } \\
\text { are characterized by short vegetative phase }\end{array}$ \\
\hline biennials & plants which require two years to complete their life cycle, \\
\hline perennials & $\begin{array}{l}\text { plants that survive for several years and restrict the duration of reproduction by } \\
\text { cycling between vegetative growth and flowering; perennials are characterized by } \\
\text { prolonged vegetative phase that can last from a few weeks to several years }\end{array}$ \\
\hline shoot apical meristem (SAM) & $\begin{array}{l}\text { population of cells located at the tip of the shoot axis that produce lateral organs, } \\
\text { stem tissue and regenerates itself }\end{array}$ \\
\hline inflorescence meristem (IM) & $\begin{array}{l}\text { a meristem that underwent transition from vegetative to reproductive fate and can } \\
\text { produce floral meristems }\end{array}$ \\
\hline floral meristem (FM) & group of cells responsible for the formation of floral organs \\
\hline facultative photoperiod & $\begin{array}{l}\text { plants that flower faster under a particular photoperiod but will eventually flower } \\
\text { under all photoperiods (also called "quantitative") }\end{array}$ \\
\hline obligate photoperiod & plants that flower only under a particular photoperiod (also called "qualitative") \\
\hline long days & day length more than about $12 \mathrm{~h}$, usually $16 \mathrm{~h}$ light and $8 \mathrm{~h}$ dark periods \\
\hline short days & day length less than about $12 \mathrm{~h}$, usually $8 \mathrm{~h}$ light and $16 \mathrm{~h}$ dark periods \\
\hline Double Haploid (DH) & chromosome doubling of haploid cells to produce genetically homozygous plants \\
\hline genome-wide association study (GWAS) & $\begin{array}{l}\text { observational study of a genome-wide set of genetic variants in different individuals } \\
\text { that occur more frequently in correlation with a specific trait, identifying inherited } \\
\text { genetic variants associated with a trait }\end{array}$ \\
\hline homolog & a gene related to a second gene by descent from a common ancestral DNA sequence \\
\hline ortholog & $\begin{array}{l}\text { genes in different species that evolved from a common ancestral gene by speciation; } \\
\text { normally, orthologs retain the same function in the course of evolution }\end{array}$ \\
\hline paralog & genes related by duplication within a genome that may evolve new functions \\
\hline maturity & the state of being fully developed or full grown \\
\hline uniformity & $\begin{array}{l}\text { a state or condition of the plant in which everything is regular, homogeneous, } \\
\text { or unvarying }\end{array}$ \\
\hline predictable & always behaving or occurring in the way expected \\
\hline robust & $\begin{array}{l}\text { is a characteristic of being strong that, when transposed into a system, it refers to the } \\
\text { ability of tolerating perturbations and remain effective }\end{array}$ \\
\hline QTL & $\begin{array}{l}\text { (or Quantitative Trait Locus), is a locus (section of DNA) which correlates with } \\
\text { variation of a quantitative trait in the phenotype of a population of organisms }\end{array}$ \\
\hline vernalization & $\begin{array}{l}\text { cold treatment needed to get many perennials to flower; usually the minimum period } \\
\text { is six to twelve weeks at } 4{ }^{\circ} \mathrm{C}\end{array}$ \\
\hline spring types & plants which flower early without vernalization \\
\hline winter types & $\begin{array}{l}\text { plants which have an obligate requirement for prolonged periods of } \\
\text { cold temperatures }\end{array}$ \\
\hline semi-winter types & plants which require mild vernalization and lack frost hardiness \\
\hline
\end{tabular}

Controlling flowering time would therefore help grow crops in all seasons to speed up the production of new hybrids and produce high yield throughout the year. Early bolting potentially limits vegetative growth and can severely decrease yield, while non-flowering inhibits seed production. The timing of bolting and flowering are especially important for vegetable crops. For cauliflower and broccoli, synchronization of flowering is essential as the plants are harvested in the inflorescence meristems phase (curds). For lettuce, plants flower early when grown at high temperature. Early stages of bolting are not visible, but the flavor changes more towards bitter. Therefore, late bolting is preferred to enhance yield without the bitterness.

In the past, selection for flowering time was based on plant phenotyping in the greenhouse or in the field. The increasing availability of crop genetic and genomic resources, and the current knowledge on both gene function and natural genetic variation, are of great value and can be used in breeding. The development of trait specific markers, e.g., based on QTL (see Glossary in Table 1) analysis, are useful to select for favorable genotypes in a breeding program [3-5]. On the other hand, reverse screening for genetic variation in specific flowering time related genes in wild accessions or mutant populations could be of benefit for the trait. The latter approach is still underexploited as knowledge about the flowering pathways, the molecular mechanisms, and the genes involved is still 
limited in most crops [6,7]. However, the flowering time genetic network is extensively studied in the model species Arabidopsis thaliana [6,8-11] (Figure 1a), which is an annual facultative long-day (LD) plant belonging to the Brassicaceae family. Hence, if the function of the $A$. thaliana flowering time genes would be conserved in the crops of interest, this would provide targets for genetic selection and improvement to speed up breeding and agricultural biotechnology.

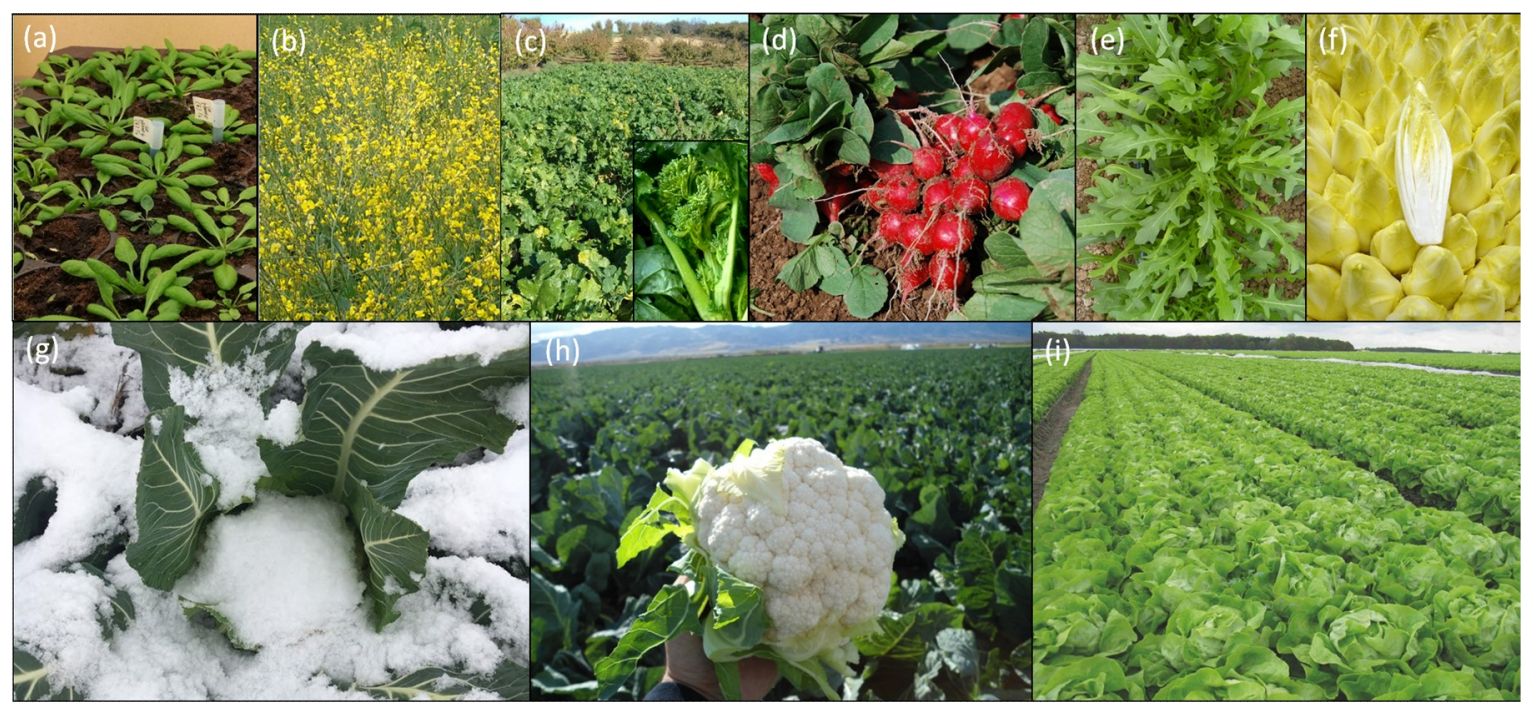

Figure 1. Plant species considered in this review. (a) Arabidopsis thaliana, (b) Brassica napus (rapeseed), (c) Brassica rapa (turnip), (d) Raphanus sativus (radish), (e) Diplotaxis tenuifolia (wild rocket), (f) Cichorium intybus (chicory), (g) Brassica oleracea (cauliflower) in winter, (h) Brassica oleracea (cauliflower) in summer and (i) Lactuca sativa (lettuce).

Here, we review current knowledge regarding the conservation and divergence of the mechanisms that regulate flowering time in A. thaliana related crop species from the Brassicaceae family and more distantly related leafy crops within the Asteraceae family, that are of great interest for food market and vegetable breeding. We will focus on Brassica napus (Figure 1b), Brassica rapa (Figure 1c), Brassica oleracea (Figure 1g-h), Raphanus sativus (Figure 1d and Diplotaxis tenuifolia (Figure 1e) for the Brassicaceae and on Lactuca sativa (Figure 1i) and Cichorium intybus (Figure 1f) as key leafy crops within the Asteraceae family. The possible exploitation of this knowledge in vegetable crop breeding, and the potential of translational biology and genomics to crops, will be discussed. The different flowering time pathways and genes explored in these crops will be discussed, and gene function will be compared to the knowledge acquired in $A$. thaliana.

\section{Flowering Requirements of Brassicaceae and Asteraceae Species}

Optimal conditions for flowering vary between and within species, as plants respond and adapt to specific combination of light (quality and day length) and temperature (cold, warm, hot) to undergo floral transition [11]. Plants can be either long-day or short-day if they flower when exposed to light periods longer (as in summer) or shorter (as in winter) of a certain critical length. Many plant species require prolonged exposure to low temperatures (vernalization) to flower, while others flower independently of cold conditions [8]. Plants have annual, biennial or perennial life cycles depending on the number of growing seasons required to complete their life cycle [11]. Further classification of plant types can be made based on geographical origin and growing season.

The plant model species Arabidopsis thaliana (Figure 1a, Table 2) can be annual or biennial. Annual plants flowers earlier in response to long days (facultative long-day), and natural accessions are classified into summer annuals and winter annuals [11]. Summer annuals flower rapidly when grown under long days, whereas in winter annuals flowering is not induced until they are exposed to low temperature $\left(4^{\circ} \mathrm{C}\right)$ for several weeks (vernalization), followed by warmer temperatures in spring [11]. 
Table 2. Brief description of the plant species.

\begin{tabular}{|c|c|c|c|c|c|c|c|}
\hline Species & Chr. & Life Span & Vernalization & Types & Breeding Goal & Day Length ${ }^{1}$ & Ref. \\
\hline A. thaliana & $2 n=10$ & Annual/biennial & Yes/no & Spring/semi-winter/winter & none & facultative LD & [12] \\
\hline B.napus & $2 \mathrm{n}=38($ AACC $)$ & Annual/biennial & Yes/no & Spring/semi-winter/winter & flowering time adaptation & LD & {$[13,14]$} \\
\hline B. rapa & $2 \mathrm{n}=20(\mathrm{AA})$ & Annual/biennial & Yes/no & Spring/semi-winter/winter & Late bolting & LD & [15] \\
\hline B. oleracea & $2 \mathrm{n}=18(\mathrm{CC})$ & Annual/biennial & Yes/no & Spring/semi-winter/winter & Predictable harvest time & LD & [16] \\
\hline R. sativus & $2 \mathrm{n}=18$ & Annual & No & & Late bolting & facultative LD & {$[17,18$} \\
\hline D. tenuifolia & $2 n=22$ & Annual & No & & Late bolting & LD & [19] \\
\hline L. sativa & $2 \mathrm{n}=18$ & Annual & No & & Heat resistance & facultative LD & [20] \\
\hline C. intybus & $2 \mathrm{n}=18$ & Biennial/perennial & Yes & & Resistance to bolting & LD & {$[21,22]$} \\
\hline
\end{tabular}

${ }^{1}$ All species flower early under long-day (LD, $16 \mathrm{~h} / 8 \mathrm{~h}$ of light/dark) conditions. 
B. napus, B. rapa and B. oleracea, closely related to A. thaliana, share similar life cycles (annuals and biennials) and have spring, semi-winter and winter types: Spring types flower early without vernalization and are grown in geographical regions with strong winters or in subtropical climates; winter types have an obligate requirement for prolonged periods of cold temperatures and are grown in moderate temperate climates; semi-winter types, which are sown before winter, flower after winter and are grown in geographical regions with moderate winter temperatures $\left(>0^{\circ} \mathrm{C}\right)$ (Figure 2) [14]. B. napus is a domesticated allotetraploid species with two genomes, AA and CC, derived from B. rapa and B. oleracea, respectively. Two other Brassicaceae species, R. sativus and D. tenuifolia, and the Asteraceae species Lactuca sativa, are annuals that do not require vernalization to flower. In contrast, the Asteraceae species Cichorium intybus is biennial or perennial and does require a cold period for flowering induction. All species considered in this review flower faster in response to longer photoperiods and warmer temperatures (more details about species characteristics are in Table 2). Despite similarities amongst these species, breeding goals with regard to plant growth and flowering time differ for each crop.

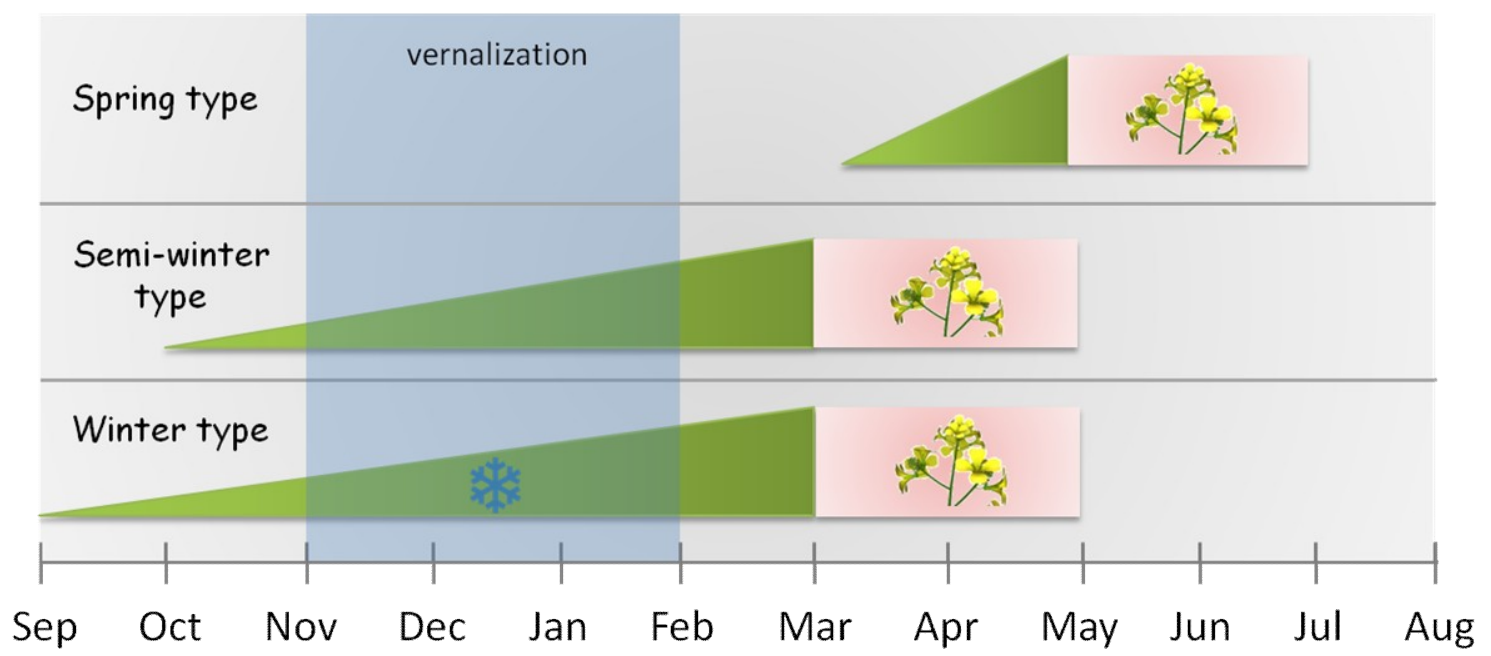

Figure 2. Schematic representation of the life cycles of annual Brassica species. Green triangles represent vegetative growth, pink boxes plant flowering. Periods of cold required for vernalization are indicated by a blue box. Frost symbols indicate frost hardiness in winter types that does not occur in semi-winter plants.

\section{Breeding Goals}

Breeders aim to improve varieties by adapting them to climate changes, new environments or increasing yield in general, and flowering time affects all these traits [2].

B. napus L. (Figure 1b) is one of the most important oilseed crops worldwide and includes oilseed rape and rapeseed (Figure 3). The yield potential of rapeseed largely depends on flowering time, thus creating lines with optimal flowering time is a major breeding goal [14].

B. rapa (Figure 1c) is cultivated worldwide, particularly in Asia, and includes the vegetable crops Chinese cabbage, pak choi, turnip and cime di rapa (Figure 3). Premature bolting is a severe problem as it reduces yield of the harvested crops, e.g., for the spring cultivation of Chinese cabbage. Extremely late bolting is a major breeding goal in this crop as unexpectedly low temperatures can induce flowering and so yield loss [23].

B. oleracea (Figure 1g-h) encompasses multiple cultivar groups (Figure 3) that are classified based on the morphology of their edible structures: Kohlrabi, kales and cabbages are harvested at vegetative stage; broccoli and cauliflower are cultivated for their curd (the edible flower head of the plant) that is harvested at the transition to reproductive phase. Cultivars and wild species accumulate anti-carcinogenic and antioxidants, which are beneficial for human health [16]. Breeding strategies for broccoli and cauliflower include uniformity in time to curd production for easy crop handling 
during production. In cauliflower, slight deviations from optimal growth temperature, either lower or higher, lead to uneven curd formation and therefore less predictable harvest times. On one hand, vernalization is required to produce a harvestable curd, while on the other hand, high temperatures in spring result in prolonged vegetative growth before the curd is produced. Adjusting the vernalization and temperature sensitivity of plants will help to create cauliflower varieties with a predictable curd formation, for example by exploring genetic variation in temperature-dependent flowering time genes. Early prediction of the thermal time to curd induction in untested genotypes and environments can be achieved by using the genome-based model proposed by Rosen et al. [24], making this a good tool for early selection of the desired genotypes to be incorporated into breeding material.

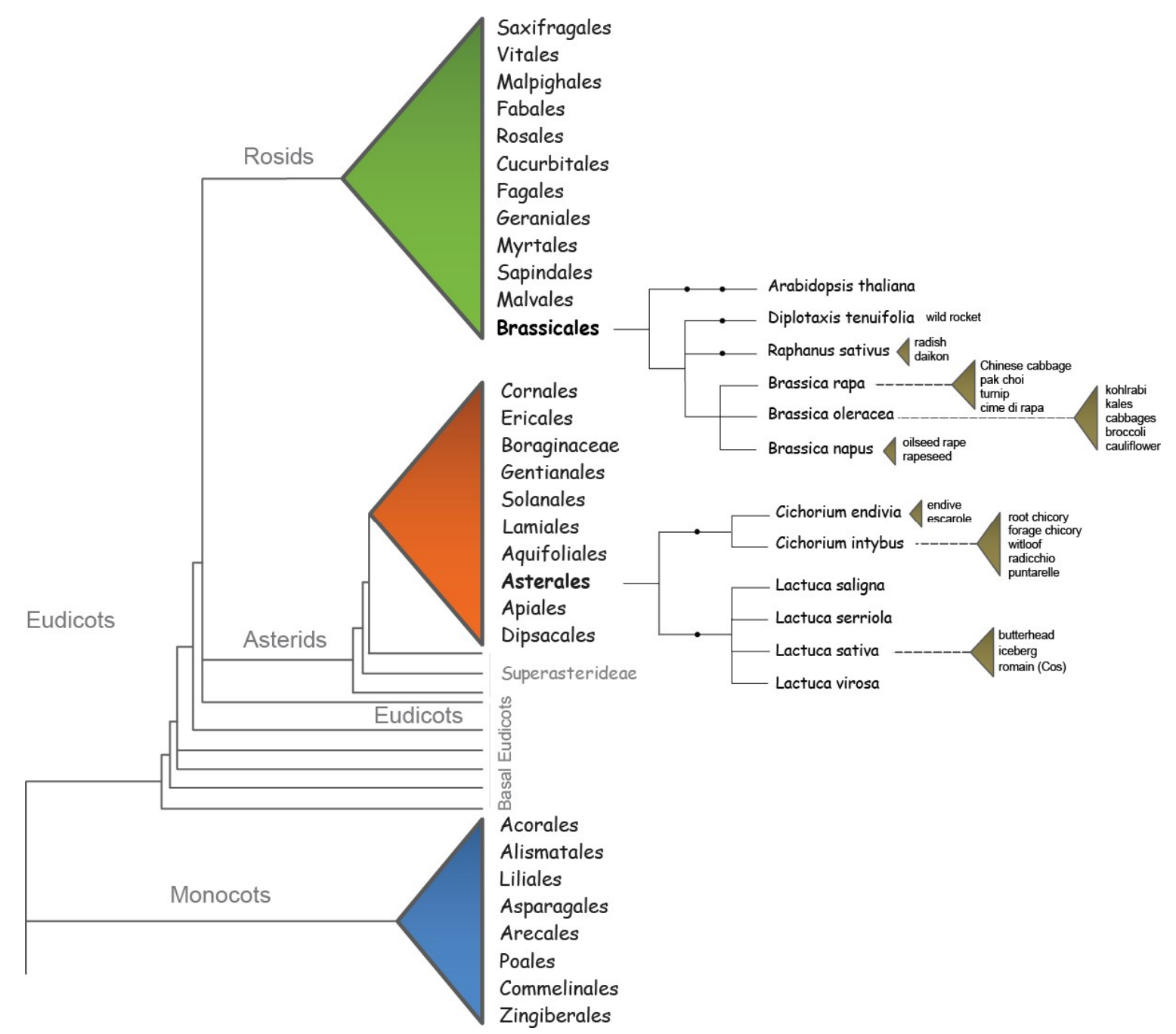

Figure 3. Schematic phylogenetic tree of eudicot and monocot species. Plant families are indicated for the main phylogenetic groups (http://science.kennesaw.edu/jmcneal7/plantsys/index.html). Phylogenetic relationships within Brassicaceae and Asteraceae species of interest were obtained using phyloT, a phylogenetic tree generator based on NCBI taxonomy (https:/ / phylot.biobyte.de/). Cultivated crops for the different plant species are shown.

R. sativus (Figure 1d), including radish and daikon (Figure 3), are important vegetable root crops with large variation in root size and shapes [18,25]. Late flowering is a relevant breeding goal as some varieties are sensitive to premature bolting. In radish, when plants are grown under LD conditions, premature bolting reduces yield and quality of the harvested product. Enhancing the quality of radish can be achieved by late flowering, combined with increased post-harvest shelf life through delayed leaf 
senescence, as the whole plant (bulb and leaves) is harvested and the leaves are used as an indication for the post-harvest quality of the plant.

Wild rocket (D. tenuifolia) (Figures 1e and 3) is a popular salad leaf that has a similar shape and taste as rucola (Eruca sativa), but with a stronger peppery flavor. The crop can be harvested multiple times. For cultivation, D. tenuifolia is selected against pre-harvest flowering as it leads to unsaleable crops.

L. sativa (Figure 1i) encompasses multiple lettuce cultivars that are classified based on the morphology of the leafy or head type: Iceberg types form a close head resembling that of a cabbage; butterhead types form a head with large ruffled outer leafs; and romaine (Cos) types do not form a head but have long, broad and upright leaves. Wild relatives used in breeding include L. virosa, L. serriola and L. saligna (Figure 3). While cultivated lettuce is annual, the wild species L. virosa is biennial and does require vernalization for flower initiation. High temperature during the cultivation of lettuce results in heat-induced early bolting. Heat resistance is therefore a major breeding goal to produce better tasting lettuce when grown at high temperature. Although early bolting is beneficial for fast seed production in the creation of varieties, it does reduce the quality of harvestable crops. The early stages of bolting are not visible when the crop is harvested, but the flavor changes towards an undesirable bitter taste [26]. Exploring the genetic determinants of this response will help understand the mechanism of heat-induced early flowering, and enable breeders to produce better tasting lettuce when grown at high temperature.

C. intybus (Figure 1f) includes multiple cultivar groups that are classified based on purpose and use of the harvested product: Root and forage chicory is used for inulin extraction and grown for live stock, respectively; witloof and radicchio are leafy vegetables that can be cooked or eaten fresh [27]. Among the leaf chicory groups, several "Catalogna" landraces are cultivated in Italy for both leaves and stems/buds, the latter appreciated for the bitter and crispy taste (puntarelle) (Figure 3) [28]. If sown too early in spring, the plants could be vernalized and flower during the first growing period [22]. Breeding goals include uniformity in crop yield and maturity, and resistance to bolting [22,29]. For the production of root chicory, a cold season during growth induces early bolting and therefore decreases yield. Investigating the cold-response of root chicory in more detail is needed to delay bolting under these conditions.

\section{Conserved and Divergent Flowering Time Genes in Brassicaceae and Asteraceae}

The switch from plant vegetative growth to reproductive development (transition to flowering), is a critical stage in the life cycle of a plant. Plants need to coordinate their developmental programs precisely in response to seasonal changes and in an ecological context in order to ensure their reproductive success. As such, flowering is tightly controlled by diverse developmental, hormonal and environmental cues, day length and temperature being the most important of these environmental signals. [10]. Six major genetic pathways, converging to a small number of floral integrator genes, have been described in Arabidopsis thaliana (Figure 4): The vernalization and photoperiod pathways, which control flowering in response to seasonal changes; the ambient temperature pathway, which regulates flowering time in response to changing ambient temperature; the age, autonomous, and gibberellin pathways, acting more independently of environmental stimuli $[9,10]$. When the switch towards flowering is made, the shoot apical meristem (SAM) transforms into an inflorescence meristem (IM) as an intermediate step. From the IM, floral meristems (FM) are initiated that can produce floral primordia [30]. The transition to reproduction is accompanied by shoot stem elongation (bolting).

\subsection{Floral Integrator Genes: An Overview}

In plants, the signaling pathways that are activated by various endogenous and environmental cues ultimately converge to a few floral integrator genes to control flowering time, leading to the activation of floral meristem identity genes, the first step in the formation of a flower [10]. In Arabidopsis, two floral integrators play a major role in the transition to flowering, FLOWERING 
LOCUS T (FT), which belongs to the PEBP (phosphatidylethanolamine-binding protein) family, and SUPPRESSOR OF OVEREXPRESSION OF CONSTANS 1 (SOC1/AGL20), a MADS-box transcription factor [9] (Figure 4). Two homologs of FT, TWIN SISTER OF FT (TSF) and TERMINAL FLOWER 1 (TFL1), act redundantly or antagonistically to $F T$, respectively [31,32]. If floral integrator genes were conserved between Arabidopsis and crops, mutations reducing FT, TSF and SOC1 orthologs activity would result in late flowering plants, whereas increased expression of the corresponding genes should induce early flowering. The opposite would occur for mutations or increased expression of TFL1.

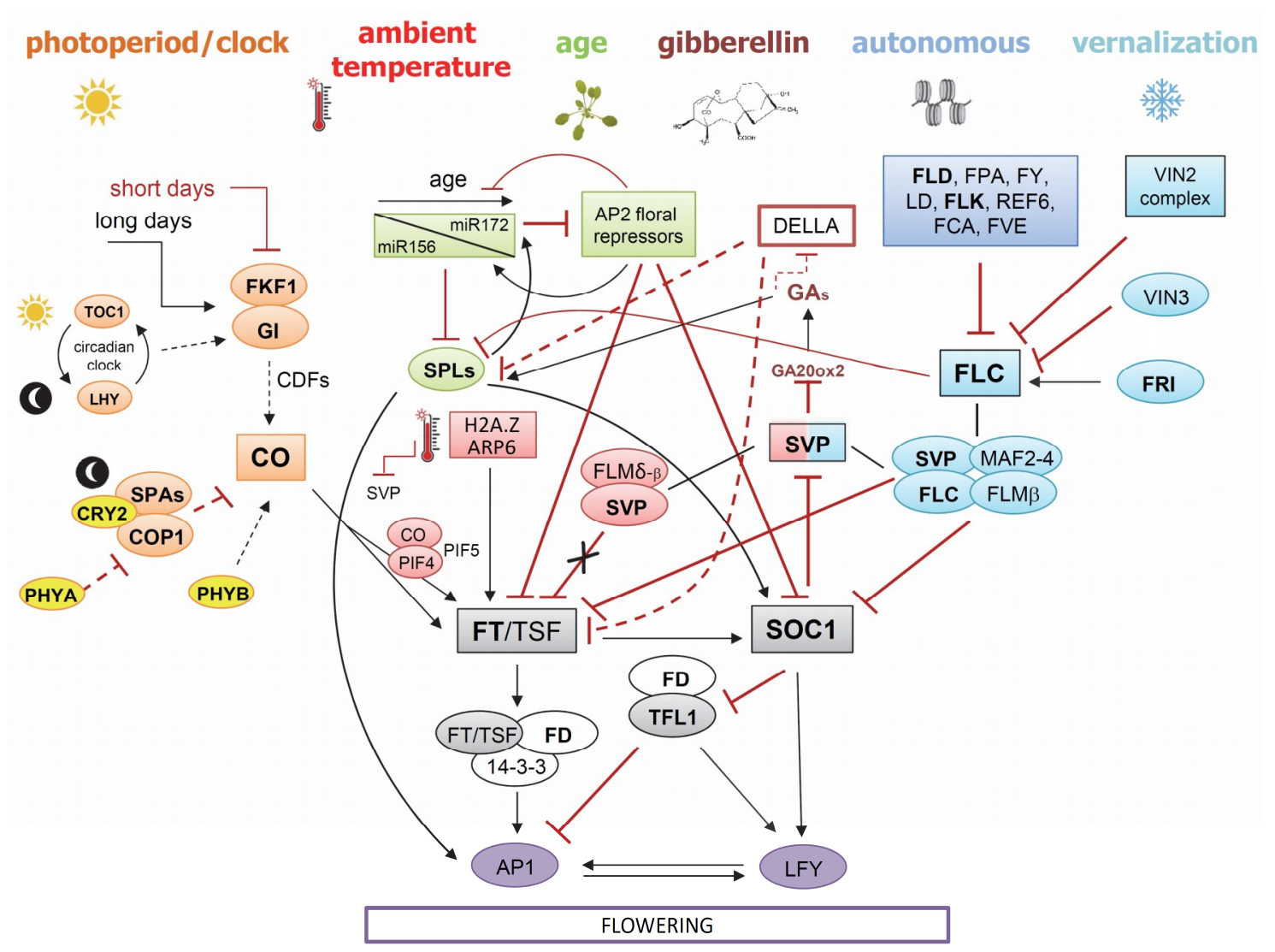

Figure 4. Main flowering time pathways acting in Arabidopsis thaliana: Photoperiod (orange and yellow), ambient temperature (red), age (green), gibberellins (brown), autonomous (sky blue), vernalization (light blue). Grey boxes represent the main floral integrators FT/TSF and SOC1. The two main genes conferring inflorescence meristem identity, AP1 and LFY, are indicated in purple. Squared boxes indicate genes having a pivotal role in the specific pathway. Boxes with rounded corners represent several genes or complexes. Solid and dotted lines indicate either direct or indirect regulation, black arrows and red T-ends indicate positive or negative regulation, respectively. The cartoon represents only the main regulatory genes in the different pathways, whereas the complete flowering time network, involving more than 300 genes, is available at the WikiPathways Web Site [33].

The FT/TFL family and SOC1 have a major role in flowering time response that seems to be conserved across different species [34]. However, due to Brassica genus evolutionary history, with genome triplication within diploid species of Brassica and polyploidism, B. napus, B. oleracea and B. napus contain several copies of floral integrator homologs. Among these, only some conserve a key role in flowering time whereas others may have been either inactivated or undergone a process of neofunctionalization [35]. Lettuce SOC1 shows a unique role in heat-promoted bolting [36], whereas its role downstream of $F T$ to induce flowering transition in natural conditions is yet to be determined. 


\subsubsection{Floral Integrator Genes in Brassicaceae}

In Arabidopsis, FT plays a key role in the floral transition process, since it is the mobile signal moving from the leaves, through the phloem, to promote flowering at the SAM [37,38]. In the leaves, the circadian clock-associated gene CONSTANS (CO) enhances FT expression under long-day (LD) conditions, while temperature-dependent genes such as SHORT VEGETATIVE PHASE (SVP) and FLOWERING LOCUS C (FLC) repress FT expression independently of day length [39-41]. FT protein is produced in the leaves and transported through the phloem to the SAM, with FT-INTERACTING PROTEIN 1 (FTIP1) assisting with FT protein transport [37]. At the SAM, FT interacts via a 14-3-3 protein with FLOWERING LOCUS D (FD) [42] to activate the floral promoter SOC1 and the downstream floral meristem identity genes APETALA 1 (AP1) and the AP1 paralog CAULIFLOWER (CAL) [38]. SOC1 also activates floral meristem identity through LEAFY (LFY) and AGAMOUS-LIKE 24 (AGL24). LFY, AP1 and CAL direct certain groups of cells in the flanks of the SAM to differentiate into floral meristems, leading to the transition from vegetative to reproductive phase [43]. A close homolog of FT, TWIN SISTER OF FT (TSF) with $82 \%$ amino acid identity, seems to act redundantly to $F T$. Overexpression of either FT or TSF results in early flowering, a mutation in FT results in late flowering under LD conditions and a mutation in TSF shows a greater effect under short-day (SD) conditions [31]. A more distantly related homolog of FT, TERMINAL FLOWER 1 (TFL1) with 59\% amino acid identity, acts antagonistically to FT. Plants overexpressing TFL1 are late flowering with an extended first inflorescence phase, during which they form cauline leaves and branches [44]. TFL1 is a mobile signal like FT [45], but acts as a transcription repressor rather than a transcriptional activator as FT [46]. The antagonistic activity of TFL1 and FT originates from an external loop in the protein [32] and interchanging one specific residue in the loop (Y85 in FT and H88 in TFL1) is sufficient to convert TFL1 into FT function and vice versa [44].

B. napus contains six paralogs of $F T$, four of TFL1 [47,48] and four paralogs of SOC1 (Table 3) [35]. FT paralogs map to six distinct regions of conserved blocks of the A and $\mathrm{C}$ genomes homologous to a common ancestral block of Arabidopsis chromosome 1. BnFT gene coding sequences show $92 \%$ to $99 \%$ identities to each other and $85 \%$ to $87 \%$ identity with those of Arabidopsis. Bna.FT.C02 and the corresponding ortholog in B. oleracea are not expressed, possibly due to the presence of a transposable element (TE) causing high cytosine methylation at the promoter [47]. Differently, three Bna.FT paralogs, Bna.FT.A02, BnaFT.C06a and Bna.FT.C06b, are expressed and were associated with two major QTL clusters for flowering time, one of which encompasses two Bna.FT paralogs Bna.FT-C06a and Bna.FT.C06b. Their function in flowering time variation was confirmed by association analysis in vernalization-free conditions in both spring and winter type cultivars of rapeseed. Bna.FT.A02 is expressed in leaves of both winter and spring type plants, with and without vernalization $[47,49]$, and was found to associate with flowering time in a panel of 188 Brassica spp. accessions collected from different geographic locations worldwide [50]. Bna.FT.C06 and Bna.FT.A07 are expressed in winter type plants after vernalization and spring type plants, but not in winter types without vernalization $[47,49]$. EMS (ethyl methanesulfonate) lines harboring different mutant alleles of Bna.FT.C06b were late flowering and displayed reduced fertility [51]. Plants harboring different mutant alleles of Bna.TFL1 paralogs were not affected in flowering time [51], whereas amongst the four paralogs of SOC1, only Bna.SOC1.A03 was associated with flowering time and seed yield-related QTLs on chromosome A03, and its expression was induced by vernalization [52]. These data point to a function of Bna.FT.A02 and Bna.FT.C06 in controlling flowering time, the latter also in response to vernalization similarly to their paralog in Arabidopsis, whereas B. napus paralogs of TFL1 seem to affect seed yield but not flowering time [51]. Bna.SOC1.A03 might play a role in flowering time control, but this is yet to be explored in B. napus species. These data are consistent with the association of Bna.FT-A02, but not B. napus TLF1 and SOC1 paralogs, with a spring-environment specific flowering QTL in double haploid populations grown in different environmental conditions [53]. 
Table 3. Flowering time genes in Brassica species.

\begin{tabular}{|c|c|c|c|c|c|c|c|c|}
\hline Pathway & Gene & Arabidopsis & $\begin{array}{l}\text { B. napus } \\
\text { gene ID }\end{array}$ & $\begin{array}{c}\text { B. napus } \\
\text { Chr position }\end{array}$ & $\begin{array}{l}\text { B. rapa } \\
\text { gene ID }\end{array}$ & $\begin{array}{c}\text { B. rapa } \\
\text { Chr position }\end{array}$ & $\begin{array}{l}\text { B. oleracea } \\
\text { gene ID }\end{array}$ & $\begin{array}{l}\text { B. oleracea } \\
\text { Chr position }\end{array}$ \\
\hline \multirow{19}{*}{$\begin{array}{c}\text { Floral } \\
\text { integrators }\end{array}$} & \multirow{2}{*}{ FT } & \multirow{2}{*}{ AT1G65480 } & $\begin{array}{l}\text { GSBRNA2T00090951001 } \\
\text { Bna.FT.A02 }\end{array}$ & A02:6375936.6379058 & $\begin{array}{c}\text { Bra022475 } \\
\text { BrFT1 }\end{array}$ & A02:8551268.8553758 & \multirow[b]{2}{*}{ Bol045330 } & \\
\hline & & & $\begin{array}{c}\text { GSBRNA2T00030311001 } \\
\text { Bna.FT.C02 }\end{array}$ & C02:996695.998788 & & & & $\begin{array}{l}\text { Scaffold000001_P2: } \\
\text { 1990327.1992083 }\end{array}$ \\
\hline & \multirow{6}{*}{ TSF } & \multirow{6}{*}{ AT4G20370 } & $\begin{array}{l}\text { GSBRNA2T00124448001 } \\
\text { Bna.FT.A07 }\end{array}$ & A07:18855196.18857952 & $\begin{array}{c}\text { Bra004117 } \\
\text { BrFT2 }\end{array}$ & A07:20213069.20215397 & \multirow{4}{*}{$\begin{array}{l}\text { Bol039209 } \\
\text { Bol017639 }\end{array}$} & \\
\hline & & & GSBRNA2T00146560001 & A07:22787807.22790354 & Bra015710 & A07:24515213.24516895 & & \\
\hline & & & GSBRNA2T00077948001 & C02:20907503.20909228 & & & & C02:19450855.19452577 \\
\hline & & & GSBRNA2T00113342001 & C04:12435074.12437644 & & & & C04:17148775.17151658 \\
\hline & & & $\begin{array}{l}\text { GSBRNA2T00067517001 } \\
\text { Bna FT C06 }\end{array}$ & C06:28552966.28555216 & & & Bol012573 & C07:9349005.9351279 \\
\hline & & & GSBRNA2T00050890001 & Cnn:48285424.48286397 & & & Bol027595 & C07:1423408.1425153 \\
\hline & \multirow{6}{*}{ TFL1 } & \multirow{6}{*}{ AT5G03840 } & GSBRNA2T00136426001 & A10:16767409.16768474 & Bra009508 & A10:15774055.15775120 & \multirow{6}{*}{$\begin{array}{l}\text { Bol005471 } \\
\text { Bol015337 } \\
\text { Bol010027 }\end{array}$} & \multirow{6}{*}{$\begin{array}{c}\text { C02:1447642.1448756 } \\
\text { C03:438359.439413 } \\
\text { C09:39511589.39512660 }\end{array}$} \\
\hline & & & GSBRNA2T00119620001 & Ann:609805.611005 & Bra028815 & A02:545667.546787 & & \\
\hline & & & GSBRNA2T00078727001 & C02:1320757.1321835 & & & & \\
\hline & & & GSBRNA2T00134290001 & C03:673349.674628 & & & & \\
\hline & & & GSBRNA2T00073025001 & Cnn:9572005.9573076 & & & & \\
\hline & & & & & Bra005783 & A03:603455.604516 & & \\
\hline & \multirow{5}{*}{ SOC1 } & \multirow{5}{*}{ AT2G45660 } & GSBRNA2T00011646001 & $\begin{array}{l}\text { A03:901877.905188 } \\
\text { BnSOC1-A3 }\end{array}$ & Bra000393 & A03:10918286.10920672 & \multirow{5}{*}{$\begin{array}{l}\text { Bol021742 } \\
\text { Bol030200 } \\
\text { Bol029556 }\end{array}$} & \multirow{5}{*}{$\begin{array}{c}\text { C04:40413670.404148880 } \\
\text { C04:2998426.2999594 } \\
\text { C03:13421127.13422327 }\end{array}$} \\
\hline & & & GSBRNA2T00063263001 & A04:18732428.18735897 & Bra039324 & A04:18723546.18725960 & & \\
\hline & & & GSBRNA2T00116723001 & A05:2627051.2630394 & Bra004928 & A05:2530305.2532747 & & \\
\hline & & & $\begin{array}{l}\text { GSBRNA2T00037309001 } \\
\text { GSBRNA2T00083011001 }\end{array}$ & $\begin{array}{c}\text { C04:48074887.48078345 } \\
\text { C04:867297.870707 }\end{array}$ & & & & \\
\hline & & & GSBRNA2T00029970001 & Cnn:35198162.35204681 & & & & \\
\hline \multirow{10}{*}{ Vernalization } & \multirow{10}{*}{ FLC } & \multirow{10}{*}{ AT5G10140 } & $\begin{array}{l}\text { GSBRNA2T00143535001 } \\
\text { Bna FLC A02 }\end{array}$ & A02:134362.138212 & $\begin{array}{c}\text { Bra028599 } \\
\text { BrFLC2 }\end{array}$ & A02:1524995.1528254 & \multirow{10}{*}{$\begin{array}{c}\text { Bol024642 } \\
\text { BoFLC4 } \\
\text { BoFLC2 } \\
\text { Bol008758 } \\
\text { BoFLC3 } \\
\text { BoFLC5 } \\
\text { Bol043693 } \\
\text { BoFLC1 }\end{array}$} & \\
\hline & & & GSBRNA2T00129741001 & A03:1360971.1364359 & $\begin{array}{l}\text { Bra006051 } \\
\text { BrFLC3 }\end{array}$ & A03:1764912.1767856 & & \\
\hline & & & GSBRNA2T00142187001 & A03:6240056.6245305 & Bra022771 & A03:6971946.6976797 & & \\
\hline & & & GSBRNA2T00135921001 & A10:14998617.15003197 & Bra009055 & A10:13856133.13860473 & & \\
\hline & & & GSBRNA2T00068991001 & C02:208562.212139 & & & & C02:2720826.2721596 \\
\hline & & & DHA.ГLC.CUL & & & & & C02:2722189.2724345 \\
\hline & & & GSBRNA2T00134620001 & C03:2001058.2004665 & & & & С03:1890867.1893743 \\
\hline & & & GSBRNA2T00024568001 & С03:8403312.8410062 & & & & C03:49708405.49709316 \\
\hline & & & GSBRNA2T00016124001 & C09:46345350.46350092 & & & & \multirow{2}{*}{ C09:37175182.37179020 } \\
\hline & & & GSBRNA2T00016119001 & C09:46366645.46371180 & & & & \\
\hline
\end{tabular}


Table 3. Cont.

\begin{tabular}{|c|c|c|c|c|c|c|c|c|}
\hline Pathway & Gene & Arabidopsis & $\begin{array}{l}\text { B. napus } \\
\text { gene ID }\end{array}$ & $\begin{array}{l}\text { B. napus } \\
\text { Chr position } \\
\end{array}$ & $\begin{array}{l}\text { B. rapa } \\
\text { gene ID }\end{array}$ & $\begin{array}{c}\text { B. rapa } \\
\text { Chr position } \\
\end{array}$ & $\begin{array}{l}\text { B. oleracea } \\
\text { gene ID }\end{array}$ & $\begin{array}{l}\text { B. oleracea } \\
\text { Chr position }\end{array}$ \\
\hline & \multirow{4}{*}{ FRI } & \multirow{4}{*}{ AT4G00650 } & $\begin{array}{l}\text { GSBRNA2T00066686001 } \\
\text { Bna.FRI.Xa }\end{array}$ & A03:6053113.6055294 & $\begin{array}{c}\text { Bra029192 } \\
\text { BrFRIa }\end{array}$ & A03:6784863.6787013 & & \\
\hline & & & $\begin{array}{l}\text { GSBRNA2T00120967001 } \\
\text { Bna.FRI.Xb }\end{array}$ & A10:4019556.4021675 & $\begin{array}{l}\text { Bra035723 } \\
\text { BrFRIb }\end{array}$ & A10:4133444.4134764 & & \\
\hline & & & $\begin{array}{l}\text { GSBRNA2T00052682001 } \\
\text { Bna.FRI.Xd }\end{array}$ & С03:8149599.8151810 & & & $\begin{array}{l}\text { Bol028107 } \\
\text { BoFRIa }\end{array}$ & C03:7962008.7964180 \\
\hline & & & $\begin{array}{l}\text { GSBRNA2T00152364001 } \\
\text { Bna.FRI.XC }\end{array}$ & C09:29041826.29043953 & & & Bol004294BoFRIb & Scaffold000327:204688.206816 \\
\hline \multirow{4}{*}{$\begin{array}{l}\text { Ambient } \\
\text { temperature }\end{array}$} & \multirow{4}{*}{ SVP } & \multirow{4}{*}{ AT2G22540 } & GSBRNA2T00032884001 & A04:10961147.10963402 & Bra030228 & A04:10192172.10194736 & & \\
\hline & & & GSBRNA2T00078179001 & А09:29590705.29594744 & Bra038511 & A09:33434743.33437921 & \multirow{3}{*}{ Bol031759 } & \multirow{3}{*}{ Scaffold000053:1406474.1408404 } \\
\hline & & & GSBRNA2T00149752001 & C04:36478652.36481951 & & & & \\
\hline & & & GSBRNA2T00127429001 & C08:32995398.32998881 & Bol044741 & C08:35213085.35214818 & & \\
\hline \multirow{4}{*}{ Photoperiod } & \multirow[b]{2}{*}{$\mathrm{CO}$} & \multirow{3}{*}{ AT5G15840 } & GSBRNA2T00135488001 & A10:13358777.13360064 & Bra008669 & A10:12117648.12118929 & \multirow{3}{*}{ Bol030488 } & \multirow{3}{*}{ C09:33143053.33144339 } \\
\hline & & & GSBRNA2T00035272001 & C09:43745679.43747139 & & & & \\
\hline & \multirow{2}{*}{ GI } & & GSBRNA2T00015763001 & A09:22588149.22593013 & Bra024536 & A09:25756404.25760934 & & \\
\hline & & AT1G22770 & GSBRNA2T00119480001 & C05:11778931.11784461 & & & Bol023541 & $\begin{array}{l}\text { Scaffold000099_P1: } \\
\quad 794479.799157\end{array}$ \\
\hline \multirow{23}{*}{ Age } & \multirow{5}{*}{ SPL3 } & \multirow{5}{*}{ AT2G33810 } & GSBRNA2T00064576001 & A04:15462653.15463366 & Bra021880 & A04:15123762.15124274 & \multirow{5}{*}{$\begin{array}{l}\text { Bol036997 } \\
\text { Bol037895 } \\
\text { Bolo27299 }\end{array}$} & \multirow{5}{*}{$\begin{array}{l}\text { C06:40526300.40526809 } \\
\text { C04:35540992.35541501 } \\
\text { C04:20510435.20510961 } \\
\end{array}$} \\
\hline & & & GSBRNA2T00095270001 & A05:5425249.5426076 & Bra005470 & A05:5668800.5669314 & & \\
\hline & & & GSBRNA2T00132295001 & C03:9629272.9630113 & & & & \\
\hline & & & GSBRNA2T00020688001 & $\begin{array}{l}\text { C04:44354526.443555241 } \\
\text { Con:4854484 485511? }\end{array}$ & & & & \\
\hline & & & $\begin{array}{l}\text { GSBRNA2TT00038835001 } \\
\text { GSBRNA200123166001 }\end{array}$ & $\begin{array}{l}\text { Cnn:18854484.4855112 } \\
\text { A04:17845227.17447617 }\end{array}$ & Bra016891 & A04:17839490.17841541 & & \\
\hline & \multirow{5}{*}{ SPL9 } & \multirow{5}{*}{ AT2G42200 } & GSBRNA2T00132740001 & A05:1443071.1445187 & Bra004674 & A05:1325605.1327587 & \multirow{3}{*}{ Bol004847 } & \multirow{4}{*}{ C04:966922.968875 } \\
\hline & & & GSBRNA2T00010840001 & C04:1886612.1888780 & & & & \\
\hline & & & GSBRNA2T00084688001 & C04:46904649.46905101 & & & & \\
\hline & & & GSBRNA2T00084692001 & C04:46915351.46917939 & & & Bol002678 & \\
\hline & & & & & Bra015085 & A07:5833985.5836119 & & \\
\hline & \multirow{4}{*}{ SPL15 } & \multirow{4}{*}{ AT3G57920 } & GSBRNA2T00034335001 & A04:154881.156614 & Bra014599 & A04:1684031.1685273 & & \multirow{4}{*}{$\begin{array}{c}\text { C04:9176952.9178238 } \\
\text { C07:28887260.28888520 }\end{array}$} \\
\hline & & & GSBRNA2T00098900001 & A07:14658857.14660105 & Bra003305 & A07:15783674.15784920 & & \\
\hline & & & GSBRNA2T00087887001 & C04:25001142.25003655 & & & Bol011022 & \\
\hline & & & GSBRNA2T00105779001 & C06:19172101.19173360 & & & Bol007052 & \\
\hline & \multirow{4}{*}{ GA20OX1 } & & & & Bra013890 & $\begin{array}{l}\text { A01:8279446.8280885 } \\
\end{array}$ & & \\
\hline & & & & & Bra019165 & A03:25974634.25976038 & & \\
\hline & & AT4G25420 & & & & & Bol042237 & C06:43862307.43863764 \\
\hline & & & & & & & Bol041615 & $\begin{array}{l}\text { Scaffold000009_P1: } \\
\text { 317473.317667 }\end{array}$ \\
\hline & & & GSBRNA2T00036929001 & $\begin{array}{l}\text { A02:5851980.5853392 } \\
\text { A10:6243369.6244766 }\end{array}$ & $\begin{array}{l}\text { Bra022565 } \\
\text { Bra028277 }\end{array}$ & A02:7878457.7879856 & & \\
\hline & & & GSBRINA210011021/001 & $\begin{array}{l}\text { AlU:6243369.6244/66 } \\
\text { C02.11109632 11111035 }\end{array}$ & & & & Scaffold000001_P2: \\
\hline & GA200X2 & AT5G51810 & GSBRNA2T00153037001 & C02:11109632.11111035 & & & Bol045266 & 739593.740993 \\
\hline & & & $\begin{array}{l}\text { GSBRNA2T00108688001 } \\
\text { GSBRNA2T00108686001 }\end{array}$ & $\begin{array}{l}\text { C09:30358041.30359437 } \\
C 09 \cdot 3036857830369971\end{array}$ & & & Bol029404 & C09:18392061.18393124 \\
\hline & & & GSBRNA2T00025818001 & Cnn:77727013.77728046 & & & & \\
\hline
\end{tabular}


Table 3. Cont.

\begin{tabular}{|c|c|c|c|c|c|c|c|c|}
\hline Pathway & Gene & Arabidopsis & $\begin{array}{l}\text { B. napus } \\
\text { gene ID }\end{array}$ & $\begin{array}{c}\text { B. napus } \\
\text { Chr position }\end{array}$ & $\begin{array}{l}\text { B. rapa } \\
\text { gene ID }\end{array}$ & $\begin{array}{c}\text { B. rapa } \\
\text { Chr position }\end{array}$ & $\begin{array}{l}\text { B. oleracea } \\
\text { gene ID }\end{array}$ & $\begin{array}{l}\text { B. oleracea } \\
\text { Chr position }\end{array}$ \\
\hline \multirow{10}{*}{ Gibberellin } & \multirow{4}{*}{ GA20OX3 } & \multirow{4}{*}{ AT5G07200 } & & & $\begin{array}{l}\text { Bra028706 } \\
\text { Bra005927 } \\
\text { Bra010064 } \\
\text { Bra009285 }\end{array}$ & $\begin{array}{l}\text { A02:1065763.1067251 } \\
\text { A03:1251910.1253082 } \\
\text { A06:14066314.14068214 } \\
\text { A10:14501966.14503398 }\end{array}$ & & \multirow{4}{*}{$\begin{array}{c}\text { C02:2131323.2133012 } \\
\text { C03:1262233.1263937 } \\
\text { C09:38109369.38110750 } \\
\text { Scaffoldo000009_P1: } \\
\text { 3131428.3323030 } \\
\text { Scaffold000091:1192479.119591 }\end{array}$} \\
\hline & & & & & & & $\begin{array}{l}\text { Bol024532 } \\
\text { Bolo088872 }\end{array}$ & \\
\hline & & & & & & & Bol041616 & \\
\hline & & & & & & & Bol024814 & \\
\hline & \multirow{5}{*}{ GA20OX4 } & \multirow{5}{*}{ AT1G60980 } & GSBRNA2T00070537001 & A09:7950969.7952898 & Bra027106 & A09:8952409.8954196 & & \multirow{5}{*}{$\begin{array}{c}\text { C03:52855996.52857792 } \\
\text { Scaffold000003_P1: } \\
\text { 2530105.2531509 } \\
\text { Scaffold000262:280424.282063 }\end{array}$} \\
\hline & & & GSBRNA2T00043758001 & Ann:21491303.21492435 & Bra039251 & $\begin{array}{l}\text { Scaffold000162: } \\
\text { 175188.176593 }\end{array}$ & & \\
\hline & & & $\begin{array}{l}\text { GSBRNA2T00043759001 } \\
\text { GSBRNA2T00080857001 }\end{array}$ & $\begin{array}{l}\text { Ann:21493033.21494525 } \\
\text { Cnn:11274341.11276251 }\end{array}$ & Bra031467 & A01:17039613.17041240 & Bol014320 & \\
\hline & & & GSBRNA2T00028142001 & Cnn:34189212.34190700 & & & Bol044153 & \\
\hline & & & & & & & Bol007374 & \\
\hline & GA20OX5 & AT1G44090 & $\begin{array}{l}\text { GSBRNA2T00097054001 } \\
\text { GSBRNA2T00060328001 } \\
\text { GSBRNA2T00013490001 }\end{array}$ & $\begin{array}{c}\text { A08:969550.970698 } \\
\text { C08:6199021.6199389 } \\
\text { Cnn: } 72340763.72341689\end{array}$ & Bra014019 & A08:4525615.4527790 & Bol021441 & C07:30202821.30203904 \\
\hline
\end{tabular}

Note: Gene symbols, gene names and position in the chromosome of the paralogs for B. napus, B. rapa and B. oleracea, and corresponding A. thaliana genes, are shown for each pathway. Black text means the same chromosome in all Brassica species, grey text means best B. napus hit from B. rapa or B. oleracea protein sequence; brown text means no direct homolog available in the list with A. thaliana syntheny (http://brassicadb.org/brad/searchAll.php). 
Three paralogs of SOC1 (Br004928, Br000393 and Br009324) and two paralogs of FT (BrFT) are found and expressed in B. rapa (Table 3) [47,54]. BrFT1 and BrFT2 show a similar expression as their corresponding B. napus orthologs Bna.FT.A02 and Bna.FT.A07, respectively. BrFT1 is expressed in all plant types and diurnally regulated $[47,54] . B r F T 2$ is only expressed in winter type plants after vernalization and spring-type plants [47]. A TE in exon 2 of BrFT2 causes plants to flower 4.9 days later in spring and 14.7 days later in autumn. Due to the bigger effect under SD conditions, it was suggested that BrFT2 might be an ortholog of AtTSF [49], but this still needs to be confirmed. Overexpression of a B. rapa SOC1 ortholog (BrAGL20) in B. napus causes early flowering [55], suggesting that the function of this gene may be conserved in Brassicaceae. Moreover, association between flowering time and expression of the two SOC1 paralogs Br004928 and Br000393 was found in a natural population of B. rapa [56].

Four paralogs of FT (BoFT) (two copies on C02 and one on C04 and C06), and three homologs of SOC1 (BoSOC1) (C03 and two copies on C04) have been identified in the genomes of B. oleracea (Table 3) [35], but no functional studies are available so far.

One FT, TFL1, TSF and two SOC1 genes, sharing $82.58 \%, 89.47 \%, 83.3 \%, 85.49 \%$ and $88.82 \%$ of nucleotide homology with their Arabidopsis homologs, can be found in the de novo assembled transcriptome of D. tenuifolia [57] that was obtained from leaves of stressed young plants. However, no characterization of floral integrator genes is available for this species.

\subsubsection{Floral Integrator Genes in Asteraceae}

In L. sativa, an FT homolog (LsFT) was characterized [58] and shown to express in the largest lettuce leaves, stems and flower bud in controlled high temperature $\left(35 / 25^{\circ} \mathrm{C}\right)$ conditions which induce lettuce flowering [58]. LsFT overexpression could induce early flowering in transgenic A. thaliana, although the phenotype was less strong compared to AtFT overexpressing plants. However, other studies showed that expression of LSFT under the viral 35S constitutive promoter control could fully complement Arabidopsis ft null mutant [59]. Correlation between LsFT expression and lettuce bolting (measured as the days to the first visible elongated stem) was further analyzed in nine lettuce varieties, which were selected amongst 705 lettuce accessions, with either late, middle and early bolting times [59]. Heat treatment $\left(35^{\circ} \mathrm{C}\right.$ day $/ 25^{\circ} \mathrm{C}$ night) for $48 \mathrm{~h}$ also promoted expression of LsFT in all lettuce varieties. RNAi-mediated knockdown of $L s F T$ in $L$. sativa results in a late bolting phenotype, lack of response to heat treatment and reduced levels of LsLFY and LsAP1 [59], which expression is most abundant at the onset of bolting $[58,60]$. Induction of high LsFT expression during the transition to reproductive growth and activation of LSLFY and LSAP1 was also observed in three heading and non-heading lettuce varieties grown in the field in natural conditions [60].

Transcriptomic data from lines that are either bolting resistant or sensitive to high temperature, identified floral integrator genes like LsSOC1, LSFT and LsAP1 as upregulated in the bolting sensitive line. [61]. Gene expression analysis of shoot apical meristem cells undergoing flowering transition in response to high temperature on the bolting-sensitive lettuce line S39, and further gene function studies, confirmed a role of $L S S O C 1$ in heat-promoted bolting in lettuce [36]. When expressed from the $35 \mathrm{~S}$ promoter, $\mathrm{LSSOC1}$ acts as an activator of flowering in A. thaliana and can fully complement the Arabidopsis soc1 null mutant [36]. RNAi-mediated knockdown of LsSOC1 in L. sativa results in late flowering plants with reduced LSLFY expression [36]. The important function of LsSOC1 in heat induced bolting in lettuce was further supported by the identification of two heat shock transcription factors that bind to the promoter of LSSOC1 [36].

Overall, LsFT and LSSOC1, and their putative floral meristem identity targets LSAP1 and LsLFY seem to play a key role in flowering transition in L. sativa, similar to other plant species. However, the key role of LSSOC1 in promoting heat-induced flowering was not observed in other species so far, and may constitute a unique feature whose conservation amongst other Asteraceae species should be investigated. 


\subsection{Overview of the Vernalization and Autonomous Pathways}

Vernalization refers to a process by which prolonged period of cold (winter) renders plants competent to flower, often many weeks later when other conditions, like day length or ambient temperature, are favorable [62]. Duration of cold exposure and the optimal temperature for vernalization vary among species, and among ecotypes of a given species, as plants adapt to periods of cold that are typical of a winter season in their natural habitat [8]. Plants can be either annual, biennial or perennial depending on the time required to complete their life cycles, from germination to seed setting, and the length of vegetative phase. Perennial plants can reproduce several times with recurrent vegetative to flowering cycles, and often do not respond to vernalization in the first year(s) of life. In annuals and biennials, vegetative to reproductive transition occurs once and flowering is associated with senescence and death of the whole plant [63].

In Arabidopsis, two genes are responsible for much of the variation in flowering time among natural population, FLOWERING LOCUS C (FLC), which acts as a repressor of flowering, and FRIGIDA $(F R I)$, which promotes expression of $F L C$. In response to prolonged exposure to low temperatures, $F L C$ is progressively repressed through epigenetic and silencing mechanisms, leading to flowering response. VERNALIZATION INSENSITIVE3 (VIN3), a factor needed for epigenetic silencing of FLC, was recently found to have a key and complex role in vernalization and response to different temperatures [64]. These studies indicate that the absence of warmth rather than the presence of cold might be necessary for vernalization. Pivotal roles of FLC and VIN3 in flowering time adaptation to natural environments were also confirmed by genome-wide association studies with nearly complete genotype information from 1135 Arabidopsis accessions [65].

The vernalization response is largely conserved within the Brassicaceae species due to conserved function of the main regulators FLC and FRI. However, the complex rearrangements occurred in the Brassica genomes [66-68] likely led to neofunctionalization processes of some FLC and FRI paralogs, which have lost their role in flowering control in response to vernalization.

In perennial Brassicaceae (e.g., Arabis alpine), orthologs of FLC are repressed by winter cold and reactivated in spring conferring seasonal flowering patterns, differently from annuals where they are stably repressed by cold as in Arabidopsis. Sequence comparisons of FLC orthologs from annuals and perennials identified two regulatory regions in the first intron whose sequence variation correlates with divergence of the annual and perennial expression patterns [69]. Unstable repression of a C. intybus FLC homolog during the cold season was also confirmed in root chicory that is perennial [22]. This points to key role of $F L C$ regulation in evolutionary transitions between perenniality and annuality that seems to have occurred often among higher plants.

Questions regarding flowering response to vernalization in Lactuca species remain open as cultivated plants seem to have lost the need for the vernalization that is present in wild relatives. More generally, several species in the Asteraceae family require vernalization to flower, however molecular mechanisms underlying this trait have been poorly investigated.

Overall, null mutations or decreased expression of either FLC or FRI, as well increased expression of FLC negative regulators, would result in early and vernalization-independent flowering induction.

\subsubsection{Vernalization and Autonomous Pathway in Brassicaceae}

In A. thaliana, winter annuals contain active alleles at two loci, FLOWERING LOCUS C (FLC) and FRIGIDA (FRI), whereas summer annuals harbor inactivating mutations in one or both of these genes [70-73]. FLC is a MADS box transcription factor that acts as a repressor of flowering by directly binding to the floral promoting genes FT, SOC1 and SQUAMOSA PROMOTER-BINDNG PROTEIN-LIKE 15 (SPL15) to block their transcription [40,70] (Figure 4). FRIGIDA encodes a coiled-coil protein that promotes FLC transcription, probably by affecting its chromatin structure [72]. During cold treatment, FLC is repressed through chromatin remodeling [74], and epigenetic mechanisms maintain the repressed state of $F L C$ upon return to higher temperatures. [75]. During vernalization, transcription of several long noncoding RNAs (lncRNAs) starts from sites within the intron 
(COLDAIR) and promoter of FLC (COLDWRAP) and a set of antisense transcripts of FLC, collectively named COOLAIR, are induced and physically associate with the FLC locus. This accelerates the transcriptional shutdown of $F L C$ by recruitment of chromatin remodelers and switching of chromatin states [76-79]. Histone modifications mediated by genes like VERNALIZATION 1 (VRN1), VRN2, VERNALIZATION INSENSITIVE 3 (VIN3), cooperate to repress FLC at chromatin level [80-84]. FLOWERING LOCUS CA (FCA), FLOWERING LOCUS D (FLD), FLOWERING LOCUS KH DOMAIN (FLK), FLOWERING LOCUS PA (FPA), FLOWERING LOCUS VE (FVE), FLOWERING LOCUS Y (FY), and LUMINIDEPENDENS (LD) also repress FLC to accelerate flowering independently of vernalization. The corresponding genes are part of the so-called autonomous flowering pathway and act through repressive chromatin remodeling complexes and small RNAs to negatively regulate FLC [8]. FLC-like proteins form a specific phylogenetic clade, some members of which (MADS AFFECTING FLOWERING, MAF) can form protein complexes with FLC and redundantly affect flowering in response to vernalization [85].

Many Brassica species are biennial and require vernalization at seedling or mature plant stage. The temperature and duration of vernalization varies between spring, semi-winter and winter type plants: Flowering occurs without vernalization in spring types, with low vernalization (exposure to cold for shorter periods) in semi-winter types and with longer exposure to cold temperature in winter types. Rapid cycling populations, with extremely short reproductive cycles and which flower early independent of vernalization, have been developed in different Brassica species [86]. Comparative phylogenetic analysis of B. napus, B. rapa and B. oleracea identified three FLC clades which reflects the whole-genome triplication events that occurred during the evolution of the Brassica genome [66,87]. Four FLC paralogs in B. rapa (BrFLC) [67], five in B. olearacea (BoFLC) [68] and nine in B. napus (BnaFLC) [66] were identified (Table 3). FLC homologs in the chromosome A10 and C02 of B. napus, and an additional one in A03 (Bna.FLC.A03b), were initially associated with flowering time in $B$. napus. However, genome-wide association studies of flowering time and vernalization response in 188 different accessions demonstrated that Bna.FLC.A02 and Bna.FLC.C02 account for a significant proportion (22\%) of natural variation in diverse accessions [50]. Expression of eight out of nine BnaFLC genes were downregulated during vernalization. This suggests that vernalization modulates FLC expression levels in a similar manner as in Arabidopsis. A cold-responsive FLC-FRI-CBF1 cluster including Bna.FLC.A03b and Bna.FRI.A3/Bna.FRI.Xa was identified. It has been shown in other species that gene clusters with functionally related genes might be maintained by selection pressure to enable adaptation to extremely diverse environments in a similar manner as the cold-responsive cluster FLC-FRI-CBF1 [88,89]. Bna.FLC.A03b shows enhanced expression levels in winter compared to semi-winter type plants [66]. Four FRI possible orthologs were identified in B. napus. [14]. Association analysis in a double-haploid population revealed that six SNPs (Single Nucleotide Polymorphism) in Bna.FRI.A03 are associated with flowering time variation in 248 accessions, and that specific haplotypes are over-represented in semi-winter or winter types, while spring type plants did not show this correlation $[3,14,90]$. These data suggest that Bna.FLC.A03b and Bna.FRI.A03 are functionally related, similar to $F L C$ and $F R I$ in $A$. thaliana, and have a key role in $B$. napus flowering response to vernalization.

In B. rapa, both Bra.FLC.A10 (BrFLC1) and Bra.FLC.A02 (BrFLC2), were found to underlie QTLs for flowering time in different studies [49,91-94], possibly due to alternative splicing and a 57 InDel (INsertion/DELetion) leading to a non-functional allele [91], respectively. However, the most similar B. rapa homolog of Bna.FLC.A03b, BrFLC5, is truncated and is expected to be not functional [95]. A recent study showed that the reference genome sequence indeed contains a truncated BrFLC5 sequence, while other accessions contain functional genes with different splicing patterns resulting from a single nucleotide mutation. Genetic variation within the BrFLC5 locus indicates that BrFLC5 is not a major regulator of flowering time [96]. BrFLC2 acts as a repressor of flowering when overexpressed in A. thaliana and shows early flowering when silenced in B. rapa ssp. chinensis (Pak-choi) [95,97]. BrFLC2 seems to negatively regulate flowering by enhancing MADS AFFECTING FLOWERING2 (BrMAF2) expression, while inhibiting expression of BrSOC1 and BrSPL15 [97]. In B. rapa seedlings, BrFLC2 
expression levels decrease upon vernalization treatment and remained low after return to higher temperatures. Contrarily to $B r F L C 2$, expression of $B r V I N 3$, a negative regulator of $F L C$, is very low in 14-day-old seedlings without vernalization, activates after four-week vernalization treatment on seeds and decreases again after transfer to higher temperature [95].

At chromatin level, BrFLC genes contained active chromatin marks H3K4me3 and H3K37me3 under normal growth conditions. During vernalization, alternative splicing of five BrCOOLAIR transcripts (BrFLC2as406, -477, -599, -755 and -816) reduced H3K37me3 levels of BrFLC1, BrFLC2 and BrFLC3. Differently from the Arabidopsis COOLAIR, BrCOOLAIR is located further downstream of BrFLC2 and, during vernalization, class II transcripts, which are polyadenylated in the region complementary to the BrFLC promoter, are more abundant than class I, which are polyadenylated in the region complementary to the last intron of BrFLC [98]. Together with reduced H3K37me3 levels, an increase of H3K27me3 was detected in BrFLC1, BrFLC2 and BrFLC3 upon vernalization, which was maintained when plants were transferred to higher temperatures [95]. Besides affecting $F L C$, vernalization also resulted in enhanced H3K27 methylation in BrMAF1 and DNA demethylation of two subunits of casein kinase II (CK2), BrCKA2 and BrCKB4, altering daily expression period of clock-related gene CIRCADIAN CLOCK-ASSOCIATED1 (BrCCA1) [95,99]. These findings indicate that the mechanisms underlying vernalization in B. rapa are very similar to those of Arabidopsis and involve chromatin modifications and COOLAIR antisense transcription.

In B. oleracea, expression levels of BoFLC2 and BoVRN are enhanced in early compared to late flowering $B$. oleracea genotypes when grown at ambient temperature $\left(22.5^{\circ} \mathrm{C}\right.$ and $12 / 12 \mathrm{~h}$ light $/$ dark period) [100]. Two alleles for BoFLC4 are described, which both confer a requirement for vernalization but respond with different kinetics to temperature shifts. Plants containing allele E9 require longer cold periods and flower late compared to those harboring allele E5. Introduction of genomic fragments containing the BoFLC4 $4^{E 5}$ or BoFLC $C^{E 9}$ allele complemented an Arabidopsis flc null mutant, with a stronger effect for BoFLC ${ }^{E 9}$ [101]. The closest B. oleracea ortholog of BnaXFRId, BoFRIa, also acts as a repressor of flowering when transformed into an Arabidopsis fri null mutant [90,101,102]. This indicates that FLC and FRI function in vernalization is also conserved in B. olearacea.

$R$. sativus is not a vernalization-requiring plant, but cold treatment does accelerate flowering. Radish transcriptome analysis during vernalization resulted in the identification of several vernalization-related differentially expressed genes [18]. Three copies of RsFLC were detected and all three act as flowering repressors when overexpressed in A. thaliana [103]. RsFLC expression before vernalization was enhanced in a late- compared to an early-bolting $R$. sativus inbred line, and reduced during vernalization or after GA treatment $[18,104,105]$. Overall, negative regulators of the vernalization pathway, such as RsFLC, RsMAF2, RsSPA1, and RsAGL18, were highly expressed in the late-bolting line, whereas positive regulators of vernalization, such as RsVRN1, RsVIN3, and RsAGL19 were relatively highly expressed in the early-bolting line [104]. These results suggest that the vernalization pathway is conserved between radish and Arabidopsis.

D. tenuifolia is not a vernalization-requiring plant, and cold treatment of either seeds or plantlets does not accelerate flowering. Hence, even though DtFLC acts as repressor of flowering when overexpressed in A. thaliana and can complement the Arabidopsis flc null mutant, its role as a regulator of flowering time in wild rocket has to be further investigated $[19,106]$.

\subsubsection{Vernalization and Autonomous Pathway in Asteraceae}

Wild lettuce-related species like L. virosa require vernalization to induce flowering. The cultivated L. sativa does not require a cold treatment for flowering, but a few days of cold does result in a better germination. Expression of the lettuce homolog of $F V E, F L D$ and $L D$ of the autonomous pathways were found to correlate with $L S F T$ expression and flowering induction in two early or late L. sativa varieties grown in the field [60]. This finding suggests the existence and function of the autonomous pathway in lettuce flowering induction. However, the expression of lettuce $F L C$ homologous genes 
was not analyzed either in this or in other studies, which impedes any further consideration about a possible role of $F L C$-like genes in cultivated lettuce.

A FLC-like gene, CiFL1, was identified and studied in C. intybus, which is biennial and requires vernalization at seedling or mature plant stage. Overexpression of CiFL1 in Arabidopsis causes late flowering and prevents upregulation of the AtFLC target FLOWERING LOCUS T by photoperiod, suggesting functional conservation between root chicory and Arabidopsis [107]. CiFL1 was repressed during vernalization of seeds or plantlets of chicory, like AtFLC in Arabidopsis. However, CiFL1 repression was not maintained when plants were returned to warmer temperatures. This may be linked to the perenniality of root chicory compared with the annual life cycle of Arabidopsis. [22]. Indeed, recent studies on the divergence of seasonal flowering behavior among annual and perennial species in Brassicaceae showed that in perennial Brassicaceae orthologs of FLC are repressed by winter cold and reactivated in spring conferring seasonal flowering patterns, whereas in annuals, they are stably repressed by cold [69].

\subsection{Overview of the Ambient Temperature Pathways}

Responsiveness to ambient temperature is an adaptive trait and varies widely between and within species and accessions [108]. Besides extreme changes in temperature (e.g., vernalization), small changes in ambient temperature can also have an effect on flowering time. In A. thaliana plants grown under controlled laboratory conditions, a shift to lower $\left(23^{\circ} \mathrm{C}\right.$ to $\left.16^{\circ} \mathrm{C}\right)$ and higher $\left(23^{\circ} \mathrm{C}\right.$ to $\left.27^{\circ} \mathrm{C}\right)$ temperature delays and enhances flowering time, respectively [109]. The MADS box transcription factor SHORT VEGETATIVE PHASE (SVP) and most genes from the FLC clade, such as FLOWERING LOCUS M (FLM/MAF1) and MADS AFFECTING FLOWERING-2-4 (MAF2-MAF4), have been implicated in the thermosensory pathway $[85,107,110]$, with SVP and FLM having key roles in this process in Arabidopsis (Figure 4). SVP represses FT transcription at lower temperatures, but the levels of $F T$ mRNA increase at higher temperatures. The control of floral transition in response to ambient temperature seems to differ among plant species, and many important questions concerning the regulation of flowering time by ambient temperature in Arabidopsis remain unsolved. However, FT-like genes seem to integrate the response to changes in ambient temperature in many species [111].

Although flowering induction in response to temperature changes may greatly affect yield and product quality in both Brassicaceae and Asteraceae crop species, insufficient work has been done to identify the genes responsible for this trait, especially in Brassica species. The floral integrator SOC1 was suggested to mediate heat-promoted bolting in lettuce, but further studies are needed to establish the exact mechanisms of flowering induction under these conditions, and whether this role is conserved in other Asteraceae [36].

Mutations that increase or decrease the expression of MAFs and SVP genes, known to be negative regulators of flowering time in Arabidopsis, may delay or speed up flowering time, respectively, if molecular mechanisms were conserved in crop species. On the other hand, reduction of $S O C 1$ in Asteraceae would potentially result in delayed timing of bolting and insensitivity to high temperature.

\subsubsection{Ambient Temperature Pathways in Brassicaceae}

Ambient temperature affects the deposition of the histone variant H2A.Z by the chromatin remodeling factor ACTIN RELATED PROTEIN 6 (ARP6). H2A.Z has been proposed to compact DNA in a temperature-dependent manner, thereby functioning as a temperature sensor in A. thaliana [112]. Accordingly, arp6 mutants display a constitutive warm temperature response, but are still temperature responsive, indicating that $\mathrm{H} 2 \mathrm{~A} . \mathrm{Z}$ is not the only thermosensor that mediates flowering. Recently, the basic helix-loop-helix (bHLH) transcription factor PHYTOCHROME INTERACTING PROTEIN 4 (PIF4) was shown to mediate flowering in response to temperature downstream of H2A.Z [113]. Mutations in PIF4 suppress the induction of flowering by high ambient temperature only in SD, whereas the pift mutant flowers normally in inductive LD [114]. The response to $27^{\circ} \mathrm{C}-\mathrm{SD}$ in the leaves was found to depend on the coordinate functions of CO, PIF4 and PIF5, as well as SVP, providing a 
genetic and molecular framework for the interaction between the photoperiod and thermosensory pathways [115].

SVP is directly activated by the chromatin remodeler BRAHMA (BRM) during the vegetative phase, whereas FLM is also regulated by the vernalization and photoperiodic pathways (reviewed in [116]). SVP can interact with FLC or FLM to form a repressor complex to prevent the expression of FT and SOC1 [117,118]. Loss-of-function of SVP or FLM results in early and temperature-insensitive flowering, although $\mathrm{flm}$ loss-of-function plants retain some temperature sensitivity below $10{ }^{\circ} \mathrm{C}$ [118]. $F L M$ is subject to temperature-dependent alternative splicing [110]. Two most abundant splice forms of $F L M, F L M \beta$ and $F L M \delta$, which differ in the incorporation of either the second or third cassette exon, are both translated into proteins and their splicing pattern changes in response to changes in ambient temperature [110,118-121]. Different studies have shown that the abundance of FLM- $\beta$ and $F L M-\delta$ splicing variants is regulated by temperature in an opposite fashion, with $F L M-\beta$ enhanced at low temperature $\left(16^{\circ} \mathrm{C}\right)$ and $F L M-\delta$ increased at high temperature $\left(27^{\circ} \mathrm{C}\right)[118,120]$. Overexpression of either FLM- $\beta$ or FLM- $\delta$ results in opposite phenotypes, with FLM- $\beta$ overexpression delaying flowering, as expected for a floral repressor, and overexpression of $F L M-\delta$ accelerating the transition to flowering $[116,120]$. A model was proposed in which only the incorporation of the FLM- $\beta$ protein in the SVP-FLM complex would result in active repression of flowering targets, whereas incorporation of $F L M-\delta$ would form an inactive complex, indirectly promoting the transition to flowering [120]. More recent studies have shown that splice variant $F L M-\beta$ has a stronger effect on flowering time compared to $F L M-\delta$ and therefore the function of $F L M-\delta$ under natural conditions is a matter of debate $[108,122]$. SVP and FLM contribute to the variation of flowering time among natural accessions of $A$. thaliana $[73,123]$. Alternative splicing is an important mechanism in sensing and adapting to changes in ambient temperature, and several genes in the thermosensory pathway undergo alternative splicing in response to temperature changes [121]. MAF2, MAF3, and circadian clock associated genes $P R R 7$ and CCA1, showed alternative splicing variants after a temperature shift.

Genes homologous to SVP and FLM/MAF1 have been identified in B. napus, B. rapa, B. oleracea and R. sativus. In B. rapa, BrSVP and BcMAF1, a MAF-related Pak-choi (B. rapa ssp chinensis) gene, cause late flowering when transformed individually into $A$. thaliana [3,107]. Silencing of BcMAF1 in Pak-choi resulted in enhanced expression of $B c F T 1, B c F T 2$ and $B c S O C 1$, reduced expression of $B c M A F 2$ and early flowering compared to control plants [3]. These findings point to a function of SVP and FLM/MAF1 in the regulation of flowering time, but their role in ambient temperature response was not explored.

$R$. sativus plants flower early in spring, with LD conditions and higher temperature, compared to autumn. Vernalization and LD conditions reduces RsSVP expression, while expression is enhanced in SD conditions [105], indicating that RsSVP may act as a repressors of flowering in radish, as in Arabidopsis.

In B. oleracea, shifting plants to higher $\left(23^{\circ} \mathrm{C}\right.$ to $\left.27^{\circ} \mathrm{C}\right)$ temperature results in differential splicing of about 156 genes. However, only $1 \%$ to $2.2 \%$ of those overlap with transcripts that are differentially expressed in the two investigated $A$. thaliana accessions (Gy- 0 and Col-0). In contrast to $A$. thaliana, no differential splicing in flowering time genes was described in $B$. oleracea in response to high temperature [121], indicating that alternative splicing may not be a general regulatory mechanism by which ambient temperature regulates flowering response in Brassica species other than Arabidopsis.

\subsubsection{Ambient Temperature Pathways in Asteraceae}

L. sativa plants grown at high temperatures $\left(35 / 25^{\circ} \mathrm{C}\right)$ flower early compared to plants grown at lower temperatures $\left(25 / 15^{\circ} \mathrm{C}\right)$ [58]. RNA-seq analysis revealed 1443 and 1216 genes that were upregulated respectively in leaves and stems of plants that had been shifted to $37^{\circ} \mathrm{C}$ for one week compared to control plants that were maintained at $25^{\circ} \mathrm{C}$ [124]. Among these genes were homologs of AP2, AP2-like, SOC1 and FLM in the leaves and homologs of AP2-like, FLC and FLM in the stem. The shift to $37^{\circ} \mathrm{C}$ resulted in the downregulation of 1038 genes in leaves and of 933 genes in stems, 
as compared to the controls at $25^{\circ} \mathrm{C}$. These included photoperiod-related genes in both leaf and stem, and two LSFLC-like homologs in leaf. Unexpectedly, SVP-like genes were not present in the sets of differentially regulated transcripts [124].

In C. intybus, treatment of non-vernalized plants with elevated temperatures (increase of $6^{\circ} \mathrm{C}$ ) in the field resulted in a variety of phenotypic differences like more leaves, reduced mean leaf area, decreased root weight and early flowering [125]. The severity of these heat stress-induced phenotypic changes was cultivar dependent. Early flowering in response to elevated temperature seems to be conserved in L. sativa and C. intybus. However, no genetic or molecular data are available in Cichorium spp. for heat-induced bolting response.

\subsection{Overview of the Photoperiodic Pathway}

Day length is an important factor for a plant to track seasonal changes, where short days (SD, 8/16 $\mathrm{h}$ light and dark) indicate winter and long days (LD, $16 / 8 \mathrm{~h}$ light and dark) indicate spring or summer. Plants can be divided into three major groups on the basis of their responses to photoperiod: Long-day plants flower when the day exceeds a critical length, short-day plants flower when the day is shorter than a critical length and day-neutral plants flower independently of day length [126]. As plants aim to flower in the optimal season, most plants show a delay in bolting when grown under SD conditions and early bolting under LD conditions. The mechanism behind light perception and integration has been intensively studied in $A$. thaliana over the past 15 years (reviewed in [11] and [127]). The circadian clock and photoreceptors influences transcription and protein stability of the transcriptional activator CONSTANS (CO) which, in a signaling cascade involving GIGANTEA (GI), in turn activates the floral integrator $F T$ in a long-day afternoon [39,128].

Photoperiod and circadian rhythm are involved in many processes of adaptive response to environmental conditions, including flowering time. Their molecular mechanisms are widely conserved amongst plant species to such an extent that mechanisms of photoperiod measurement are more diverse between long-day and short-day plants than between eudicots and monocots [129]. Based on gene expression, it is suggested that the photoperiod pathway is conserved between the Brassicaceae and Asteraceae family, which include mainly plants requiring long days to flower. Despite our knowledge on the genetic control of flowering time in response to different light conditions is quite limited in the species we are reviewing, preliminary studies suggest a key role of CO, GI and photoreceptors in adaptation to different environments $[54,106,130]$.

\subsubsection{The Photoperiodic Pathway in Brassicaceae}

CONSTANS promotes flowering by initiating transcription of the FT and TSF genes (Figure 4). The blue light receptor FLAVIN-BINDING KELCH REPEAT F-BOX 1 (FKF1) and the clock-associated protein GI form a complex to degrade transcriptional repressors of CO, CYCLING DOF FACTORs (CDFs), and to stabilize the CO protein [131-135]. Post-translational regulation of CO is essential for a flowering response to long days. The $\mathrm{CO}$ protein is ubiquitylated by a ubiquitin ligase complex that includes CONSTITUTIVE PHOTOMORPHOGENIC 1 (COP1) and SUPPRESSOR OF PHYTOCHROME A (SPA1), facilitating CO degradation by the 26S proteasome [136-138]. Activity of this complex is repressed by light so that it mainly promotes the degradation of CO protein in the dark. Thus, only the peak of $C O$ mRNA that occurs in the light at the end of a long day after degradation of the CDFs by GI-FKF1 leads to CO protein accumulation (Figure 4).

The circadian clock is a time-keeping mechanism with a periodicity of $24 \mathrm{~h}$. In Arabidopsis, the circadian clock confers diurnal patterns of gene expression on roughly one-third of the genes, and comprises interlocked feed-back loops $[139,140]$. Core clock components include the morning phased genes CCA1, LATE ELONGATED HYPOCOTYL (LHY), REVEILLE8 (RVE8) and PSEUDO-RESPONSE REGULATOR 9 (PRR9) [141-147]; the afternoon phased genes PRR5, PRR7, GI [145,147]; and the evening phased genes EARLY FLOWERING 3 (ELF3), ELF4, LUX ARRHYTHMO (LUX) and TIMING OF CAB EXPRESSION1 (TOC1) [142,147-150]. 
Homologs of all genes involved in photoperiodic response were identified in B. napus and shown to be highly variable in studies of targeted deep-sequencing of essential flowering time regulators [35] in a panel of 280 inbred lines. Four CO and four CO-like genes are present in the genome of B. napus, including those initially characterized by Robert et al. [151], one of which shown to complement $c 0$ mutants in A. thaliana [151]. One BnPHYA gene has undergone two coupled duplication-deletion events (HNRTs), where one region of the genome replaces a respective homeologous genome region. It was suggested that such rearrangements may represent a necessary co-adaptation of the photoperiodic pathway to the strong vernalization requirement in winter inbred lines [4].

Compared to A. thaliana, several duplicated or triplicated photoperiod genes, such as $\mathrm{BrCO}$, $B r F K F 1, B r C D F 1, B r L H Y$ and BrTOC1, were detected in B. rapa [35,54]. Expression of these genes throughout the day differed when plants were grown under LD or SD conditions, only BrCDF1 showed a similar trend under both growth conditions [54]. So far, no complementation or other functional studies for the core clock components are available in Brassica species. BrGI was identified as an important component for circadian rhythm and multiple abiotic stress responses and acts as an activator of flowering when transformed into an Arabidopsis gi null mutant [152]. Two putative null alleles of $B r G I$ resulted in late flowering when homozygous in B. rapa [152,153]. Furthermore, BrGI protein physically interacts with GI-interacting partners, like BrFKF1, suggesting a conserved function with Arabidopsis [152].

In both B. oleracea and R. sativus, silencing of GI resulted in delayed bolting and flowering, with a correlation between GI expression levels and days to flowering [154,155].

D. tenuifolia plants flower later under SD compared to LD conditions, with 50 and 20 days to flowering, respectively [106]. DtCO and DtGI are both diurnally regulated. Under LD conditions, $\mathrm{DtCO}$ acts as activator of flowering when transformed into A. thaliana and could complement the co null mutant [106].

\subsubsection{The Photoperiodic Pathway in Asteraceae}

Lou et al. [156] hypothesized that CCA1, RVE2, RVE4 and RVE5 function might be restricted to the Brassicaceae family. However, Higashi et al. [130] later described 215 common oscillating transcripts in L. sativa, including LsCCA1, LsGI, LsLHY, LsFKF1, LsTOC1, LsPRR7 and LsCO-like. The expression pattern of these genes show a large degree of overlap with those of A. thaliana [130], indicating a possible functional conservation in Asteraceae. Despite the great importance of photoperiodic control of flowering time for vegetable crop production and adaptation to different cultivation environments, no further molecular and genetic data are available for either lettuce or chicory species.

\subsection{Overview of the Age Pathway}

Plants go through developmental phases such as juvenile-to-adult transition and floral induction during their life cycle. As the plant ages, concentrations of the SQUAMOSA PROMOTER BINDING LIKE (SPL) transcription factors (also known as SQUAMOSA promoter binding protein, box family, SBP) increase. SPLs promote flowering by initiating the expression of several other transcription factors, such as LEAFY (LFY), FRUITFULL (FUL), and SOC1 [157,158]. SPL proteins are negatively regulated by the microRNAs [158]. MicroRNAs (miRNA) are key regulators of the age pathway, preventing precocious flowering when the plant is too young. Two major miRNAs, miR156 and miR172, have an antagonistic effect on flowering time by downregulating their own set of target genes. miR156 expression is high in young plant stage, decreases over time and is low at the onset of flowering $[159,160]$.

The involvement of miRNAs in flowering time and the important role of miR156 and miR172 and their corresponding targets, is widely conserved across plant species [161]. As expected, both miR156 and miR172 seem to be conserved between the Brassicaceae and Asteraceae families, although very few reports are available in Asteraceae. The miR156/SPL module plays a central function in age-dependent competence to flowering, but seems to be even more fundamental in perennial Brassica species that 
undergo reiterative flowering induction cycles and do not respond to vernalization in the first year of life. Therefore, miR156/SPL may play a key role in flowering control in biennial crops [162]. Other miRNA like miR824 and miR5227, the latter only detected in R. sativus [163], are less conserved and seem to be newly evolved Brassica-specific miRNAs as they were not found in families other than Brassicaceae so far. In L. sativa, a homolog of the Arabidopsis DELAY OF GERMINATION1 (DOG1) seems to have acquired a novel function in the miRNA-mediated response to flowering time, but further studies are needed to investigate DOG1 role in other Asteraceae and in other plant families [164].

\subsubsection{Age Pathway in Brassicaceae}

A. thaliana contains eight miR156 members (miR156a to miR156h) which target different SPL genes (Figure 4) $[159,165]$. Besides enhancing expression of floral meristem identify genes, SPL genes also promote miR172 expression [166]. miR172 shows an inverse expression pattern with increasing expression over time $[159,160]$. A thaliana contains five miR172 members (miR172a to miR172e) which target AP2 and the AP2-like genes TARGET OF EAT1 (TOE1), TOE2, TOE3, SCHLAFMÜTZE (SMZ) and SCHNARCHZAPFEN (SNZ) [167-169]. AP2 and AP2-like genes inhibit the onset of flowering by repressing expression of SOC1, FUL and AGAMOUS (AG) (Figure 4, [170]). Another miRNA, miR824, targets AGL16, which encodes a MADS-box repressor of flowering time that interacts with SVP and FLC to regulate FT expression levels [171]. SPL15 cooperates with SOC1 to coordinate the basal floral promotion pathways required for flowering in non-inductive environments by directly activating transcription of FUL and miR172 in the SAM [162]. The capacity of SPL15 to promote flowering is regulated by age through miR156 that targets SPL15 mRNA. Strong evidence is emerging that miR156/SPL control competence to flower as well as vegetative phase change [162]. Several studies point to a major role of SPL9 and SPL15, with SPL15 playing the larger role in floral induction, particularly under noninductive short days, and SPL9 acting in floral primordia after the floral induction. The miR156/SPL module is of special interest for the acquisition of competence to flowering in biennial and perennial Brassicaceae relatives of Arabidopsis, where miR156 levels act as the timer in controlling competence to flower, and often make plants insensitive to vernalization when too young (Figure 4, [172,173]). It was suggested that the miR156/SPL module, which is evolutionarily conserved in all flowering plants, might have acquired increased dependency for flowering in perennials, whereas annuals would have evolved genetic mechanisms to bypass this module by alternative inductive pathways such as light/photoperiod [162].

B. napus contains 36 copies of miR156, of which 17 located on the A genome and 19 on the C genome, and 14 copies of miR172, with eight located on the A genome and six on the C genome [174]. A total of 58 genes encoding putative SPL/SBP proteins are present in the B. napus genome, 44 of which harboring miR156 binding sites [175]. This suggests that relationship between miR156 and SBP genes is conserved across species, although distinct regulation pattern of the homologous genes exist between B. napus and Arabidopsis that may reveal some divergence of the SBP-box genes in oilseed rape.

B. rapa contains 17 copies of $m i R 156$ and 11 of miR172 [174]. BrmiR156 is highly expressed in early plant stages and expression decreases during plant development. BrSPL9-2 and SPL15-1 show an opposite expression pattern compared to BrmiR156, with increasing expression over time. Cabbage plants expressing a mutated BrSPL9 (mBrSPL9) allele, resistant to BrmiR156, showed enhanced BrSPL9 and BrmiR172 expression. In the field, $m B r S P L 9$ plants had dark green leaves with enhanced chlorophyll content and a prolonged heading stage with delayed flowering, but no significant change in head weight, size or shape. Overexpression of BrmiR156 in cabbage resulted in decreased BrSPL9-2 transcript levels and a prolonged seedling and rosette stage [176], pointing to conservation of the miR156/SPL module in B. rapa.

B. oleracea contains 15 copies of miR156, where BomiR156c is known to target BoSPL9 while BomiR156g targets BoSPL3. The miR172 family contains nine copies and targets BoAP2 and BoTOE2 $[174,177,178]$. A newly evolved miR824, which seems specific for Brassicaceae, was also 
identified and targets BoAGL16 [178]. This function is conserved with Arabidopsis where the miR824/AGL16 quantitatively modulate the extent of flowering time repression in a long-day photoperiod through FT [171].

In R. sativus, 11 members of miR156/miR157, five members of miR172, two members of miR824 and one member of miR5227 are detected. Different RsmiR156 copies target RsSPLs and RsmiR156a also RsTOC1, RsmiR172a targets RsAP2, RsmiR824 targets RsAGL16 and RsmiR5227 targets RsVRN1. Expression of RsmiR156a, RsmiR824 and RsmiR5227 decreased when plants shifted from vegetative to reproductive phase [163], strongly indicating that these miRNAs and their corresponding target genes might play important roles during bolting and flowering processes of radish.

\subsubsection{Age Pathway in Asteraceae}

LsmiR156 and LsmiR172 act as repressor and activator of flowering, respectively, when expressed in A. thaliana [164], and targets LSSPLs and LSAP2 in L. sativa [179]. In Arabidopsis, expression of the DELAY OF GERMINATION1 (DOG1) gene responds to seed maturation temperature and determines the depth of seed dormancy [180]. Huo et al. showed that DOG1 could regulate seed dormancy and flowering times in lettuce through the modulation of miR156 and miR172 levels [164]. LsDOG1 silencing lines flowered early compared to control L. sativa plants, with an enhanced effect in autumn, and showed reduced expression of LsmiR156, enhanced expression of LsmiR172, LsFT, LsSPL3 and LSSPL4 and no difference in transcript levels of LSSPL9. This would suggest that LsDOG1 has an additive role in LsmiR156- and LsmiR172-mediated flowering time, besides the thermo-inhibition of seed germination described in A. thaliana [164].

Srivastava et al. [181] has predicted two copies for miR156 and one copy for miR157 in C. intybus. For the miRNA targets, only CiSPL3 and CiSPL12 were detected and confirmed as targets of CimiR156 [181].

\subsection{Overview of the Hormonal Pathway}

Gibberellins (GAs) are growth regulators involved in plant developmental processes that promote transition to flowering in several plant species [61,124,182-185]. In Arabidopsis, GA contributes to flowering under inductive long days (LDs) through the activation of $S O C 1$ and $L F Y$ in the inflorescence and floral meristems, and of $F T$ in leaves. Under non-inductive short days (SDs) conditions, the GA pathway assumes a major role as under SDs flowering is delayed and correlates with a gradual increase in bioactive GA at the shoot apex [186]. Mutations that impair GA biosynthesis prevent flowering under SDs [183].

Besides GA, it has been suggested that cytokinins, major growth regulators in plants, also participate in the regulation of flowering time (reviewed in [187]). For a long time, it has been known that exogenously applied cytokinin can promote flowering in Arabidopsis [188-190]. However, it is unclear whether endogenous cytokinins can also have the same inductive activity.

Regulation of GA and its involvement in the switch to flowering seems conserved between the Brassicaceae and Asteraceae families. In grasses and cereals, GAs are similarly regulated and also involved in flowering time [191], suggesting that the GA role in promoting flowering is widely conserved in plants. Genes involved in GA metabolism or sensitivity may constitute good targets to modulate flowering time in crops, as enhanced GA content or signaling can induce early flowering whereas low GA amount or signal can delay bolting and flowering.

\subsubsection{Hormonal Pathway in Brassicaceae}

The GA pathway is well described in A. thaliana (reviewed in [192]). In brief, the last steps of the GA pathway involves the conversion of $\mathrm{GA}_{12}$ into $\mathrm{GA}_{9}$ and $\mathrm{GA}_{53}$ into $\mathrm{GA}_{20}$, by GA 20-oxidases (GA20ox1-5), the conversion of $\mathrm{GA}_{9}$ and $\mathrm{GA}_{20}$ into bioactive $\mathrm{GA}_{4}$ and $\mathrm{GA}_{1}$, respectively, by $\mathrm{GA}$ 3-oxidases (GA3ox1-3) and the deactivation of $\mathrm{GA}_{4}$ and $\mathrm{GA}_{1}$ by GA 2-oxidases (GA2ox1-5) [193-198]. Bioactive GAs binds to GIBBERELLIN INSENSITIVE DWARF1 (GID1 $a,-b$ and $-c$ ) to promote 
degradation of DELLA proteins [199-201], negative regulators of gibberellin signaling that act immediately downstream of the GA receptor. DELLA proteins repress transcription of many genes, including FT, TSF, and some SPL genes [202]. Low levels of bioactive GA result in the accumulation of DELLA proteins, which delay flowering independent of photoperiod [202,203]. The MADS box transcription factor SVP, besides repressing floral integrator gene expression, regulates bioactive GAs at the shoot apex by repressing the GA20ox2 gene [204]. In response to inductive photoperiods, repression of SVP contributes to the increase of GAs at the shoot apex, promoting rapid induction of flowering. The ambient temperature and GA pathways are tightly linked (Figure 4, [205]).

Cytokinins (CK) were also proposed to affect flowering time as exogenous application of CKs can promote flowering in Arabidopsis. It has been shown that exogenous cytokinins promote flowering independently of $F T$, but through the transcriptional activation of its paralog TSF [189]. Cytokinins are perceived by membrane-located receptors called A. THALIANA HISTIDINE KINASE2 (AHK2), AHK3 and $A H K 4$ and are involved in many plant processes during plant development. Gain-of-function variants of $A H K 2$, with enhanced cytokinin signaling, showed either early or late flowering [206]. Furthermore, it has been suggested that there is a cross-talk between cytokinins and GA, mediated by SPINDLY (SPY) [207].

In B. napus, genes encoding DELLA proteins and genes of the GA metabolism have been identified [208], however their role in flowering was not explored. During B. napus vernalization, the content of cytokinins increases significantly and reaches a maximum during reproductive transitions. Cis-Zeatin riboside accounted for ca. $87 \%$ to $89 \%$ of the total isoprenoid cytokinin content in control and vernalized plants, whilst isopentenyladenosine and cis-zeatin were the next most abundant cytokinins. In the post-vernalization period, endogenous cytokinin levels decreased, but remained significantly higher in the reproductive plants than in the vegetative controls. Changes in cytokinin accumulation during vernalization-induced reproductive development may suggest a possible role of CK in this process. [209].

In B. rapa, low-temperature treatment increases the GA content, and enhanced GA accumulation initiates floral bud differentiation [210]. Expression patterns of most genes involved in GA metabolism, particularly those of four genes including one GA20ox were consistent with observed GA levels [210].

In $B$. oleracea, treatment with bioactive $\mathrm{GA}_{3}$ and $\mathrm{GA}_{4+7}$ result in early curd formation in cauliflower and broccoli plants [184]. GA treatment induces bracting and stem elongation, but not flower initiation, when cauliflower and broccoli are at the IM or floral bud stage, respectively. As confirmation, treatment with GA does not show differences in the expression of BoAP1-a, BoAP1-c, $B o L F Y$ and BoSOC1 in cauliflower plants at the IM stage. These results suggest that GA has an effect on vegetative-to-reproductive transition and another pathway is responsible for the IM-to-FM transition [184].

In R. sativus, two homologs for GID1a, one for GID1b, one for GID1c and three for GA2ox have been described. Before vernalization, expression level of one RsGA2ox homolog was upregulated in a late compared to early bolting line. Expression level of one homolog of RsGID1a was induced by vernalization treatment [104].

\subsubsection{Hormonal Pathway in Asteraceae}

In L. sativa, plants treated with exogenous GA have enhanced levels of $\mathrm{GA}_{3}$ and $\mathrm{GA}_{4}$ in the leaves and flower early, with an enhanced effect in early flowering varieties [61,124]. Early flowering plants treated with CCC (a GA inhibitor) have reduced $\mathrm{GA}_{3}, \mathrm{GA}_{4}$ and IAA levels in the leaves and stem, are compact and do not bolt. Transferring plants from ambient $\left(25 / 15^{\circ} \mathrm{C}\right)$ to higher temperature $\left(35 / 25^{\circ} \mathrm{C}\right)$ results in enhanced expression level of LsGA2ox1, LsGA3ox1 with corresponding enhanced endogenous levels $\mathrm{GA}_{8}$ and $\mathrm{GA}_{1}$, respectively. Expression level of LsGA20ox1 and corresponding endogenous level of $\mathrm{GA}_{20}$ was unaffected by the transfer to higher temperature. Therefore, it is suggested that $L s G A 30 \times 1$ might be responsible for enhanced bioactive GA $_{1}$ levels in plants grown at higher temperatures [211]. With transcriptome analysis of a bolting resistant and 
sensitive line, Han et al. [61] have shown that LsGA3ox1, LsGA20ox1, LsGA20ox2 and 28 out of 41 auxin-related genes were upregulated in leaves of a bolting sensitive line. Liu et al. [124] showed that heat treatment of bolting sensitive plants results in early bolting, enhanced $\mathrm{GA}_{3}$ and $\mathrm{GA}_{4}$ levels in the leaves, reduced IAA levels in the leaves and enhanced IAA levels in the stem. Transcriptomic analysis of a bolting sensitive line has shown that, out of 1443 and 1038 differentially up and down regulated genes, $L s G A 200 x$ was upregulated in leaves and a gibberellin-regulated family protein upregulated in the stem tip after heat treatment [124]. L. sativa plants overexpressing Arabidopsis KNAT1, a KNOTTED1-like homeobox (KNOX) transcription factor, show altered plant architecture and early flowering compared to control plants. Their striking leaf morphology phenotype was associated to a consistent increase in cytokinin content. Based on these results, correlation between temperature, GA levels and flowering time is suggested, together with a role of KNAT1 in flowering time, directly or indirectly, through cytokinins [212]. It has been proposed that the KNOX transcription factor KNAT1 could regulate flowering by increasing cytokinin biosynthesis [212], and ISOPENTENYL TRANSFERASE (IPT) biosynthetic genes were shown to be downstream targets of KNOX transcription factors $[213,214]$. However, there is no direct evidence that the early flowering phenotype observed in KNAT1 overexpressing lettuce plants depends on CK increase as KNOXs also control other hormonal and metabolic pathways, including GA biosynthesis (reviewed in [215]). Hence, the observed early flowering phenotype may depend on mis-regulation of as of yet unknown targets in the flowering time genetic network.

\section{Quantitative Trait Loci (QTL)}

The identification and functional characterization of genes controlling different pathways of flowering time has increased the knowledge about this complex trait. In parallel, the genetic basis of natural variation in flowering time has been investigated by quantitative trait loci (QTL) analysis. Salomé et al. [216] and Brachi et al. [217] have described the QTL mapping of 17 F2 populations and 13 RIL (recombinant inbred line) families in A. thaliana, which has led to the identification of many QTLs. Most of the QTLs are located in five genomic regions (region At1-5) and contain flowering time genes previously described in this review (Figure 4). All the five QTL regions described contain large-effect alleles [216,217]. Within the detected QTL regions, epistatic interaction between FLC and FRI alleles is highly associated with flowering time and could explain up to $70 \%$ of the variation $[218,219]$. Recently, a genome wide association map of flowering time, with nearly complete genotype information, was obtained taking advantage of the genomic sequencing and phenotype information from different environments $\left(10^{\circ} \mathrm{C}\right.$ and $\left.16^{\circ} \mathrm{C}\right)$ of 1135 natural inbred lines of Arabidopsis thaliana [65]. The identified peaks from the genome wide association study (GWAS) contained VIN3, FT, SVP, FLC and DOG1, all previously linked to flowering time $[81,123,164,220,221]$.

In B. napus, a mapping population made from a cross between Tapidor (winter type) and Ningyou7 (semi-winter type) is the most used for the identification of QTLs affecting flowering time $[5,66,222-225]$. Other analyses include different mapping populations or a broad set of accessions and inbred lines. Overall, phenotyping was performed in field trials in different locations and over multiple years, and flowering time was scored when $25 \%$ or $50 \%$ of the plants within a plot had an open flower. Many QTLs have been discovered in the different populations, with 23 genomic regions (Bn1-23) overlapping between at least two QTL analyses (Table 4). Of the flowering related genes within these genomic regions, Bna.FRI.Xa (region Bn5) is shown to have specific haplotypes overrepresented in either semi-winter or winter type plants [3,14]. Long et al. [222] have shown that genomic region $\mathrm{Bn} 13$ explains $50 \%$ of the variation in flowering time, is specific for spring environments and suggested that Bna.FLC.A10 might control flowering time in non-vernalization environments. Later, Hou et al. [224] observed that one of the polymorphic sites upstream of Bna.FLC.A10 is strongly associated with vernalization requirement of rapeseed. For Bna.FT.A07b (region Bn11), differential expression between types or treatments has been described [47], but no haplotype information is available so far. 
In B. rapa, QTL analyses were performed on mapping populations mainly involving Yellow Sarson or a rapid cycling line 09A001. Phenotyping was scored based on flowering time (days to first open flower) or bolting time (days to first internode elongation). Of the detected QTLs in different populations, six genomic regions (Br1-6) were overlapping in at least two QTL analyses (Table 4). Of the flowering related genes within these genomic regions, BrFLC2 (region Br2) is a major factor in determining flowering time. A $57 \mathrm{bp}$ deletion on the exon4/intron4 border of BrFLC2, resulting in alternative splicing, is significantly associated with flowering time [91]. Zhang et al. [49] showed that a transposon insertion in exon 2 of BrFT2 (region Br5) results in late flowering, and that there is a correlation between flowering time and different BrFLC2 and BrFT2 alleles. Plants with functional or non-functional alleles for both genes result in similar flowering time. However, a non-functional allele of either BrFLC2 or BrFT2 results in early or late flowering, respectively [49]. Besides the QTLs detected in multiple analysis, Xie et al. [153] has described one QTL (ChrA09:25634145.25774304), containing $\mathrm{BrGI}$ as a candidate gene responsible for circadian period determination. Two detected $\mathrm{BrGI}$ alleles $\left(B r G I^{i m b 211}\right.$ and $B r G I^{500}$ ) could complement the late flowering phenotype of the Arabidopsis GI null mutant, but plants with allele $B r G I^{500}$ showed a shorter circadian period and could not (fully) complement the response to red and blue light [153].

In B. oleracea, different mapping populations and commercial parents have been used for QTL analysis. Phenotyping was performed in the greenhouse and was scored as days to flowering or days to curd initiation (curd larger than $1 \mathrm{~cm}$ ). Of the detected QTLs in different populations, six genomic regions (Bo1-6) were overlapping in at least two QTL analyses (Table 4). One of the candidate genes in region Bo1 is BoFLC4 (Table 4). The two main alleles BoFLC4 ${ }^{\mathrm{E} 5}$ and BoFLC4 ${ }^{\mathrm{E} 9}$ both confer a requirement for vernalization, but differ with regard to their transcription regulation in response to temperature shifts, due to cis-regulatory differences [101]. One of the candidate genes in region Bo1 is BoFRIa (Table 4). Sequencing of BoFRIa from 55 accessions detected six different alleles with numerous substitutions and InDels. Expression of the two most abundant alleles from the AtFRI promoter prolonged the time to flower equally when overexpressed in A. thaliana, suggesting that the potential effect of these alleles on flowering time in B. oleracea may result from differences in their expression [90].

For L. sativa, a RIL population of cultivar L. sativa cv. Salinas (Crisphead) and Californian L. serriola unveiled two QTLs (Ls1 and Ls3) for days to flowering [226,227]. Furthermore, backcrossed lines selfed for one generation (BC1S1) from a cross between cultivar L. sativa cv. Dynamite (Butterhead) and a L. serriola uncovered four additional QTLs (Ls2, Ls4-6) [228]. A few flowering time related genes are located within QTL regions Ls1, Ls5 and Ls6. However, it remains an open question whether polymorphisms in these candidate flowering time related genes underlie the detected QTLs. Recently the L. sativa genome sequence [20] and RNA-seq data from 240 wild and cultivated lettuce accessions were realized, which will provide valuable tools to explore genetic variations contributing to flowering time and other traits in L. sativa [229].

In general, FLC and FRI seem to be overlapping in QTL analyses between different Brassica species. This provides more evidence that indeed these are key regulators of flowering time in many Brassicaceae. However, the specific genes and alleles responsible for the other QTLs remain unexplored. Identification of the causal genes and genetic variation for all QTLs would help to further understand the regulation of flowering time in the different crops. More QTL analyses have been performed for some species other than those discussed here. Even though these data are of great value, it is difficult to determine if the QTLs overlap with the reported QTLs, as reported positions cannot be related to the physical map (e.g., QTL analysis from $[230,231])$. For L. sativa, only two populations have been used for QTL analysis, both involving wild source L. serriola. It might be worthwhile exploring other wild sources such as L. virosa or L. saligna to expand the number of currently known QTLs. The availability of new genetic and genomics resources will consistently speed up genetic studies to unravel the key regulatory nodes of flowering time pathways in Asteraceae leafy crops. 
Table 4. Flowering-time related QTL regions for $A$. thaliana, B. napus, B. rapa, B. oleracea and L. sativa with candidate flowering-time genes within these QTL regions.

\begin{tabular}{|c|c|c|c|c|}
\hline QTL Region & Species & Region $^{1}$ & Candidate Genes & References \\
\hline At1 & A. thaliana & Chr1:24500000-29000000 & $F T, F K F 1, A P 1, F L M$ & {$[216,217]$} \\
\hline At2 & A. thaliana & Chr4:300000-1900000 & $F R I$ & {$[216,217]$} \\
\hline At3 & A. thaliana & Chr4:8000000-12000000 & VRN2, TSF, GA2ox & {$[216,217]$} \\
\hline At4 & A. thaliana & Chr5:2700000-8100000 & $F L C, C O, T F L 2$ & {$[216,217]$} \\
\hline At5 & A. thaliana & Chr5:21500000-26000000 & $\begin{array}{l}\text { VIN3, PRR3, TOE2, LFY, } \\
\text { CDF1, MAF2-5 }\end{array}$ & {$[216,217]$} \\
\hline Bn1 & B. napus & chrA02:114931.1575498 & Bna.FLC.A2, CO-like, RVE1 & {$[232,233]$} \\
\hline $\mathrm{Bn} 2$ & B. napus & chrA02:1575449.4330821 & AP2-like, TOE2, PRR3 & {$[225,232,233]$} \\
\hline $\mathrm{Bn} 3$ & B. napus & chrA02:5233136.8233310 & GA20ox, Bna.FT.A02 & {$[223,225,232-235]$} \\
\hline $\mathrm{Bn} 4$ & B. napus & chrA02:8776742.9248051 & & {$[5,222,234,236]$} \\
\hline Bn5 & B. napus & chrA03:5046910.6515058 & $\begin{array}{c}\text { Bna.FRI.Xa, SPL13, CBF1, } \\
\text { Bna.FLC.A03b }\end{array}$ & {$[66,222,234,236]$} \\
\hline Bn6 & B. napus & chrA03:18872718.20131639 & AP2-like, FUL, TOC1 & {$[223,232,233,236]$} \\
\hline Bn7 & B. napus & chrA04:257040.4734286 & AP2-like & {$[233,234,236]$} \\
\hline Bn8 & B. napus & chrA04:7743947.10942653 & & {$[233,234]$} \\
\hline Bn9 & B. napus & chrA04:11898475.13460703 & CO-like, ELF3 & {$[234,236]$} \\
\hline Bn10 & B. napus & chrA06:23330530.23617143 & & {$[232,236]$} \\
\hline Bn11 & B. napus & chrA07:14463578.18916565 & $\begin{array}{c}\text { SPL15, AP2-like, GID1, AP1, } \\
\text { Bna.FT.A07b }\end{array}$ & {$[232-234,236]$} \\
\hline Bn12 & B. napus & chrA10:9835903.10695100 & PRR3, TOE2, AP2-like & {$[222,234]$} \\
\hline Bn13 & B. napus & chrA10:13375104.15191366 & Bna.FLC.A10 & {$[66,222,224,233,234]$} \\
\hline Bn14 & B. napus & chrC01:27417076.34893173 & FRI-like, VRN1 & {$[232,233]$} \\
\hline Bn15 & B. napus & chrC02:6956919.13653054 & GA20ox, SPL & {$[222,232,234]$} \\
\hline Bn16 & B. napus & chrC02:22287455.22560553 & & {$[222,234]$} \\
\hline Bn17 & B. napus & chrC02:44366336.45788246 & $F U L, M A F 2, M A F 3$ & {$[225,232]$} \\
\hline Bn18 & B. napus & chrC03:58161161.58296560 & & {$[233,234]$} \\
\hline Bn19 & B. napus & chrC04:40003810.41181656 & & {$[222,234]$} \\
\hline Bn20 & B. napus & chrC06:21784608.29654361 & ELF4, AP1 & {$[225,232,233,236]$} \\
\hline Bn21 & B. napus & chrC07:26989258.31787256 & SEP4 & {$[225,232,234]$} \\
\hline Bn22 & B. napus & chrC09:39312343.43429210 & SPL7, AP2-like, TFL2, RVE & {$[234,236]$} \\
\hline Bn23 & B. napus & chrC09:45206288.47504024 & Bna.FLC.C09b, Ga20ox & {$[225,232]$} \\
\hline $\mathrm{Br} 1$ & B. rapa & A01:81263.3282650 & AP2-like & {$[237,238]$} \\
\hline $\mathrm{Br} 2$ & B. rapa & A02:1244721.4284193 & $\begin{array}{l}\text { BrFLC2, AP2-like, } \\
\text { CO-like, SPL7 }\end{array}$ & {$[49,92,237-239]$} \\
\hline $\mathrm{Br} 3$ & B. rapa & A03:14357780.27239372 & $\begin{array}{l}\text { CO-like, AP2-like, } \\
\text { GA2ox, AGL24 }\end{array}$ & [237-239] \\
\hline $\mathrm{Br} 4$ & B. rapa & A06:13769411.18840509 & $\begin{array}{l}\text { LFY, GA20ox, CDF1, FLM, } \\
\text { MAF4, VIN3-like, CO-like, }\end{array}$ & {$[238,240]$} \\
\hline Br5 & B. rapa & A07:12545242.20240840 & $\begin{array}{c}\text { AP2-like, SPL15, ELF4-like, } \\
\text { AP1, BrFT2 }\end{array}$ & {$[49,238,240]$} \\
\hline Br6 & B. rapa & A10:12936259.13856133 & BrFLC1 & {$[237,238,241]$} \\
\hline Bo1 & B. oleracea & C02:900000.2900000 & GRF6, BoFLC4 & {$[101,242]$} \\
\hline Bo2 & B. oleracea & C03:1800000.20000000 & $\begin{array}{c}\text { BoFLC3, SOC1, BoFRIa, } \\
\text { ELF4, GA20ox }\end{array}$ & {$[100,242,243]$} \\
\hline Bo3 & B. oleracea & C04:10726862.16070000 & TOE2 & {$[100,243]$} \\
\hline Bo4 & B. oleracea & C04:32446947.35540000 & & {$[100,244]$} \\
\hline Bo5 & B. oleracea & C06:2396965.6360269 & TOE1, VIN3 & {$[242,243]$} \\
\hline Bo6 & B. oleracea & C06:22550000.32446947 & & {$[100,243]$} \\
\hline Ls1 & L. sativa & LG2:163353056.165477161 & $C D F 1, C O, F L C, P R R 5, V R N 1$ & {$[226,227]$} \\
\hline Ls2 & L. sativa & LG6:140450832.140481276 & & [228] \\
\hline Ls3 & L. sativa & LG7:158780460.159063877 & & {$[226,227]$} \\
\hline Ls4 & L. sativa & LG7:172306237.193636147 & & [228] \\
\hline Ls5 & L. sativa & LG8:25874939.47456612 & PRR3, PRR5, PRR7, PRR9 & [228] \\
\hline Ls6 & L. sativa & LG8:63537238.76202393 & FKF1 & [228] \\
\hline
\end{tabular}

1 Regions on genomes of A. thaliana (Tair10), B. napus (Brassica_napus_v4.1.chromosomes), B. rapa (Brapa_genome_sequence_v1.5), B. oleracea (B. oleracea var. capitate V1.0) and L. sativa (lettuce genome V8.1). ${ }^{2}$ For Brassica species, only QTLs detected in more than one study, encompassing different mapping populations and/or varieties, are shown. For lettuce, only two populations have been used for QTL mapping, Flowering time genes with described allelic variation are highlighted in bold.

\section{Perspectives for Breeding Strategies}

Knowledge about conservation and divergence of $A$. thaliana flowering time with its related crop species, and with more distant leafy crops within the Asteraceae family, is of great value to select candidate genes for the improvement of flowering time in commercial varieties. Introducing genetic variation in those candidate genes can be achieved by identifying novel alleles from wild relatives, the production of mutant populations or, when allowed, via a transgenic or genome editing approach. 


\subsection{Environmental Changes}

Breeders aim to produce commercial varieties that are more robust and predictable in flowering time to adapt to climate change and new environments.

In cauliflower, exploring genetic variation in temperature-dependent flowering time genes such as SVP, FLM and FLC $[3,101,107]$ would help in adjusting the vernalization and temperature sensitivity of plants for a predictable curd formation.

In lettuce, exploring genetic variation in the floral integrator genes $F T$ and $S O C 1$ will help to understand the mechanism of heat-induced early flowering and can therefore be used to produce better tasting lettuce when grown at high temperatures. Different studies have described that silencing of either LSFT or LsSOC1 results in late flowering and heat insensitive lettuce plants [36,59]. LsSOC1 expression was enhanced in both heat-treated wild type and LSFT silenced lines, indicating that LSSOC1 can induce bolting independent of LsFT upon heat treatment [36]. Heat shock elements (HSE1 and HSE2) are detected in the promoter of LsSOC1 and two heat shock proteins (LsHsfA1e and LsHsfA4c) bind to these elements to induce flowering [36]. Genetic variation at the heat-responsive promoter elements of $S O C 1$ might selectively affect heat sensitivity rather than flowering time in general.

\subsection{Yield Increase}

Prolonged vegetative phase can increase yield in leafy crops that are harvested before the transition to the reproductive phase.

In radish, premature bolting under LD conditions reduces yield and quality of the harvested product. Delayed bolting is described for RsGI loss-of-function mutants in R. sativus [154], while silencing of BoGI in B. oleracea also resulted in delayed post-harvest leaf senescence. Based on the phenotype of the B. oleracea silencing line, it is worthwhile to test the effect of genetic variation in RsGI as added value of delayed leaf senescence together with delayed bolting.

Cold season during growth induces early bolting and decreases yield in root chicory. A C. intybus homolog of the Arabidopsis FLC, CiFL1, was characterized and seems conserved in the vernalization response [22]. However, it remains to be demonstrated that the high expression level of CiFL1 in non-vernalized chicory plants is the cause of the absolute vernalization requirement for flowering. This indicates that more research about the vernalization response of chicory is required to achieve late bolting plants when grown at low temperature.

\subsection{Genetic Resources}

In the past centuries, domestication has led to the creating of edible vegetables from their wild relatives. During this domestication process, plants are selected for specific desirable traits, thereby losing some of the genetic variation in the current germplasm. As a result, some variation in flowering time genes, producing crops that are adapting to specific environments, are not present in our current breeding material. Exploring phenotypic and genotypic differences in closely related (wild) species, and introducing desired traits back into breeding material, will help create new varieties that are adapted to climate change and produce higher yield.

The Brassicaceae family contains both annual, biennial and perennial species, and spring, semi-winter and winter type plants within a species, indicating that this family varies greatly in flowering time response $[3,86]$. Within the family, different family members are closely related and can be crossed through interspecific crosses, making it easier to introduce new genetics. Hybridization between R. sativus and Brassica species B. napus, B. rapa and B. oleracea, and between D. tenuifolia and $B$. rapa has been proven to be successful even though the number of successful hybridizations might be rather low [244]. Schiessl et al. [35] have described the amount of copies of 35 flowering time regulatory genes and their genetic variation between $B$. rapa and B. oleracea. This genetic information could be used as a basis to look for candidate genes to follow in an interspecific cross. As an example, Shea et al. [245] have developed late flowering B. rapa plants by replacing the BrFLC2 genomic region 
with a $6.5 \mathrm{Mb}$ region containing BoFLC2 from B. oleracea. As many of the flowering pathways are conserved within the Brassicaceae family, it is worthwhile to explore introgression of flowering time genes from Brassica species into R. sativus or D. tenuifolia to alter flowering time.

Introducing genetic variation in flowering time genes from wild material into cultivated lettuce and chicory is possible [246,247], however, the flowering pathway is largely undiscovered in these species. Recently, high quality transcriptomes of both C. intybus and C. endivia were obtained by de novo assembly using RNA of several organs and Illumina HiSeq2000 technology [248,249], paving the way to the identification of flowering time transcripts in Cichorium spp. More research is required before specific candidate genes can be selected to introduce from wild material into breeding lines.

\subsection{Speeding up Breeding}

From a breeding perspective, introducing genetic variation from wild relatives or mutant populations into a new variety will take up to years. Speeding up this breeding process, using early flowering plants to grow more generations in one year would be of added value for the breeding companies. Similar to adapting plants to climate change or increasing yield, generating early flowering plants is possible by the use of genetic variation in flowering time genes. Besides exploring the genetics of wild material, it has also been shown for lettuce that screening mutant populations are a great source to discover plants with an altered flowering time. In Brassica spp., rapid-cycling lines and RIL populations have been obtained [86], which can be used to speed up breeding and for rapid analysis of QTL.

In Arabidopsis, winter type plants that require vernalization contain functional alleles for both FLC and FRI, while summer type plants lack a functional allele for either FLC or FRI [70-73]. With this system, early bolting parental lines can be created, while the F1 hybrids are late flowering. As an example, by producing a female line containing an FLC knock-out and a male line with FRI knock-out. The parents do not require vernalization to initiate flowering, as both parents lack a functional allele for either FLC or FRI. In the F1 hybrid, both genes are heterozygous, resulting in winter type plants that do require vernalization.

Different articles have shown that treatment with bioactive GAs can induce early flowering in both bolting sensitive and bolting resistance lettuce lines [61,124]. The benefit of GA application is that it will speed up the breeding process, when this is desired, but will not have a negative influence on flowering time during crop production.

\section{Conclusions}

Overall, most flowering time pathways seem to be genetically conserved between Brassicaceae and Asteraceae families, paving the way for exploitation of the fundamental knowledge acquired in the Brassica model species Arabidopsis to closely or more distantly related vegetable crops. This is highlighted in Figure 5, which represents a simplified model of the main regulatory genes shown to have a function in the various species within the Brassicaceae or Asteraceae family. However, a comprehensive comparison of the different flowering time pathways between Brassicaceae and Asteraceae is impaired by the poor knowledge available about molecular biology and gene function in D. tenuifolia, L. sativa and C. intybus. Fundamental biology studies in crop species to identify casual genes of advantageous traits is advisable to apply candidate gene approaches for successful breeding strategies. An increasing number of tools for molecular marker assisted breeding is expected to come in the near future from genomic and transcriptomic studies. With the rapid development of sequencing technology, whole genome sequences assembly and resequencing from crop plants is becoming routine, enabling genome-wide investigations into fundamental genetic pathways that underlie important agricultural traits. In addition, generating a pan-genome, capturing the genomic diversity of ecotypes, geographical isolates, and domesticated crop varieties, will make comparative approaches and association studies possible to identify the genetic components of adaptive and domestication traits. Increasing "omics" information (e.g., genomics, transcriptomics, metabolomics, 
SNP-omics) will enable systems biology approaches to understand complex traits, such as flowering time, and identify hub/master gene regulators for the so-called "smart" or "precision breeding," which aims to develop new varieties more precisely and rapidly.

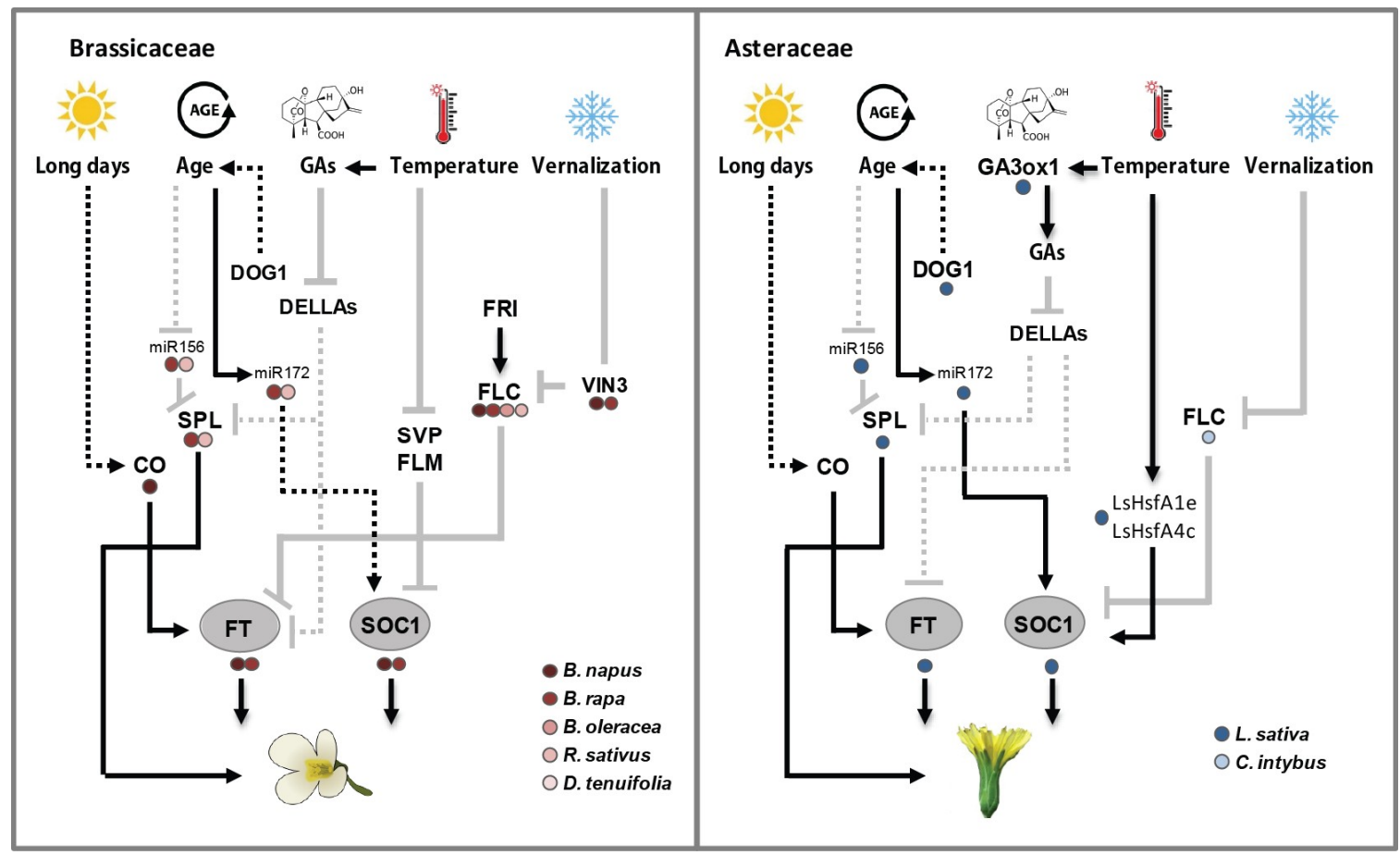

Figure 5. Simplified model of the main regulatory genes and flowering pathways acting in various crops within the Brassicaceae and Asteraceae family. Grey and black lines represent repression and induction, respectively, dotted lines indicate indirect regulation.

Author Contributions: Conceptualization, R.K., I.R. and G.F.; Investigation, W.L.; Writing-Original Draft Preparation, W.L.; Writing-Review \& Editing, W.L., R.K., I.R. and G.F.; Visualization, W.L., I.R. and G.F.; Supervision, I.R. and G.F.

Funding: This research received no external funding.

Acknowledgments: The authors thank the lettuce and brassica breeding team of Enza Zaden Research \& Development B.V. for providing information about crops; the manager of the Biotechnology Research Department, G.J. de Boer for his input in the breeding strategy session; S.A. Raccuia for provinding the picture of the B. napus field in Figure 1; Rita Romani for providing the pictures of her own cultivated field of B. rapa, and delicious "broccoletti" product, in Figure 1; the Communication Department of Enza Zaden Marketing and Sales B.V. for providing the remaining pictures in Figure 1; Giulio Testone for helping to prepare Figure 3.

Conflicts of Interest: The authors declare no conflict of interest.

\section{References}

1. Blackman, B.K. Changing Responses to Changing Seasons: Natural Variation in the Plasticity of Flowering Time. Plant Physiol. 2017, 173, 16-26. [CrossRef] [PubMed]

2. Jung, C.; Muller, A.E. Flowering time control and applications in plant breeding. Trends Plant Sci. 2009, 14, 563-573. [CrossRef] [PubMed]

3. Huang, F.; Liu, T.; Hou, X. Isolation and Functional Characterization of a Floral Repressor, BcMAF1, from Pak-choi (Brassica rapa ssp. Chinensis). Front. Plant Sci. 2018, 9, 290. [CrossRef] [PubMed]

4. Schiessl, S.; Huettel, B.; Kuehn, D.; Reinhardt, R.; Snowdon, R.J. Targeted deep sequencing of flowering regulators in Brassica napus reveals extensive copy number variation. Sci. Data 2017, 4, 170013. [CrossRef] [PubMed] 
5. Shi, J.; L, R.; Qiu, D.; Jiang, C.; Long, Y.; Morgan, C.; Bancroft, I.; Zhao, J.; Meng, J. Unraveling the complex trait of crop yield with quantitative trait loci mapping in Brassica napus. Genetics 2009, 182, 851-861. [CrossRef] [PubMed]

6. Bluemel, M.; Dally, N.; Jung, C. Flowering time regulation in crops-What did we learn from Arabidopsis? Curr. Opin. Biotechnol. 2015, 32, 121-129. [CrossRef] [PubMed]

7. Higuchi, Y. Florigen and anti-florigen: Flowering regulation in horticultural crops. Breed. Sci. 2018, 68, 109-118. [CrossRef] [PubMed]

8. Amasino, R. Seasonal and developmental timing of flowering. Plant J. 2010, 61, 1001-1013. [CrossRef] [PubMed]

9. Fornara, F.; de Montaigu, A.; Coupland, G. SnapShot: Control of flowering in Arabidopsis. Cell 2010, 141, 550-550.e2. [CrossRef] [PubMed]

10. Srikanth, A.; Schmid, M. Regulation of flowering time: All roads lead to Rome. Cell. Mol. Life Sci. 2011, 68, 2013-2037. [CrossRef] [PubMed]

11. Andrés, F.; Coupland, G. The genetic basis of flowering responses to seasonal cues. Nat. Rev. Genet. 2012, 13, 627-639. [CrossRef] [PubMed]

12. Koornneef, M.; Alonso-Blanco, C.; Vreugdenhil, D. Naturally occurring genetic variation in Arabidopsis thaliana. Annu. Rev. Plant. Biol. 2004, 55, 141-172. [CrossRef] [PubMed]

13. Gulden, R.H.; Warwick, S.I.; Thomas, A.G. The biology of Canadian weeds. 137. Brassica napus L. and B. rapa L. Can. J. Plant Sci. 2008, 88, 951-996. [CrossRef]

14. Wang, N.; Qian, W.; Suppanz, I.; Wei, L.; Mao, B.; Long, Y.; Meng, J.; Müller, A.E.; Jung, C. Flowering time variation in oilseed rape (Brassica napus L.) is associated with allelic variation in the FRIGIDA homologue BnaA. FRI. a. J. Exp. Bot. 2011, 62, 5641-5658. [CrossRef] [PubMed]

15. Wang, X.; Wang, H.; Wang, J.; Sun, R.; Wu, J.; Liu, S.; Bai, Y.; Mun, J.-H.; Bancroft, I.; Cheng, F. The genome of the mesopolyploid crop species Brassica rapa. Nat. Genet. 2011, 43, 1035-1039. [CrossRef] [PubMed]

16. Parkin, I.A.; Koh, C.; Tang, H.; Robinson, S.J.; Kagale, S.; Clarke, W.E.; Town, C.D.; Nixon, J.; Krishnakumar, V.; Bidwell, S.L. Transcriptome and methylome profiling reveals relics of genome dominance in the mesopolyploid Brassica oleracea. Genome Boil. 2014, 15, R77. [CrossRef] [PubMed]

17. Kitashiba, H.; Li, F.; Hirakawa, H.; Kawanabe, T.; Zou, Z.; Hasegawa, Y.; Tonosaki, K.; Shirasawa, S.; Fukushima, A.; Yokoi, S. Draft sequences of the radish (Raphanus sativus L.) genome. DNA Res. 2014, 21, 481-490. [CrossRef] [PubMed]

18. Liu, C.; Wang, S.; Xu, W.; Liu, X. Genome-wide transcriptome profiling of radish (Raphanus sativus L.) in response to vernalization. PLOS ONE 2017, 12, e0177594. [CrossRef] [PubMed]

19. Taylor, J.L.; Massiah, A.; Kennedy, S.; Hong, Y.; Jackson, S.D. FLC expression is down-regulated by cold treatment in Diplotaxis tenuifolia (wild rocket), but flowering time is unaffected. J. Plant Physiol. 2017, 214, 7-15. [CrossRef] [PubMed]

20. Reyes-Chin-Wo, S.; Wang, Z.; Yang, X.; Kozik, A.; Arikit, S.; Song, C.; Xia, L.; Froenicke, L.; Lavelle, D.O.; Truco, M.J.; et al. Genome assembly with in vitro proximity ligation data and whole-genome triplication in lettuce. Nat. Commun. 2017, 8, 14953. [CrossRef] [PubMed]

21. Gonthier, L.; Bellec, A.; Blassiau, C.; Prat, E.; Helmstetter, N.; Rambaud, C.; Huss, B.; Hendriks, T.; Bergès, H.; Quillet, M.-C. Construction and characterization of two BAC libraries representing a deep-coverage of the genome of chicory (Cichorium intybus L., Asteraceae). BMC Res. Notes 2010, 3, 225. [CrossRef] [PubMed]

22. Périlleux, C.; Pieltain, A.; Jacquemin, G.; Bouché, F.; Detry, N.; D’aloia, M.; Thiry, L.; Aljochim, P.; Delansnay, M.; Mathieu, A.S. A root chicory MADS box sequence and the Arabidopsis flowering repressor FLC share common features that suggest conserved function in vernalization and de-vernalization responses. Plant J. 2013, 75, 390-402. [CrossRef] [PubMed]

23. Kitamoto, N.; Nishikawa, K.; Tanimura, Y.; Urushibara, S.; Matsuura, T.; Yokoi, S.; Takahata, Y.; Yui, S. Development of late-bolting F1 hybrids of Chinese cabbage (Brassica rapa L.) allowing early spring cultivation without heating. Euphytica 2017, 213, 292. [CrossRef]

24. Rosen, A.; Hasan, Y.; Briggs, W.; Uptmoor, R. Genome-based prediction of time to curd induction in cauliflower. Front. Plant Sci. 2018, 9, 78. [CrossRef] [PubMed]

25. Kitamoto, N.; Yui, S.; Nishikawa, K.; Takahata, Y.; Yokoi, S. A naturally occurring long insertion in the first intron in the Brassica rapaFLC2 gene causes delayed bolting. Euphytica 2014, 196, 213-223. [CrossRef] 
26. Simonne, A.; Simonne, E.; Eitenmiller, R.; Coker, C.H. Bitterness and composition of lettuce varieties grown in the southeastern United States. HortTechnology 2002, 12, 721-726. [CrossRef]

27. Street, R.A.; Sidana, J.; Prinsloo, G. Cichorium intybus: Traditional uses, phytochemistry, pharmacology, and toxicology. Evid.-Based Complement. Altern. Med. 2013, 2013, 579319. [CrossRef] [PubMed]

28. Renna, M.; Gonnella, M.; Giannino, D.; Santamaria, P. Quality evaluation of cook-chilled chicory stems (Cichorium intybus L., Catalogna group) by conventional and sous vide cooking methods. J. Sci. Food Agric. 2014, 94, 656-665. [CrossRef] [PubMed]

29. Barcaccia, G.; Ghedina, A.; Lucchin, M. Current advances in genomics and breeding of leaf Chicory (Cichorium intybus L.). Agriculture 2016, 6, 50. [CrossRef]

30. Kwiatkowska, D. Flowering and apical meristem growth dynamics. J. Exp. Bot. 2008, 59, 187-201. [CrossRef] [PubMed]

31. Yamaguchi, A.; Kobayashi, Y.; Goto, K.; Abe, M.; Araki, T. TWIN SISTER OF FT (TSF) acts as a floral pathway integrator redundantly with FT. Plant Cell Physiol. 2005, 46, 1175-1189. [CrossRef] [PubMed]

32. Ahn, J.H.; Miller, D.; Winter, V.J.; Banfield, M.J.; Lee, J.H.; Yoo, S.Y.; Henz, S.R.; Brady, R.L.; Weigel, D. A divergent external loop confers antagonistic activity on floral regulators FT and TFL1. EMBO J. 2006, 25, 605-614. [CrossRef] [PubMed]

33. Flowering Time Pathway (Arabidopsis thaliana). Available online: https://www.wikipathways.org/index. php/Pathway:WP2312 (accessed on 19 September 2018).

34. Wickland, D.P.; Hanzawa, Y. The FLOWERING LOCUS T/TERMINAL FLOWER 1 gene family: Functional evolution and molecular mechanisms. Mol. Plant 2015, 8, 983-997. [CrossRef] [PubMed]

35. Schiessl, S.V.; Huettel, B.; Kuehn, D.; Reinhardt, R.; Snowdon, R.J. Flowering time gene variation in Brassica species shows evolutionary principles. Front. Plant Sci. 2017, 8, 1742. [CrossRef] [PubMed]

36. Chen, Z.; Zhao, W.; Ge, D.; Han, Y.; Ning, K.; Luo, C.; Wang, S.; Liu, R.; Zhang, X.; Wang, Q. LCM-seq reveals the crucial role of Ls SOC 1 in heat-promoted bolting of lettuce (Lactuca sativa L.). Plant J. 2018. [CrossRef] [PubMed]

37. Liu, L.; Liu, C.; Hou, X.; Xi, W.; Shen, L.; Tao, Z.; Wang, Y.; Yu, H. FTIP1 is an essential regulator required for florigen transport. PLoS Boil. 2012, 10, e1001313. [CrossRef] [PubMed]

38. Abe, M.; Kobayashi, Y.; Yamamoto, S.; Daimon, Y.; Yamaguchi, A.; Ikeda, Y.; Ichinoki, H.; Notaguchi, M.; Goto, K.; Araki, T. FD, a bZIP protein mediating signals from the floral pathway integrator FT at the shoot apex. Science 2005, 309, 1052-1056. [CrossRef] [PubMed]

39. Suárez-López, P.; Wheatley, K.; Robson, F.; Onouchi, H.; Valverde, F.; Coupland, G. CONSTANS mediates between the circadian clock and the control of flowering in Arabidopsis. Nature 2001, 410, 1116-1120. [CrossRef] [PubMed]

40. Deng, W.; Ying, H.; Helliwell, C.A.; Taylor, J.M.; Peacock, W.J.; Dennis, E.S. FLOWERING LOCUS C (FLC) regulates development pathways throughout the life cycle of Arabidopsis. Proc. Natl. Acad. Sci. USA 2011, 108, 6680-6685. [CrossRef] [PubMed]

41. Mateos, J.L.; Madrigal, P.; Tsuda, K.; Rawat, V.; Richter, R.; Romera-Branchat, M.; Fornara, F.; Schneeberger, K.; Krajewski, P.; Coupland, G. Combinatorial activities of SHORT VEGETATIVE PHASE and FLOWERING LOCUS C define distinct modes of flowering regulation in Arabidopsis. Genome Boil. 2015, 16, 31. [CrossRef] [PubMed]

42. Taoka, K.-i.; Ohki, I.; Tsuji, H.; Furuita, K.; Hayashi, K.; Yanase, T.; Yamaguchi, M.; Nakashima, C.; Purwestri, Y.A.; Tamaki, S. 14-3-3 proteins act as intracellular receptors for rice Hd3a florigen. Nature 2011, 476, 332-335. [CrossRef] [PubMed]

43. Liu, C.; Chen, H.; Er, H.L.; Soo, H.M.; Kumar, P.P.; Han, J.-H.; Liou, Y.C.; Yu, H. Direct interaction of AGL24 and SOC1 integrates flowering signals in Arabidopsis. Development 2008, 135, 1481-1491. [CrossRef] [PubMed]

44. Hanzawa, Y.; Money, T.; Bradley, D. A single amino acid converts a repressor to an activator of flowering. Proc. Natl. Acad. Sci. USA 2005, 102, 7748-7753. [CrossRef] [PubMed]

45. Conti, L.; Bradley, D. TERMINAL FLOWER1 is a mobile signal controlling Arabidopsis architecture. Plant Cell 2007, 19, 767-778. [CrossRef] [PubMed]

46. Hanano, S.; Goto, K. Arabidopsis TERMINAL FLOWER1 is involved in the regulation of flowering time and inflorescence development through transcriptional repression. Plant Cell 2011, 23, 3172-3184. [CrossRef] [PubMed] 
47. Wang, J.; Hopkins, C.J.; Hou, J.; Zou, X.; Wang, C.; Long, Y.; Kurup, S.; King, G.J.; Meng, J. Promoter variation and transcript divergence in Brassicaceae lineages of FLOWERING LOCUS T. PLOS ONE 2012, 7, e47127. [CrossRef] [PubMed]

48. Wang, J.; Long, Y.; Wu, B.; Liu, J.; Jiang, C.; Shi, L.; Zhao, J.; King, G.J.; Meng, J. The evolution of Brassica napus FLOWERING LOCUST paralogues in the context of inverted chromosomal duplication blocks. BMC Evol. Boil. 2009, 9, 271. [CrossRef] [PubMed]

49. Zhang, X.; Meng, L.; Liu, B.; Hu, Y.; Cheng, F.; Liang, J.; Aarts, M.G.; Wang, X.; Wu, J. A transposon insertion in FLOWERING LOCUS T is associated with delayed flowering in Brassica rapa. Plant Sci. 2015, 241, 211-220. [CrossRef] [PubMed]

50. Raman, H.; Raman, R.; Coombes, N.; Song, J.; Prangnell, R.; Bandaranayake, C.; Tahira, R.; Sundaramoorthi, V.; Killian, A.; Meng, J. Genome-wide association analyses reveal complex genetic architecture underlying natural variation for flowering time in canola. Plant Cell Environ. 2016, 39, 1228-1239. [CrossRef] [PubMed]

51. Guo, Y.; Hans, H.; Christian, J.; Molina, C. Mutations in single FT-and TFL1-paralogs of rapeseed (Brassica napus L.) and their impact on flowering time and yield components. Front. Plant Sci. 2014, 5, 282. [CrossRef] [PubMed]

52. Shah, S.; Weinholdt, C.; Jedrusik, N.; Molina, C.; Zou, J.; Große, I.; Schiessl, S.; Jung, C.; Emrani, N. Whole transcriptome analysis reveals genetic factors underlying flowering time regulation in rapeseed (Brassica napus L.). Plant Cell Environ. 2018. [CrossRef] [PubMed]

53. Li, B.; Zhao, W.; Li, D.; Chao, H.; Zhao, X.; Ta, N.; Li, Y.; Guan, Z.; Guo, L.; Zhang, L. Genetic dissection of the mechanism of flowering time based on an environmentally stable and specific QTL in Brassica napus. Plant Sci. 2018, 277, 296-310. [CrossRef] [PubMed]

54. Song, X.; Duan, W.; Huang, Z.; Liu, G.; Wu, P.; Liu, T.; Li, Y.; Hou, X. Comprehensive analysis of the flowering genes in Chinese cabbage and examination of evolutionary pattern of CO-like genes in plant kingdom. Sci. Rep. 2015, 5, 14631. [CrossRef] [PubMed]

55. Hong, J.K.; Kim, S.-Y.; Kim, K.-S.; Kwon, S.-J.; Kim, J.S.; Kim, J.A.; Lee, S.I.; Lee, Y.-H. Overexpression of a Brassica rapa MADS-box gene, BrAGL20, induces early flowering time phenotypes in Brassica napus. Plant. Biotechnol. Rep. 2013, 7, 231-237. [CrossRef]

56. Franks, S.J.; Perez-Sweeney, B.; Strahl, M.; Nowogrodzki, A.; Weber, J.J.; Lalchan, R.; Jordan, K.P.; Litt, A. Variation in the flowering time orthologs BrFLC and BrSOC1 in a natural population of Brassica rapa. PeerJ 2015, 3, e1339. [CrossRef] [PubMed]

57. Cavaiuolo, M.; Cocetta, G.; Spadafora, N.D.; Müller, C.T.; Rogers, H.J.; Ferrante, A. Gene expression analysis of rocket salad under pre-harvest and postharvest stresses: A transcriptomic resource for Diplotaxis tenuifolia. PLoS ONE 2017, 12, e0178119. [CrossRef] [PubMed]

58. Fukuda, M.; Matsuo, S.; Kikuchi, K.; Kawazu, Y.; Fujiyama, R.; Honda, I. Isolation and functional characterization of the FLOWERING LOCUS T homolog, the LsFT gene, in lettuce. J. Plant Physiol. 2011, 168, 1602-1607. [CrossRef] [PubMed]

59. Chen, Z.; Han, Y.; Ning, K.; Ding, Y.; Zhao, W.; Yan, S.; Luo, C.; Jiang, X.; Wang, Q.; Zhang, X. Inflorescence development and the role of LsFT in regulating bolting in lettuce (Lactuca sativa L.). Front. Plant Sci. 2017, 8, 2248. [CrossRef] [PubMed]

60. Fukuda, M.; Yanai, Y.; Nakano, Y.; Sasaki, H.; Uragami, A.; Okada, K. Isolation and Gene Expression Analysis of Flowering-related Genes in Lettuce (Lactuca sativa L.). Hortic. J. 2017, 86, 340-348. [CrossRef]

61. Han, Y.; Chen, Z.; Lv, S.; Ning, K.; Ji, X.; Liu, X.; Wang, Q.; Liu, R.; Fan, S.; Zhang, X. MADS-box genes and gibberellins regulate bolting in Lettuce (Lactuca sativa L.). Front. Plant Sci. 2016, 7, 1889. [CrossRef] [PubMed]

62. Chouard, P. Vernalization and its relations to dormancy. Annu. Rev. Plant Physiol. 1960, 11, 191-238. [CrossRef]

63. Albani, M.C.; Coupland, G. Comparative analysis of flowering in annual and perennial plants. In Current Topics in Developmental Biology; Elsevier: Amsterdam, The Netherlands, 2010; Volume 91, pp. 323-348.

64. Hepworth, J.; Antoniou-Kourounioti, R.L.; Bloomer, R.H.; Selga, C.; Berggren, K.; Cox, D.; Collier Harris, B.R.; Irwin, J.A.; Holm, S.; Sall, T.; et al. Absence of warmth permits epigenetic memory of winter in Arabidopsis. Nat. Commun 2018, 9, 639. [CrossRef] [PubMed] 
65. Alonso-Blanco, C.; Andrade, J.; Becker, C.; Bemm, F.; Bergelson, J.; Borgwardt, K.M.; Cao, J.; Chae, E.; Dezwaan, T.M.; Ding, W. 1,135 genomes reveal the global pattern of polymorphism in Arabidopsis thaliana. Cell 2016, 166, 481-491. [CrossRef] [PubMed]

66. Zou, X.; Suppanz, I.; Raman, H.; Hou, J.; Wang, J.; Long, Y.; Jung, C.; Meng, J. Comparative analysis of FLC homologues in Brassicaceae provides insight into their role in the evolution of oilseed rape. PLoS ONE 2012, 7, e45751. [CrossRef] [PubMed]

67. Schranz, M.E.; Quijada, P.; Sung, S.-B.; Lukens, L.; Amasino, R.; Osborn, T.C. Characterization and effects of the replicated flowering time gene FLC in Brassica rapa. Genetics 2002, 162, 1457-1468. [PubMed]

68. Razi, H.; Howell, E.C.; Newbury, H.J.; Kearsey, M.J. Does sequence polymorphism of FLC paralogues underlie flowering time QTL in Brassica oleracea? Theor. Appl. Genet. 2008, 116, 179-192. [CrossRef] [PubMed]

69. Kiefer, C.; Severing, E.; Karl, R.; Bergonzi, S.; Koch, M.; Tresch, A.; Coupland, G. Divergence of annual and perennial species in the Brassicaceae and the contribution of cis-acting variation at FLC orthologues. Mol. Ecol. 2017, 26, 3437-3457. [CrossRef] [PubMed]

70. Michaels, S.D.; Amasino, R.M. FLOWERING LOCUS C encodes a novel MADS domain protein that acts as a repressor of flowering. Plant Cell 1999, 11, 949-956. [CrossRef] [PubMed]

71. Sheldon, C.C.; Burn, J.E.; Perez, P.P.; Metzger, J.; Edwards, J.A.; Peacock, W.J.; Dennis, E.S. The FLF MADS box gene: A repressor of flowering in Arabidopsis regulated by vernalization and methylation. Plant Cell 1999, 11, 445-458. [CrossRef] [PubMed]

72. Johanson, U.; West, J.; Lister, C.; Michaels, S.; Amasino, R.; Dean, C. Molecular analysis of FRIGIDA, a major determinant of natural variation in Arabidopsis flowering time. Science 2000, 290, 344-347. [CrossRef] [PubMed]

73. Werner, J.D.; Borevitz, J.O.; Uhlenhaut, N.H.; Ecker, J.R.; Chory, J.; Weigel, D. FRIGIDA-independent variation in flowering time of natural Arabidopsis thaliana accessions. Genetics 2005, 170, 1197-1207. [CrossRef] [PubMed]

74. Liu, F.; Marquardt, S.; Lister, C.; Swiezewski, S.; Dean, C. Targeted $3^{\prime}$ processing of antisense transcripts triggers Arabidopsis FLC chromatin silencing. Science 2010, 327, 94-97. [CrossRef] [PubMed]

75. Yang, H.; Howard, M.; Dean, C. Antagonistic roles for H3K36me3 and H3K27me3 in the cold-induced epigenetic switch at Arabidopsis FLC. Curr. Boil. 2014, 24, 1793-1797. [CrossRef] [PubMed]

76. Csorba, T.; Questa, J.I.; Sun, Q.; Dean, C. Antisense COOLAIR mediates the coordinated switching of chromatin states at FLC during vernalization. Proc. Natl. Acad. Sci. USA 2014, 111, 16160-16165. [CrossRef] [PubMed]

77. Heo, J.B.; Sung, S. Vernalization-mediated epigenetic silencing by a long intronic noncoding RNA. Science 2011, 331, 76-79. [CrossRef] [PubMed]

78. Kim, D.-H.; Sung, S. Vernalization-triggered intragenic chromatin loop formation by long noncoding RNAs. Dev. Cell 2017, 40, 302.e4-312.e4. [CrossRef] [PubMed]

79. Kim, D.-H.; Xi, Y.; Sung, S. Modular function of long noncoding RNA, COLDAIR, in the vernalization response. PLoS Genet. 2017, 13, e1006939. [CrossRef] [PubMed]

80. Bastow, R.; Mylne, J.S.; Lister, C.; Lippman, Z.; Martienssen, R.A.; Dean, C. Vernalization requires epigenetic silencing of FLC by histone methylation. Nature 2004, 427, 164-167. [CrossRef] [PubMed]

81. Sung, S.; Amasino, R.M. Vernalization in Arabidopsis thaliana is mediated by the PHD finger protein VIN3. Nature 2004, 427, 159. [CrossRef] [PubMed]

82. Ausín, I.; Alonso-Blanco, C.; Jarillo, J.A.; Ruiz-García, L.; Martínez-Zapater, J.M. Regulation of flowering time by FVE, a retinoblastoma-associated protein. Nat. Genet. 2004, 36, 162-166. [CrossRef] [PubMed]

83. Gendall, A.R.; Levy, Y.Y.; Wilson, A.; Dean, C. The VERNALIZATION 2 gene mediates the epigenetic regulation of vernalization in Arabidopsis. Cell 2001, 107, 525-535. [CrossRef]

84. Levy, Y.Y.; Mesnage, S.; Mylne, J.S.; Gendall, A.R.; Dean, C. Multiple roles of Arabidopsis VRN1 in vernalization and flowering time control. Science 2002, 297, 243-246. [CrossRef] [PubMed]

85. Gu, X.; Le, C.; Wang, Y.; Li, Z.; Jiang, D.; Wang, Y.; He, Y. Arabidopsis FLC clade members form flowering-repressor complexes coordinating responses to endogenous and environmental cues. Nat. Commun. 2013, 4, 1947. [CrossRef] [PubMed]

86. Williams, P.H.; Hill, C.B. Rapid-cycling populations of Brassica. Science 1986, 232, 1385-1389. [CrossRef] [PubMed] 
87. Okazaki, K.; Sakamoto, K.; Kikuchi, R.; Saito, A.; Togashi, E.; Kuginuki, Y.; Matsumoto, S.; Hirai, M. Mapping and characterization of FLC homologs and QTL analysis of flowering time in Brassica oleracea. Theor. Appl. Genet. 2007, 114, 595-608. [CrossRef] [PubMed]

88. Al-Shahrour, F.; Minguez, P.; Marqués-Bonet, T.; Gazave, E.; Navarro, A.; Dopazo, J. Selection upon genome architecture: Conservation of functional neighborhoods with changing genes. PLoS Comput. Boil. 2010, 6, e1000953. [CrossRef] [PubMed]

89. Lee, J.M.; Sonnhammer, E.L. Genomic gene clustering analysis of pathways in eukaryotes. Genome Res. 2003, 13, 875-882. [CrossRef] [PubMed]

90. Irwin, J.A.; Lister, C.; Soumpourou, E.; Zhang, Y.; Howell, E.C.; Teakle, G.; Dean, C. Functional alleles of the flowering time regulator FRIGIDA in the Brassica oleracea genome. BMC Plant Boil. 2012, 12, 21. [CrossRef] [PubMed]

91. Wu, J.; Wei, K.; Cheng, F.; Li, S.; Wang, Q.; Zhao, J.; Bonnema, G.; Wang, X. A naturally occurring InDel variation in BraA. FLC. b (BrFLC2) associated with flowering time variation in Brassica rapa. BMC Plant Boil. 2012, 12, 151.

92. Xiao, D.; Zhao, J.J.; Hou, X.L.; Basnet, R.K.; Carpio, D.P.; Zhang, N.W.; Bucher, J.; Lin, K.; Cheng, F.; Wang, X.W. The Brassica rapa FLC homologue FLC2 is a key regulator of flowering time, identified through transcriptional co-expression networks. J. Exp. Bot. 2013, 64, 4503-4516. [CrossRef] [PubMed]

93. Yuan, Y.-X.; Wu, J.; Sun, R.-F.; Zhang, X.-W.; Xu, D.-H.; Bonnema, G.; Wang, X.-W. A naturally occurring splicing site mutation in the Brassica rapa FLC1 gene is associated with variation in flowering time. J. Exp. Bot. 2009, 60, 1299-1308. [CrossRef] [PubMed]

94. Zhao, J.; Kulkarni, V.; Liu, N.; Pino Del Carpio, D.; Bucher, J.; Bonnema, G. BrFLC2 (FLOWERING LOCUS C) as a candidate gene for a vernalization response QTL in Brassica rapa. J. Exp. Bot. 2010, 61, 1817-1825. [CrossRef] [PubMed]

95. Kawanabe, T.; Osabe, K.; Itabashi, E.; Okazaki, K.; Dennis, E.S.; Fujimoto, R. Development of primer sets that can verify the enrichment of histone modifications, and their application to examining vernalization-mediated chromatin changes in Brassica rapa L. Genes Genet. Syst. 2016, 91, 1-10. [CrossRef] [PubMed]

96. Xi, X.; Wei, K.; Gao, B.; Liu, J.; Liang, J.; Cheng, F.; Wang, X.; Wu, J. BrFLC5: A weak regulator of flowering time in Brassica rapa. Theor. Appl. Genet. 2018, 1-10. [CrossRef] [PubMed]

97. Huang, F.; Liu, T.; Wang, J.; Hou, X. Isolation and functional characterization of a floral repressor, BcFLC2, from Pak-choi (Brassica rapa ssp. chinensis). Planta 2018, 248, 423-435. [CrossRef] [PubMed]

98. Li, X.; Zhang, S.; Bai, J.; He, Y. Tuning growth cycles of Brassica crops via natural antisense transcripts of Br FLC. Plant. Biotechnol. J. 2016, 14, 905-914. [CrossRef] [PubMed]

99. Duan, W.; Zhang, H.; Zhang, B.; Wu, X.; Shao, S.; Li, Y.; Hou, X.; Liu, T. Role of vernalization-mediated demethylation in the floral transition of Brassica rapa. Planta 2017, 245, 227-233. [CrossRef] [PubMed]

100. Matschegewski, C.; Zetzsche, H.; Hasan, Y.; Leibeguth, L.; Briggs, W.; Ordon, F.; Uptmoor, R. Genetic variation of temperature-regulated curd induction in cauliflower: Elucidation of floral transition by genome-wide association mapping and gene expression analysis. Front. Plant Sci. 2015, 6, 720. [CrossRef] [PubMed]

101. Irwin, J.A.; Soumpourou, E.; Lister, C.; Ligthart, J.D.; Kennedy, S.; Dean, C. Nucleotide polymorphism affecting FLC expression underpins heading date variation in horticultural brassicas. Plant J. 2016, 87, 597-605. [CrossRef] [PubMed]

102. Fadina, O.; Pankin, A.; Khavkin, E. Molecular characterization of the flowering time gene FRIGIDA in Brassica genomes A and C. Russ. J. Plant Physiol. 2013, 60, 279-289. [CrossRef]

103. Yi, G.; Park, H.; Kim, J.-S.; Chae, W.B.; Park, S.; Huh, J.H. Identification of three FLOWERING LOCUS C genes responsible for vernalization response in radish (Raphanus sativus L.). Hortic. Environ. Biotechnol. 2014, 55, 548-556. [CrossRef]

104. Jung, W.Y.; Park, H.J.; Lee, A.; Lee, S.S.; Kim, Y.-S.; Cho, H.S. Identification of flowering-related genes responsible for differences in bolting time between two radish inbred lines. Front. Plant Sci. 2016, 7, 1844. [CrossRef] [PubMed]

105. Li, C.; Wang, Y.; Xu, L.; Nie, S.; Chen, Y.; Liang, D.; Sun, X.; Karanja, B.K.; Luo, X.; Liu, L. Genome-wide characterization of the MADS-Box gene family in Radish (Raphanus sativus L.) and assessment of its roles in flowering and floral organogenesis. Front. Plant Sci. 2016, 7, 1390. [CrossRef] [PubMed] 
106. Taylor, J.L. Delayed Bolting in Rocket for Improved Quality and GREATER Sustainability. Ph.D. Thesis, University of Warwick, Coventry, UK, 2015.

107. Lee, J.H.; Park, S.H.; Lee, J.S.; Ahn, J.H. A conserved role of SHORT VEGETATIVE PHASE (SVP) in controlling flowering time of Brassica plants. Biochim. Biophys. Acta (BBA)-Gene Struct. Expr. 2007, 1769, 455-461. [CrossRef] [PubMed]

108. Lutz, U.; Nussbaumer, T.; Spannagl, M.; Diener, J.; Mayer, K.F.; Schwechheimer, C. Natural haplotypes of FLM non-coding sequences fine-tune flowering time in ambient spring temperatures in Arabidopsis. eLife 2017, 6, e22114. [CrossRef] [PubMed]

109. Balasubramanian, S.; Sureshkumar, S.; Lempe, J.; Weigel, D. Potent induction of Arabidopsis thaliana flowering by elevated growth temperature. PLoS Genet. 2006, 2, e106. [CrossRef] [PubMed]

110. Balasubramanian, S.; Weigel, D. Temperature induced flowering in Arabidopsis thaliana. Plant Signal. Behav. 2006, 1, 227-228. [CrossRef] [PubMed]

111. Capovilla, G.; Schmid, M.; Pose, D. Control of flowering by ambient temperature. J. Exp. Bot 2015, 66, 59-69. [CrossRef] [PubMed]

112. Kumar, S.V.; Wigge, P.A. H2A. Z-containing nucleosomes mediate the thermosensory response in Arabidopsis. Cell 2010, 140, 136-147. [CrossRef] [PubMed]

113. Kumar, S.V.; Lucyshyn, D.; Jaeger, K.E.; Alós, E.; Alvey, E.; Harberd, N.P.; Wigge, P.A. Transcription factor PIF4 controls the thermosensory activation of flowering. Nature 2012, 484, 242-245. [CrossRef] [PubMed]

114. Thines, B.C.; Youn, Y.; Duarte, M.I.; Harmon, F.G. The time of day effects of warm temperature on flowering time involve PIF4 and PIF5. J. Exp. Bot. 2014, 65, 1141-1151. [CrossRef] [PubMed]

115. Fernández, V.; Takahashi, Y.; Le Gourrierec, J.; Coupland, G. Photoperiodic and thermosensory pathways interact through CONSTANS to promote flowering at high temperature under short days. Plant J. 2016, 86, 426-440. [CrossRef] [PubMed]

116. Capovilla, G.; Pajoro, A.; Immink, R.G.; Schmid, M. Role of alternative pre-mRNA splicing in temperature signaling. Curr. Opin. Plant Boil. 2015, 27, 97-103. [CrossRef] [PubMed]

117. Li, D.; Liu, C.; Shen, L.; Wu, Y.; Chen, H.; Robertson, M.; Helliwell, C.A.; Ito, T.; Meyerowitz, E.; Yu, H. A repressor complex governs the integration of flowering signals in Arabidopsis. Dev. Cell 2008, 15, 110-120. [CrossRef] [PubMed]

118. Lee, J.H.; Ryu, H.-S.; Chung, K.S.; Posé, D.; Kim, S.; Schmid, M.; Ahn, J.H. Regulation of temperature-responsive flowering by MADS-box transcription factor repressors. Science 2013, 342, 628-632. [CrossRef] [PubMed]

119. Jiao, Y.; Meyerowitz, E.M. Cell-type specific analysis of translating RNAs in developing flowers reveals new levels of control. Mol. Syst. Boil. 2010, 6, 419. [CrossRef] [PubMed]

120. Posé, D.; Verhage, L.; Ott, F.; Yant, L.; Mathieu, J.; Angenent, G.C.; Immink, R.G.; Schmid, M. Temperature-dependent regulation of flowering by antagonistic FLM variants. Nature 2013, 503, 414-417. [CrossRef] [PubMed]

121. Verhage, L.; Severing, E.I.; Bucher, J.; Lammers, M.; Busscher-Lange, J.; Bonnema, G.; Rodenburg, N.; Proveniers, M.C.; Angenent, G.C.; Immink, R.G. Splicing-related genes are alternatively spliced upon changes in ambient temperatures in plants. PLoS ONE 2017, 12, e0172950. [CrossRef] [PubMed]

122. Capovilla, G.; Symeonidi, E.; Wu, R.; Schmid, M. Contribution of major FLM isoforms to temperature-dependent flowering in Arabidopsis thaliana. J. Exp. Bot. 2017, 68, 5117-5127. [CrossRef] [PubMed]

123. Méndez-Vigo, B.; Martínez-Zapater, J.M.; Alonso-Blanco, C. The flowering repressor SVP underlies a novel Arabidopsis thaliana QTL interacting with the genetic background. PLoS Genet. 2013, 9, e1003289. [CrossRef] [PubMed]

124. Yi, L.; Chen, C.; Yin, S.; Li, H.; Li, Z.; Wang, B.; King, G.J.; Wang, J.; Liu, K. Sequence variation and functional analysis of a FRIGIDA orthologue (BnaA3. FRI) in Brassica napus. BMC Plant Boil. 2018, 18, 32. [CrossRef] [PubMed]

125. Mathieu, A.-S.; Lutts, S.; Vandoorne, B.; Descamps, C.; Périlleux, C.; Dielen, V.; Van Herck, J.-C.; Quinet, M. High temperatures limit plant growth but hasten flowering in root chicory (Cichorium intybus) independently of vernalisation. J. Plant Physiol. 2014, 171, 109-118. [CrossRef] [PubMed]

126. Garner, W.W.; Allard, H.A. Effect of the relative length of day and night and other factors of the environment on growth and reproduction in plants. Mon. Weather. Rev. 1920, 48, 415. [CrossRef] 
127. Hernando, C.E.; Romanowski, A.; Yanovsky, M.J. Transcriptional and post-transcriptional control of the plant circadian gene regulatory network. Biochim. Biophys. Acta (BBA)-Gene Regul. Mech. 2017, 1860, 84-94. [CrossRef] [PubMed]

128. Valverde, F.; Mouradov, A.; Soppe, W.; Ravenscroft, D.; Samach, A.; Coupland, G. Photoreceptor regulation of CONSTANS protein in photoperiodic flowering. Science 2004, 303, 1003-1006. [CrossRef] [PubMed]

129. Song, Y.H.; Ito, S.; Imaizumi, T. Similarities in the circadian clock and photoperiodism in plants. Curr. Opin. Plant Biol. 2010, 13, 594-603. [CrossRef] [PubMed]

130. Higashi, T.; Aoki, K.; Nagano, A.J.; Honjo, M.N.; Fukuda, H. Circadian Oscillation of the Lettuce Transcriptome under Constant Light and Light-Dark Conditions. Front. Plant Sci. 2016, 7, 1114. [CrossRef] [PubMed]

131. Fornara, F.; Panigrahi, K.C.; Gissot, L.; Sauerbrunn, N.; Rühl, M.; Jarillo, J.A.; Coupland, G. Arabidopsis DOF transcription factors act redundantly to reduce CONSTANS expression and are essential for a photoperiodic flowering response. Dev. Cell 2009, 17, 75-86. [CrossRef] [PubMed]

132. Imaizumi, T.; Schultz, T.F.; Harmon, F.G.; Ho, L.A.; Kay, S.A. FKF1 F-box protein mediates cyclic degradation of a repressor of CONSTANS in Arabidopsis. Science 2005, 309, 293-297. [CrossRef] [PubMed]

133. Song, Y.H.; Smith, R.W.; To, B.J.; Millar, A.J.; Imaizumi, T. FKF1 conveys timing information for CONSTANS stabilization in photoperiodic flowering. Science 2012, 336, 1045-1049. [CrossRef] [PubMed]

134. Sawa, M.; Nusinow, D.A.; Kay, S.A.; Imaizumi, T. FKF1 and GIGANTEA complex formation is required for day-length measurement in Arabidopsis. Science 2007, 318, 261-265. [CrossRef] [PubMed]

135. Song, Y.H.; Estrada, D.A.; Johnson, R.S.; Kim, S.K.; Lee, S.Y.; MacCoss, M.J.; Imaizumi, T. Distinct roles of FKF1, GIGANTEA, and ZEITLUPE proteins in the regulation of CONSTANS stability in Arabidopsis photoperiodic flowering. Proc. Natl. Acad. Sci. USA 2014, 111, 17672-17677. [CrossRef] [PubMed]

136. Jang, S.; Marchal, V.; Panigrahi, K.C.; Wenkel, S.; Soppe, W.; Deng, X.W.; Valverde, F.; Coupland, G. Arabidopsis COP1 shapes the temporal pattern of $\mathrm{CO}$ accumulation conferring a photoperiodic flowering response. EMBO J. 2008, 27, 1277-1288. [CrossRef] [PubMed]

137. Laubinger, S.; Marchal, V.; Gentilhomme, J.; Wenkel, S.; Adrian, J.; Jang, S.; Kulajta, C.; Braun, H.; Coupland, G.; Hoecker, U. Arabidopsis SPA proteins regulate photoperiodic flowering and interact with the floral inducer CONSTANS to regulate its stability. Development 2006, 133, 3213-3222. [CrossRef] [PubMed]

138. Liu, L.-J.; Zhang, Y.-C.; Li, Q.-H.; Sang, Y.; Mao, J.; Lian, H.-L.; Wang, L.; Yang, H.-Q. COP1-mediated ubiquitination of CONSTANS is implicated in cryptochrome regulation of flowering in Arabidopsis. Plant Cell 2008, 20, 292-306. [CrossRef] [PubMed]

139. Covington, M.F.; Maloof, J.N.; Straume, M.; Kay, S.A.; Harmer, S.L. Global transcriptome analysis reveals circadian regulation of key pathways in plant growth and development. Genome Boil. 2008, 9, R130. [CrossRef] [PubMed]

140. Nohales, M.A.; Kay, S.A. Molecular mechanisms at the core of the plant circadian oscillator. Nat. Struct. Mol. Boil. 2016, 23, 1061-1069. [CrossRef] [PubMed]

141. Lu, S.X.; Knowles, S.M.; Andronis, C.; Ong, M.S.; Tobin, E.M. CIRCADIAN CLOCK ASSOCIATED1 and LATE ELONGATED HYPOCOTYL function synergistically in the circadian clock of Arabidopsis. Plant Physiol. 2009, 150, 834-843. [CrossRef] [PubMed]

142. Huang, W.; Pérez-García, P.; Pokhilko, A.; Millar, A.; Antoshechkin, I.; Riechmann, J.L.; Mas, P. Mapping the core of the Arabidopsis circadian clock defines the network structure of the oscillator. Science 2012, 336, 75-79. [CrossRef] [PubMed]

143. Kamioka, M.; Takao, S.; Suzuki, T.; Taki, K.; Higashiyama, T.; Kinoshita, T.; Nakamichi, N. Direct repression of evening genes by CIRCADIAN CLOCK-ASSOCIATED 1 in Arabidopsis circadian clock. Plant Cell 2016, 28, 696-711. [CrossRef] [PubMed]

144. Lu, S.X.; Webb, C.J.; Knowles, S.M.; Kim, S.H.; Wang, Z.-Y.; Tobin, E.M. CCA1 and ELF3 Interact in the control of hypocotyl length and flowering time in Arabidopsis. Plant Physiol. 2012, 158, 1079-1088. [CrossRef] [PubMed]

145. Farré, E.M.; Harmer, S.L.; Harmon, F.G.; Yanovsky, M.J.; Kay, S.A. Overlapping and distinct roles of PRR7 and PRR9 in the Arabidopsis circadian clock. Curr. Boil. 2005, 15, 47-54. [CrossRef] [PubMed]

146. Hsu, P.Y.; Devisetty, U.K.; Harmer, S.L. Accurate timekeeping is controlled by a cycling activator in Arabidopsis. eLife 2013, 2, e00473. [CrossRef] [PubMed] 
147. Nakamichi, N.; Kiba, T.; Henriques, R.; Mizuno, T.; Chua, N.-H.; Sakakibara, H. PSEUDO-RESPONSE REGULATORS 9, 7, and 5 are transcriptional repressors in the Arabidopsis circadian clock. Plant Cell 2010, 22, 594-605. [CrossRef] [PubMed]

148. Herrero, E.; Kolmos, E.; Bujdoso, N.; Yuan, Y.; Wang, M.; Berns, M.C.; Uhlworm, H.; Coupland, G.; Saini, R.; Jaskolski, M. EARLY FLOWERING4 recruitment of EARLY FLOWERING3 in the nucleus sustains the Arabidopsis circadian clock. Plant Cell 2012, 24, 428-443. [CrossRef] [PubMed]

149. Chow, B.Y.; Helfer, A.; Nusinow, D.A.; Kay, S.A. ELF3 recruitment to the PRR9 promoter requires other Evening Complex members in the Arabidopsis circadian clock. Plant Signal. Behav. 2012, 7, 170-173. [CrossRef] [PubMed]

150. Gendron, J.M.; Pruneda-Paz, J.L.; Doherty, C.J.; Gross, A.M.; Kang, S.E.; Kay, S.A. Arabidopsis circadian clock protein, TOC1, is a DNA-binding transcription factor. Proc. Natl. Acad. Sci. USA 2012, 109, 3167-3172. [CrossRef] [PubMed]

151. Robert, L.S.; Robson, F.; Sharpe, A.; Lydiate, D.; Coupland, G. Conserved structure and function of the Arabidopsis flowering time gene CONSTANS in Brassica napus. Plant Mol. Boil. 1998, 37, 763-772. [CrossRef]

152. Kim, J.A.; Jung, H.-E.; Hong, J.K.; Hermand, V.; McClung, C.R.; Lee, Y.-H.; Kim, J.Y.; Lee, S.I.; Jeong, M.-J.; Kim, J. Reduction of GIGANTEA expression in transgenic Brassica rapa enhances salt tolerance. Plant Cell Rep. 2016, 35, 1943-1954. [CrossRef] [PubMed]

153. Xie, Q.; Lou, P.; Hermand, V.; Aman, R.; Park, H.J.; Yun, D.-J.; Kim, W.Y.; Salmela, M.J.; Ewers, B.E.; Weinig, C. Allelic polymorphism of GIGANTEA is responsible for naturally occurring variation in circadian period in Brassica rapa. Proc. Natl. Acad. Sci. USA 2015, 112, 3829-3834. [PubMed]

154. Curtis, I.S.; Nam, H.G.; Yun, J.Y.; Seo, K.-H. Expression of an antisense GIGANTEA (GI) gene fragment in transgenic radish causes delayed bolting and flowering. Transgenic Res. 2002, 11, 249-256. [CrossRef] [PubMed]

155. Thiruvengadam, M.; Shih, C.-F.; Yang, C.-H. Expression of an antisense Brassica oleracea GIGANTEA (BoGI) gene in transgenic broccoli causes delayed flowering, leaf senescence, and post-harvest yellowing retardation. Plant Mol. Boil. Rep. 2015, 33, 1499-1509. [CrossRef]

156. Lou, P.; Wu, J.; Cheng, F.; Cressman, L.G.; Wang, X.; McClung, C.R. Preferential retention of circadian clock genes during diploidization following whole genome triplication in Brassica rapa. Plant Cell 2012, 24, 2415-2426. [CrossRef] [PubMed]

157. Yamaguchi, A.; Wu, M.-F.; Yang, L.; Wu, G.; Poethig, R.S.; Wagner, D. The microRNA-regulated SBP-Box transcription factor SPL3 is a direct upstream activator of LEAFY, FRUITFULL, and APETALA1. Dev. Cell 2009, 17, 268-278. [CrossRef] [PubMed]

158. Wang, J.-W.; Czech, B.; Weigel, D. miR156-regulated SPL transcription factors define an endogenous flowering pathway in Arabidopsis thaliana. Cell 2009, 138, 738-749. [CrossRef] [PubMed]

159. Wu, G.; Poethig, R.S. Temporal regulation of shoot development in Arabidopsis thaliana by miR156 and its target SPL3. Development 2006, 133, 3539-3547. [CrossRef] [PubMed]

160. Wu, G.; Park, M.Y.; Conway, S.R.; Wang, J.-W.; Weigel, D.; Poethig, R.S. The sequential action of miR156 and miR172 regulates developmental timing in Arabidopsis. Cell 2009, 138, 750-759. [CrossRef] [PubMed]

161. Teotia, S.; Tang, G. To bloom or not to bloom: Role of microRNAs in plant flowering. Mol. Plant 2015, 8, 359-377. [CrossRef] [PubMed]

162. Hyun, Y.; Richter, R.; Coupland, G. Competence to flower: Age-controlled sensitivity to environmental cues. Plant Physiol. 2017, 173, 36-46. [CrossRef] [PubMed]

163. Nie, S.; Xu, L.; Wang, Y.; Huang, D.; Muleke, E.M.; Sun, X.; Wang, R.; Xie, Y.; Gong, Y.; Liu, L. Identification of bolting-related microRNAs and their targets reveals complex miRNA-mediated flowering-time regulatory networks in radish (Raphanus sativus L.). Sci. Rep. 2015, 5, 14034. [CrossRef] [PubMed]

164. Huo, H.; Wei, S.; Bradford, K.J. DELAY OF GERMINATION1 (DOG1) regulates both seed dormancy and flowering time through microRNA pathways. Proc. Natl. Acad. Sci. USA 2016, 113, E2199-E2206. [CrossRef] [PubMed]

165. Schwarz, S.; Grande, A.V.; Bujdoso, N.; Saedler, H.; Huijser, P. The microRNA regulated SBP-box genes SPL9 and SPL15 control shoot maturation in Arabidopsis. Plant Mol. Boil. 2008, 67, 183-195. [CrossRef] [PubMed]

166. Xu, M.; Hu, T.; Zhao, J.; Park, M.-Y.; Earley, K.W.; Wu, G.; Yang, L.; Poethig, R.S. Developmental functions of miR156-regulated SQUAMOSA PROMOTER BINDING PROTEIN-LIKE (SPL) genes in Arabidopsis thaliana. PLoS Genet. 2016, 12, e1006263. [CrossRef] [PubMed] 
167. Aukerman, M.J.; Sakai, H. Regulation of flowering time and floral organ identity by a microRNA and its APETALA2-like target genes. Plant Cell 2003, 15, 2730-2741. [CrossRef] [PubMed]

168. Jung, J.-H.; Seo, Y.-H.; Seo, P.J.; Reyes, J.L.; Yun, J.; Chua, N.-H.; Park, C.-M. The GIGANTEA-regulated microRNA172 mediates photoperiodic flowering independent of CONSTANS in Arabidopsis. Plant Cell 2007, 19, 2736-2748. [CrossRef] [PubMed]

169. Mathieu, J.; Yant, L.J.; Mürdter, F.; Küttner, F.; Schmid, M. Repression of flowering by the miR172 target SMZ. PLoS Boil. 2009, 7, e1000148. [CrossRef] [PubMed]

170. Yant, L.; Mathieu, J.; Dinh, T.T.; Ott, F.; Lanz, C.; Wollmann, H.; Chen, X.; Schmid, M. Orchestration of the floral transition and floral development in Arabidopsis by the bifunctional transcription factor APETALA2. Plant Cell 2010, 22, 2156-2170. [CrossRef] [PubMed]

171. Hu, J.-Y.; Zhou, Y.; He, F.; Dong, X.; Liu, L.-Y.; Coupland, G.; Turck, F.; de Meaux, J. miR824-regulated AGAMOUS-LIKE16 contributes to flowering time repression in Arabidopsis. Plant Cell 2014, 26, 2024-2037. [CrossRef] [PubMed]

172. Bergonzi, S.; Albani, M.C.; van Themaat, E.V.L.; Nordström, K.J.V.; Wang, R.; Schneeberger, K.; Moerland, P.D.; Coupland, G. Mechanisms of age-dependent response to winter temperature in perennial flowering of Arabis alpina. Science 2013, 340, 1094-1097. [CrossRef] [PubMed]

173. Zhou, M.; Luo, H. MicroRNA-mediated gene regulation: Potential applications for plant genetic engineering. Plant Mol. Boil. 2013, 83, 59-75. [CrossRef] [PubMed]

174. Shen, E.; Zou, J.; Hubertus Behrens, F.; Chen, L.; Ye, C.; Dai, S.; Li, R.; Ni, M.; Jiang, X.; Qiu, J. Identification, evolution, and expression partitioning of miRNAs in allopolyploid Brassica napus. J. Exp. Bot. 2015, 66, 7241-7253. [CrossRef] [PubMed]

175. Cheng, H.; Hao, M.; Wang, W.; Mei, D.; Tong, C.; Wang, H.; Liu, J.; Fu, L.; Hu, Q. Genomic identification, characterization and differential expression analysis of SBP-box gene family in Brassica napus. BMC Plant Boil. 2016, 16, 196. [CrossRef] [PubMed]

176. Wang, J.; Hou, X.; Yang, X. Identification of conserved microRNAs and their targets in Chinese cabbage (Brassica rapa subsp. pekinensis). Genome 2011, 54, 1029-1040. [CrossRef] [PubMed]

177. Wang, J.; Yang, X.; Xu, H.; Chi, X.; Zhang, M.; Hou, X. Identification and characterization of microRNAs and their target genes in Brassica oleracea. Gene 2012, 505, 300-308. [CrossRef] [PubMed]

178. Geng, M.; Li, H.; Jin, C.; Liu, Q.; Chen, C.; Song, W.; Wang, C. Genome-wide identification and characterization of miRNAs in the hypocotyl and cotyledon of cauliflower (Brassica oleracea L. var. botrytis) seedlings. Planta 2014, 239, 341-356. [CrossRef] [PubMed]

179. Han, Y.; Zhu, B.; Luan, F.; Zhu, H.; Shao, Y.; Chen, A.; Lu, C.; Luo, Y. Conserved miRNAs and their targets identified in lettuce (Lactuca) by EST analysis. Gene 2010, 463, 1-7. [CrossRef] [PubMed]

180. Footitt, S.; Huang, Z.; Clay, H.A.; Mead, A.; Finch-Savage, W.E. Temperature, light and nitrate sensing coordinate A rabidopsis seed dormancy cycling, resulting in winter and summer annual phenotypes. Plant J. 2013, 74, 1003-1015. [CrossRef] [PubMed]

181. Srivastava, S.; Singh, N.; Srivastava, G.; Sharma, A. MiRNA mediated gene regulatory network analysis of Cichorium intybus (chicory). Agric. Gene 2017, 3, 37-45. [CrossRef]

182. Bernier, G.; Havelange, A.E.; Houssa, C.; Petitjean, A.; Lejeune, P. Physiological signals that induce flowering. Plant Cell 1993, 5, 1147-1155. [CrossRef] [PubMed]

183. Wilson, R.N.; Heckman, J.W.; Somerville, C.R. Gibberellin is required for flowering in Arabidopsis thaliana under short days. Plant Physiol. 1992, 100, 403-408. [CrossRef] [PubMed]

184. Duclos, D.V.; Björkman, T. Gibberellin Control of Reproductive Transitions in Brassica oleracea Curd Development. J. Am. Soc. Hortic. Sci. 2015, 140, 57-67.

185. Bernier, G. The control of floral evocation and morphogenesis. Annu. Rev. Plant Physiol. Plant Mol. Boil. 1988, 39, 175-219. [CrossRef]

186. Eriksson, S.; Böhlenius, H.; Moritz, T.; Nilsson, O. GA4 is the active gibberellin in the regulation of LEAFY transcription and Arabidopsis floral initiation. Plant Cell 2006, 18, 2172-2181. [CrossRef] [PubMed]

187. Bernier, G. My favourite flowering image: The role of cytokinin as a flowering signal. J. Exp. Bot. 2011, 64, 5795-5799. [CrossRef] [PubMed]

188. Besnard-Wibaut, C. Effectiveness of gibberellins and 6-benzyladenine on flowering of Arabidopsis thaliana. Physiol. Plant. 1981, 53, 205-212. [CrossRef] 
189. D’aloia, M.; Bonhomme, D.; Bouché, F.; Tamseddak, K.; Ormenese, S.; Torti, S.; Coupland, G.; Périlleux, C. Cytokinin promotes flowering of Arabidopsis via transcriptional activation of the FT paralogue TSF. Plant J. 2011, 65, 972-979. [CrossRef] [PubMed]

190. Michniewicz, M.; Kamieńska, A. Studies on the role of kinetin and vitamin $\mathrm{E}$ in the flowering of the cold requiring plant Cichorium intybus) and the long-day plant (Arabidopsis thaliana) grown in non-inductive. Acta Soc. Bot. Pol. 1967, 36, 67-72. [CrossRef]

191. King, R.W.; Evans, L.T. Gibberellins and flowering of grasses and cereals: Prizing open the lid of the "florigen" black box. Annu. Rev. Plant. Boil. 2003, 54, 307-328. [CrossRef] [PubMed]

192. Hedden, P.; Phillips, A.L. Gibberellin metabolism: New insights revealed by the genes. Trends Plant Sci. 2000, 5, 523-530. [CrossRef]

193. Rieu, I.; Ruiz-Rivero, O.; Fernandez-Garcia, N.; Griffiths, J.; Powers, S.J.; Gong, F.; Linhartova, T.; Eriksson, S.; Nilsson, O.; Thomas, S.G. The gibberellin biosynthetic genes AtGA20ox1 and AtGA20ox2 act, partially redundantly, to promote growth and development throughout the Arabidopsis life cycle. Plant J. 2008, 53, 488-504. [CrossRef] [PubMed]

194. Plackett, A.R.; Powers, S.J.; Fernandez-Garcia, N.; Urbanova, T.; Takebayashi, Y.; Seo, M.; Jikumaru, Y.; Benlloch, R.; Nilsson, O.; Ruiz-Rivero, O. Analysis of the developmental roles of the Arabidopsis gibberellin 20-oxidases demonstrates that GA20ox1,-2, and-3 are the dominant paralogs. Plant Cell 2012, 24, 941-960. [CrossRef] [PubMed]

195. Mitchum, M.G.; Yamaguchi, S.; Hanada, A.; Kuwahara, A.; Yoshioka, Y.; Kato, T.; Tabata, S.; Kamiya, Y.; Sun, T.p. Distinct and overlapping roles of two gibberellin 3-oxidases in Arabidopsis development. Plant J. 2006, 45, 804-818. [CrossRef] [PubMed]

196. Chen, M.-L.; Su, X.; Xiong, W.; Liu, J.-F.; Wu, Y.; Feng, Y.-Q.; Yuan, B.-F. Assessing gibberellins oxidase activity by anion exchange/hydrophobic polymer monolithic capillary liquid chromatography-mass spectrometry. PLoS ONE 2013, 8, e69629. [CrossRef] [PubMed]

197. Porri, A.; Torti, S.; Romera-Branchat, M.; Coupland, G. Spatially distinct regulatory roles for gibberellins in the promotion of flowering of Arabidopsis under long photoperiods. Development 2012, 139, 2198-2209. [CrossRef] [PubMed]

198. Rieu, I.; Eriksson, S.; Powers, S.J.; Gong, F.; Griffiths, J.; Woolley, L.; Benlloch, R.; Nilsson, O.; Thomas, S.G.; Hedden, P. Genetic analysis reveals that C19-GA 2-oxidation is a major gibberellin inactivation pathway in Arabidopsis. Plant Cell 2008, 20, 2420-2436. [CrossRef] [PubMed]

199. Ariizumi, T.; Murase, K.; Sun, T.-p.; Steber, C.M. Proteolysis-independent downregulation of DELLA repression in Arabidopsis by the gibberellin receptor GIBBERELLIN INSENSITIVE DWARF1. Plant Cell 2008, 20, 2447-2459. [CrossRef] [PubMed]

200. Willige, B.C.; Ghosh, S.; Nill, C.; Zourelidou, M.; Dohmann, E.M.; Maier, A.; Schwechheimer, C. The DELLA domain of GA INSENSITIVE mediates the interaction with the GA INSENSITIVE DWARF1A gibberellin receptor of Arabidopsis. Plant Cell 2007, 19, 1209-1220. [CrossRef] [PubMed]

201. Nakajima, M.; Shimada, A.; Takashi, Y.; Kim, Y.C.; Park, S.H.; Ueguchi-Tanaka, M.; Suzuki, H.; Katoh, E.; Iuchi, S.; Kobayashi, M. Identification and characterization of Arabidopsis gibberellin receptors. Plant J. 2006, 46, 880-889. [CrossRef] [PubMed]

202. Galvão, V.C.; Horrer, D.; Küttner, F.; Schmid, M. Spatial control of flowering by DELLA proteins in Arabidopsis thaliana. Development 2012, 139, 4072-4082. [CrossRef] [PubMed]

203. Yu, S.; Galvão, V.C.; Zhang, Y.-C.; Horrer, D.; Zhang, T.-Q.; Hao, Y.-H.; Feng, Y.-Q.; Wang, S.; Markus, S.; Wang, J.-W. Gibberellin regulates the Arabidopsis floral transition through miR156-targeted SQUAMOSA PROMOTER BINDING-LIKE transcription factors. Plant Cell 2012, 24, 3320-3332. [CrossRef] [PubMed]

204. Andrés, F.; Porri, A.; Torti, S.; Mateos, J.; Romera-Branchat, M.; García-Martínez, J.L.; Fornara, F.; Gregis, V.; Kater, M.M.; Coupland, G. SHORT VEGETATIVE PHASE reduces gibberellin biosynthesis at the Arabidopsis shoot apex to regulate the floral transition. Proc. Natl. Acad. Sci. USA 2014, 201409567.

205. Galvão, V.C.; Collani, S.; Horrer, D.; Schmid, M. Gibberellic acid signaling is required for ambient temperature-mediated induction of flowering in Arabidopsis thaliana. Plant J. 2015, 84, 949-962. [CrossRef] [PubMed]

206. Bartrina, I.; Jensen, H.; Novak, O.; Strnad, M.; Werner, T.; Schmülling, T. Gain-of-function mutants of the cytokinin receptors AHK2 and AHK3 regulate plant organ size, flowering time and plant longevity. Plant Physiol. 2017. [CrossRef] [PubMed] 
207. Greenboim-Wainberg, Y.; Maymon, I.; Borochov, R.; Alvarez, J.; Olszewski, N.; Ori, N.; Eshed, Y.; Weiss, D. Cross talk between gibberellin and cytokinin: The Arabidopsis GA response inhibitor SPINDLY plays a positive role in cytokinin signaling. Plant Cell 2005, 17, 92-102. [CrossRef] [PubMed]

208. Zhao, B.; Li, H.; Li, J.; Wang, B.; Dai, C.; Wang, J.; Liu, K. Brassica napus DS-3, encoding a DELLA protein, negatively regulates stem elongation through gibberellin signaling pathway. Theor. Appl. Genet. 2017, 130, 727-741. [CrossRef] [PubMed]

209. Tarkowská, D.; Filek, M.; Biesaga-Kościelniak, J.; Marcińska, I.; Macháčková, I.; Krekule, J.; Strnad, M. Cytokinins in shoot apices of Brassica napus plants during vernalization. Plant Sci. 2012, 187, 105-112. [CrossRef] [PubMed]

210. Shang, M.; Wang, X.; Zhang, J.; Qi, X.; Ping, A.; Hou, L.; Xing, G.; Li, G.; Li, M. Genetic Regulation of GA Metabolism during Vernalization, Floral Bud Initiation and Development in Pak Choi (Brassica rapa ssp. chinensis Makino). Front. Plant Sci. 2017, 8, 1533. [CrossRef] [PubMed]

211. Fukuda, M.; Matsuo, S.; Kikuchi, K.; Mitsuhashi, W.; Toyomasu, T.; Honda, I. The endogenous level of GA1 is upregulated by high temperature during stem elongation in lettuce through LsGA3ox1 expression. J. Plant Physiol. 2009, 166, 2077-2084. [CrossRef] [PubMed]

212. Frugis, G.; Giannino, D.; Mele, G.; Nicolodi, C.; Chiappetta, A.; Bitonti, M.B.; Innocenti, A.M.; Dewitte, W.; Van Onckelen, H.; Mariotti, D. Overexpression of KNAT1 in lettuce shifts leaf determinate growth to a shoot-like indeterminate growth associated with an accumulation of isopentenyl-type cytokinins. Plant Physiol. 2001, 126, 1370-1380. [CrossRef] [PubMed]

213. Jasinski, S.; Piazza, P.; Craft, J.; Hay, A.; Woolley, L.; Rieu, I.; Phillips, A.; Hedden, P.; Tsiantis, M. KNOX action in Arabidopsis is mediated by coordinate regulation of cytokinin and gibberellin activities. Curr. Boil. 2005, 15, 1560-1565. [CrossRef] [PubMed]

214. Yanai, O.; Shani, E.; Dolezal, K.; Tarkowski, P.; Sablowski, R.; Sandberg, G.; Samach, A.; Ori, N. Arabidopsis KNOXI proteins activate cytokinin biosynthesis. Curr. Boil. 2005, 15, 1566-1571. [CrossRef] [PubMed]

215. Di Giacomo, E.; Iannelli, M.A.; Frugis, G. TALE and shape: How to make a leaf different. Plants 2013, 2, 317-342. [CrossRef] [PubMed]

216. Salomé, P.A.; Bomblies, K.; Laitinen, R.A.; Yant, L.; Mott, R.; Weigel, D. Genetic architecture of flowering time variation in Arabidopsis thaliana. Genetics 2011, 188, 421-433. [CrossRef] [PubMed]

217. Brachi, B.; Faure, N.; Horton, M.; Flahauw, E.; Vazquez, A.; Nordborg, M.; Bergelson, J.; Cuguen, J.; Roux, F. Linkage and association mapping of Arabidopsis thaliana flowering time in nature. PLoS Genet. 2010, 6, e1000940. [CrossRef] [PubMed]

218. Shindo, C.; Aranzana, M.J.; Lister, C.; Baxter, C.; Nicholls, C.; Nordborg, M.; Dean, C. Role of FRIGIDA and FLOWERING LOCUS C in determining variation in flowering time of Arabidopsis. Plant Physiol. 2005, 138, 1163-1173. [CrossRef] [PubMed]

219. Caicedo, A.L.; Stinchcombe, J.R.; Olsen, K.M.; Schmitt, J.; Purugganan, M.D. Epistatic interaction between Arabidopsis FRI and FLC flowering time genes generates a latitudinal cline in a life history trait. Proc. Natl. Acad. Sci. USA 2004, 101, 15670-15675. [CrossRef] [PubMed]

220. Li, P.; Filiault, D.; Box, M.S.; Kerdaffrec, E.; van Oosterhout, C.; Wilczek, A.M.; Schmitt, J.; McMullan, M.; Bergelson, J.; Nordborg, M. Multiple FLC haplotypes defined by independent cis-regulatory variation underpin life history diversity in Arabidopsis thaliana. Genes Dev. 2014, 28, 1635-1640. [CrossRef] [PubMed]

221. Schwartz, C.; Balasubramanian, S.; Warthmann, N.; Michael, T.P.; Lempe, J.; Sureshkumar, S.; Kobayashi, Y.; Maloof, J.N.; Borevitz, J.O.; Chory, J. Cis-regulatory changes at FLOWERING LOCUS T mediate natural variation in flowering responses of Arabidopsis thaliana. Genetics 2009, 183, 723-732. [CrossRef] [PubMed]

222. Long, Y.; Shi, J.; Qiu, D.; Li, R.; Zhang, C.; Wang, J.; Hou, J.; Zhao, J.; Shi, L.; Park, B.-S. Flowering time quantitative trait loci analysis of oilseed Brassica in multiple environments and genomewide alignment with Arabidopsis. Genetics 2007, 177, 2433-2444. [PubMed]

223. Li, L.; Long, Y.; Zhang, L.; Dalton-Morgan, J.; Batley, J.; Yu, L.; Meng, J.; Li, M. Genome wide analysis of flowering time trait in multiple environments via high-throughput genotyping technique in Brassica napus L. PLoS ONE 2015, 10, e0119425. [CrossRef] [PubMed]

224. Hou, J.; Long, Y.; Raman, H.; Zou, X.; Wang, J.; Dai, S.; Xiao, Q.; Li, C.; Fan, L.; Liu, B. A Tourist-like MITE insertion in the upstream region of the BnFLC. A10 gene is associated with vernalization requirement in rapeseed (Brassica napus L.). BMC Plant. Boil. 2012, 12, 238. 
225. Luo, Z.; Wang, M.; Long, Y.; Huang, Y.; Shi, L.; Zhang, C.; Liu, X.; Fitt, B.D.; Xiang, J.; Mason, A.S. Incorporating pleiotropic quantitative trait loci in dissection of complex traits: Seed yield in rapeseed as an example. Theor. Appl. Genet. 2017, 130, 1569-1585. [CrossRef] [PubMed]

226. Hartman, Y.; Hooftman, D.A.; Schranz, M.E.; van Tienderen, P.H. QTL analysis reveals the genetic architecture of domestication traits in Crisphead lettuce. Genet. Resour. Crop. Evol. 2013, 60, 1487-1500. [CrossRef]

227. Hartman, Y.; Hooftman, D.A.; Uwimana, B.; van de Wiel, C.; Smulders, M.J.; Visser, R.G.; van Tienderen, P.H. Genomic regions in crop-wild hybrids of lettuce are affected differently in different environments: Implications for crop breeding. Evol. Appl. 2012, 5, 629-640. [CrossRef] [PubMed]

228. Hartman, Y.; Uwimana, B.; Hooftman, D.A.; Schranz, M.E.; Wiel, C.; Smulders, M.J.; Visser, R.G.; Tienderen, P.H. Genomic and environmental selection patterns in two distinct lettuce crop-wild hybrid crosses. Evol. Appl. 2013, 6, 569-584. [CrossRef] [PubMed]

229. Zhang, L.; Su, W.; Tao, R.; Zhang, W.; Chen, J.; Wu, P.; Yan, C.; Jia, Y.; Larkin, R.M.; Lavelle, D. RNA sequencing provides insights into the evolution of lettuce and the regulation of flavonoid biosynthesis. Nat. Commun. 2017, 8, 2264. [CrossRef] [PubMed]

230. Javed, N.; Geng, J.; Tahir, M.; McVetty, P.; Li, G.; Duncan, R.W. Identification of QTL influencing seed oil content, fatty acid profile and days to flowering in Brassica napus L. Euphytica 2016, 207, 191-211. [CrossRef]

231. Rahman, H.; Bennett, R.A.; Kebede, B. Molecular mapping of QTL alleles of Brassica oleracea affecting days to flowering and photosensitivity in spring Brassica napus. PLoS ONE 2018, 13, e0189723. [CrossRef] [PubMed]

232. Shen, Y.; Xiang, Y.; Xu, E.; Ge, X.; Li, Z. Major Co-localized QTL for Plant Height, Branch Initiation Height, Stem Diameter, and Flowering Time in an Alien Introgression Derived Brassica napus DH Population. Front. Plant Sci. 2018, 9, 390. [CrossRef] [PubMed]

233. Xu, L.; Hu, K.; Zhang, Z.; Guan, C.; Chen, S.; Hua, W.; Li, J.; Wen, J.; Yi, B.; Shen, J. Genome-wide association study reveals the genetic architecture of flowering time in rapeseed (Brassica napus L.). DNA Res. 2015, 23, 43-52. [CrossRef] [PubMed]

234. Wang, N.; Chen, B.; Xu, K.; Gao, G.; Li, F.; Qiao, J.; Yan, G.; Li, J.; Li, H.; Wu, X. Association mapping of flowering time QTLs and insight into their contributions to rapeseed growth habits. Front. Plant Sci. 2016, 7, 338. [CrossRef] [PubMed]

235. Yang, S.; Zhang, B.; Liu, G.; Hong, B.; Xu, J.; Chen, X.; Wang, B.; Wu, Z.; Hou, F.; Yue, X. A comprehensive and precise set of intervarietal substitution lines to identify candidate genes and quantitative trait loci in oilseed rape (Brassica napus L.). Theor. Appl. Genet. 2018, 131, 2117-2129. [CrossRef] [PubMed]

236. Schiessl, S.; Iniguez-Luy, F.; Qian, W.; Snowdon, R.J. Diverse regulatory factors associate with flowering time and yield responses in winter-type Brassica napus. BMC Genom. 2015, 16, 737. [CrossRef] [PubMed]

237. Li, X.; Wang, W.; Wang, Z.; Li, K.; Lim, Y.P.; Piao, Z. Construction of chromosome segment substitution lines enables QTL mapping for flowering and morphological traits in Brassica rapa. Front. Plant Sci. 2015, 6, 432. [CrossRef] [PubMed]

238. Lou, P.; Zhao, J.; Kim, J.S.; Shen, S.; Del Carpio, D.P.; Song, X.; Jin, M.; Vreugdenhil, D.; Wang, X.; Koornneef, M. Quantitative trait loci for flowering time and morphological traits in multiple populations of Brassica rapa. J. Exp. Bot. 2007, 58, 4005-4016. [CrossRef] [PubMed]

239. Wang, Y.; Zhang, L.; Ji, X.; Yan, J.; Liu, Y.; Lv, X.; Feng, H. Mapping of quantitative trait loci for the bolting trait in Brassica rapa under vernalizing conditions. Genet. Mol. Res. 2014, 13, 3927-3939. [CrossRef] [PubMed]

240. Liu, Y.; Li, C.; Shi, X.; Feng, H.; Wang, Y. Identification of QTLs with additive, epistatic, and QTLX environment interaction effects for the bolting trait in Brassica rapa L. Euphytica 2016, 210, 427-439. [CrossRef]

241. Dechaine, J.M.; Brock, M.T.; Weinig, C. QTL architecture of reproductive fitness characters in Brassica rapa. BMC Plant Boil. 2014, 14, 66. [CrossRef] [PubMed]

242. Shu, J.; Liu, Y.; Zhang, L.; Li, Z.; Fang, Z.; Yang, L.; Zhuang, M.; Zhang, Y.; Lv, H. QTL-seq for rapid identification of candidate genes for flowering time in broccoli $\times$ cabbage. Theor. Appl. Genet. 2018, 131, 917-928. [CrossRef] [PubMed]

243. Hasan, Y.; Briggs, W.; Matschegewski, C.; Ordon, F.; Stützel, H.; Zetzsche, H.; Groen, S.; Uptmoor, R. Quantitative trait loci controlling leaf appearance and curd initiation of cauliflower in relation to temperature. Theor. Appl. Genet. 2016, 129, 1273-1288. [CrossRef] [PubMed] 
244. FitzJohn, R.G.; Armstrong, T.T.; Newstrom-Lloyd, L.E.; Wilton, A.D.; Cochrane, M. Hybridisation within Brassica and allied genera: Evaluation of potential for transgene escape. Euphytica 2007, 158, 209-230. [CrossRef]

245. Shea, D.J.; Tomaru, Y.; Itabashi, E.; Nakamura, Y.; Miyazaki, T.; Kakizaki, T.; Naher, T.N.; Shimizu, M.; Fujimoto, R.; Fukai, E. The production and characterization of a BoFLC2 introgressed Brassica rapa by repeated backcrossing to an F1. Breed. Sci. 2018, 68, 316-325. [CrossRef] [PubMed]

246. Lebeda, A.; Doležalová, I.; Křístková, E.; Kitner, M.; Petrželová, I.; Mieslerová, B.; Novotná, A. Wild Lactuca germplasm for lettuce breeding: Current status, gaps and challenges. Euphytica 2009, 170, 15. [CrossRef]

247. Van Cutsem, P.; Du Jardin, P.; Boutte, C.; Beauwens, T.; Jacqmin, S.; Vekemans, X. Distinction between cultivated and wild chicory gene pools using AFLP markers. Theor. Appl. Genet. 2003, 107, 713-718. [CrossRef] [PubMed]

248. Hodgins, K.A.; Lai, Z.; Oliveira, L.O.; Still, D.W.; Scascitelli, M.; Barker, M.S.; Kane, N.C.; Dempewolf, H.; Kozik, A.; Kesseli, R.V. Genomics of Compositae crops: Reference transcriptome assemblies and evidence of hybridization with wild relatives. Mol. Ecol. Resour. 2014, 14, 166-177. [CrossRef] [PubMed]

249. Testone, G.; Mele, G.; Di Giacomo, E.; Gonnella, M.; Renna, M.; Tenore, G.C.; Nicolodi, C.; Frugis, G.; Iannelli, M.A.; Arnesi, G. Insights into the sesquiterpenoid pathway by metabolic profiling and de novo transcriptome assembly of stem-chicory (Cichorium intybus cultigroup "Catalogna"). Front. Plant Sci. 2016, 7, 1676. [CrossRef] [PubMed]

(C) 2018 by the authors. Licensee MDPI, Basel, Switzerland. This article is an open access article distributed under the terms and conditions of the Creative Commons Attribution (CC BY) license (http:/ / creativecommons.org/licenses/by/4.0/). 